\title{
Pain neuroscience education for adults with chronic musculoskeletal pain: a mixed-methods systematic review and meta-analysis.
}

WATSON, J.A., RYAN, C.G., COOPER, L., ELLINGTON, D., WHITTLE, R., LAVENDER, M., DIXON, J., ATKINSON, G., COOPER, K., MARTIN D.J. 
Pain neuroscience education for adults with chronic musculoskeletal pain: a mixed-methods systematic review and meta-analysis

James A Watson BSc (Hons), Cormac G Ryan BSc, MSc, PhD , Lesley Cooper RGN, CertEd, MSc, Dominic Ellington BSc (Hons), Robbie Whittle BSc (Hons),

Michael Lavender BSc, PGCE, DClinPsy. , John Dixon BSc, PhD , Greg Atkinson BSc (Hons), PhD , Kay Cooper BSc, MSc, PhD , Denis J Martin BSc. MSc. DPhil

PII:

DOI:

Reference:

To appear in:

Received date:

Revised date:

Accepted date:
S1526-5900(18)30747-8

https://doi.org/10.1016/j.jpain.2019.02.011

YJPAI 3711

Journal of Pain

6 November 2018

3 February 2019

23 February 2019

Please cite this article as: James A Watson BSc (Hons), Cormac G Ryan BSc, MSc, PhD , Lesley Cooper RGN, CertEd, MSc, Dominic Ellington BSc (Hons), Robbie Whittle BSc (Hons), Michael Lavender BSc, PGCE, DClinPsy. , John Dixon BSc, PhD , Greg Atkinson BSc (Hons), PhD, Kay Cooper BSc, MSc, PhD, Denis J Martin BSc. MSc. DPhil, Pain neuroscience education for adults with chronic musculoskeletal pain: a mixed-methods systematic review and meta-analysis, Journal of Pain (2019), doi: https://doi.org/10.1016/j.jpain.2019.02.011

This is a PDF file of an unedited manuscript that has been accepted for publication. As a service to our customers we are providing this early version of the manuscript. The manuscript will undergo copyediting, typesetting, and review of the resulting proof before it is published in its final form. Please note that during the production process errors may be discovered which could affect the content, and all legal disclaimers that apply to the journal pertain. 


\section{Title page}

Pain neuroscience education for adults with chronic musculoskeletal pain: a mixedmethods systematic review and meta-analysis

Short title: Pain neuroscience education a mixed-methods review

Reviewers

James A Watson ${ }^{1}$ BSc (Hons) - Corresponding author

\section{J.A.Watson@tees.ac.uk}

07903195336

Cormac G Ryan ${ }^{1}$ BSc, MSc, PhD

C.Ryan@tees.ac.uk

Lesley Cooper ${ }^{1}$ RGN, CertEd, MSc

Lesley.Cooper@uws.ac.uk

Dominic Ellington ${ }^{3} \mathrm{BSc}$ (Hons)

D.Ellington@tees.ac.uk

Robbie Whittle ${ }^{3}$ BSc (Hons) 
robbie.whittle@nhs.net

Michael Lavender ${ }^{3}$ BSc, PGCE, DClinPsy.

michael.lavender1@nhs.net

John Dixon ${ }^{1}$ BSc, PhD

John.Dixon@tees.ac.uk

Greg Atkinson ${ }^{1}$ BSc (Hons), PhD

Greg.Atkinson@tees.ac.uk

Kay Cooper ${ }^{2}$ BSc, MSc, PhD

k.cooper@rgu.ac.uk

Denis J Martin ${ }^{1}$ BSc. MSc. DPhil

D.Martin@tees.ac.uk

${ }^{1}$ School of Health and Social Care, Teesside University, Middlesbrough, Tees Valley, TS1 3BX, United Kingdom.

${ }^{2}$ The Scottish Centre for Evidenced-Based, Multi-professional Practice: A Joanna Briggs Institute Centre of Excellence, School of Health Sciences, Robert Gordon University, Aberdeen, AB10 7QG, United Kingdom. 
${ }^{3}$ North Tees and Hartlepool NHS Foundation Trust, University Hospital of North Tees, Hardwick Road, Stockton on Tees, Cleveland, TS19 8PE, United Kingdom.

\section{Disclosures}

This research was funded by Teesside University.

The authors have no conflict of interest to declare.

Highlights

- Pain neuroscience education can facilitate patients' ability to cope with their condition.

- Pain neuroscience education doesn't produce clinically significant reductions in pain.

- Pain neuroscience education doesn't produce clinically significant reductions in disability.

- Pain neuroscience education does produce clinically significant reductions in kinesiophobia.

- Pain neuroscience education does produce clinically significant reductions in catastrophising.

\section{Abstract}

Chronic musculoskeletal pain (CMP) is an urgent global public health concern. Pain neuroscience education (PNE) is an intervention used in the management of CMP aiming to reconceptualise an individual's understanding of their pain as less threatening. This mixed-methods review undertook a segregated synthesis of quantitative and qualitative studies to investigate the clinical effectiveness, and patients' experience of, PNE for people with CMP. Electronic databases were searched for studies published between 01/01/2002 and 14/06/2018. Twelve 
randomised controlled trials $(n=755)$ that reported pain, disability and psychosocial outcomes and four qualitative studies $(n=50)$ that explored patients experience of PNE were included. The meta-analysed pooled treatment effects for PNE vs control had low clinical relevance in the short-term for pain $(-3.20 / 100 ; 95 \% \mathrm{Cl}-6.66$ to 0.27$)$ and disability $(-4.10 / 100 ; 95 \% \mathrm{Cl}-7.89$ to -0.32$)$ and the medium-term for pain ($4.22 / 100 ; 95 \% \mathrm{Cl}-16.44$ to 8.01$)$ and disability $(-8.23 / 100 ; 95 \% \mathrm{Cl}-15.61$ to -0.84$)$. The treatment effect of PNE for kinesiophobia was clinically relevant in the shortterm $(-13.55 / 100 ; 95 \% \mathrm{Cl}-25.89$ to -1.21$)$ and for pain catastrophising in the mediumterm $(-5.26 ; 95 \% \mathrm{Cl}-10.59$ to 0.08$)$. Meta-synthesis of 23 qualitative findings resulted in the identification of two synthesized findings that identified several key components important for enhancing the patient experience of PNE such as allowing the patient to tell their own story. These components can enhance pain reconceptualisation, which appears to be an important process to facilitate patients' ability to cope with their condition. The protocol was published on PROSPERO (CRD42017068436).

\section{Perspective}

We outline the effectiveness of PNE for the management of pain, disability and psychosocial outcomes in adults with CMP. Key components that can enhance the patient experience of PNE such as allowing the patient to tell their own story are also presented. These components may enhance pain reconceptualisation.

\section{Key words}

Pain; Neuroscience; Education; Chronic; Systematic review

\section{Introduction}


Chronic musculoskeletal pain (CMP) affects $20 \%$ of adults worldwide ${ }^{14}$ and is considered an urgent global public health concern ${ }^{16}$. In addition to the negative impact on an individual's quality-of-life ${ }^{3,56}$ there is a large societal financial burden associated with CMP. Annual healthcare costs for patients with chronic low back pain (CLBP) are double those of matched controls ${ }^{19}$. In the United Kingdom, The National Institute for Health and Care Excellence estimate the direct cost of low back pain at over £2.1 billion ${ }^{39}$. The total cost of CMP is likely to be much higher.

Interventions which encourage and empower patients to self-manage are recommended for individuals with $\mathrm{CMP}^{9,13,38,40,55}$. Education is a cornerstone of this approach with the premise that the better an individual understands their condition, the more empowered they become and the better they will be able to manage it $^{13,42}$. Given the biopsychosocial nature of CMP, an educational approach grounded in the biopsychosocial model would seem an appropriate form of education for people with this condition. An increasingly popular form of biopsychosocial education is pain neuroscience education (PNE), which has the overarching aim of facilitating individuals to reconceptualise their pain as less threatening. Alternative names for PNE used within the literature include; explain pain ${ }^{4,33,34}$; therapeutic neuroscience education $^{65}$; pain biology education ${ }^{43}$; and pain neurophysiology education ${ }^{7}$. In recent years, there has been an increase in the number and quality of PNE reviews. This reflects the rapidly growing quantitative evidence base in the area. Many of these reviews show promising results for $\mathrm{PNE}^{7,8,26,29,33,47,63,64}$. The most recent review published in English on PNE in heterogeneous CMP concluded that the current evidence supports the use of PNE for improving function, pain, psychosocial factors, movement, health care utilisation, and pain knowledge ${ }^{29}$. Two recent meta-analysis on patients with CLBP broadly support these findings for pain 
and disability but not psychosocial factors ${ }^{47,63}$. However, neither had a registered protocol and few of the individual analyses pooled the recommended five or more studies $^{22}$. Additionally, both included studies where the effect was not clearly attributable to PNE e.g. PNE + Intervention A Verses Intervention B. To date no published review has conducted a meta-analysis on PNE in heterogeneous CMP. In addition to a growth in the quantitative literature, in 2016 the first qualitative study on PNE was published ${ }^{42}$. Previous reviews of the literature have focused solely on quantitative studies $7,8,12,26,29,33,64$. The emergence of qualitative studies provides the opportunity to undertake a mixed-methods review. Mixed-methods reviews attempt to maximise the ability of their findings to inform policy and practice through the inclusion of diverse forms of evidence ${ }^{51}$.

\section{Review question/objectives}

Review questions were:

How effective is PNE as an intervention for the management of adults with CMP? What are the perceptions of RNE in adults with CMP? This question is delineated into the following three objectives:

1) To explore patient experiences of participating in PNE.

2) To explore their perceptions of its effectiveness.

3) To explore how it influenced their understanding of pain.

\section{Methods}

The Joanna Briggs Institute Reviewers Manual $2017^{52}$ was used to direct the methods of this mixed-methods systematic review and meta-analysis. 
- Studies including adults ( $\geq 18$ years) who have CMP (including chronic lower back pain, chronic neck pain, osteoarthritis or rheumatoid arthritis, in addition to those who suffer non-specific or widespread musculoskeletal pain conditions).

- Diagnosis of CMP was consistent with the British Pain Society definition (chronic pain, which lasts beyond the time that tissue healing would normally be expected to have occurred, often taken as $\geq 3$ months ${ }^{49}$

- Quantitative studies using a RCT design that (i) compared the intervention with no treatment (true control) or usual care (ii) concomitant studies where PNE was delivered in addition to another intervention where that other intervention was received by both groups and (iii) head-to-head studies where PNE was compared to another active intervention.

- Studies reporting the following objective and subjective measures - primary outcomes: pain; any validated measure of pain (numeric rating scale/visual analogue scale). Disability; any validated measure of disability (e.g. Roland Morris Disability Questionnaire). Secondary outcomes; any validated measure, which investigates the individuals' physical and/or psychosocial wellbeing.

- Qualitative studies that explored the experiences and perceptions of adults with CMP who had received PNE.

\section{Exclusion criteria}

- Studies that included participants with non-musculoskeletal pain such as cancer pain, visceral pain or post stroke pain.

\section{Search strategy and selection of studies}

A three-step search strategy was used to identify both published and unpublished studies. An initial limited search of MEDLINE and CINAHL was undertaken followed by analysis of the text words contained in the title and abstract, and of the index terms used. A second search using all identified keywords (Pain AND (Physiology OR Neurophysiology OR Neuroscience OR Biology) AND

Education) and index terms was then undertaken across all included databases (The Cochrane Library, AMED, CINAHL Complete, MEDLINE, PsycINFO, PEDro, 
Scopus, EMBASE, Education Resources Information Centre (ERIC), Web of Science, clinicaltrials.gov, dissertations indexed with ProQuest Dissertations and Theses Global and EThOS) from 2002-25 July 2017 and updated on 14 June 2018. This timeframe was selected as the first PNE study was published in $2002^{32}$. Finally, the reference lists and citing articles of all key identified articles were searched for additional studies. (See document, Supplementary Digital Content (SDC) 1 which provides the full search strategy).

After removing duplicates, the title and abstracts were screened by two authors (J.W. \& D.E. or R.W.). Disagreements were resolved through discussion or a third reviewer (D.E. or R.W.). The full-text was obtained for all records that could potentially fit the criteria. Upon reading the full-texts those deemed not to meet the inclusion criteria were rejected and the rationale recorded.

\section{Assessment of methodological quality}

Quantitative articles selected for critical appraisal were independently assessed by two reviewers (J.W., C.R.) using the Cochrane tool for assessing risk of bias ${ }^{17}$.

Qualitative articles were independently assessed by two reviewers (L.C. and either J.W or K.C.) using the standardized critical appraisal instrument from the Joanna Briggs Institute: Qualitative Assessment and Review Instrument ${ }^{50}$. As J.W. coauthored 1 of the qualitative studies ${ }^{23}$, he did not review this article.

Where there was insufficient information to make a decision regarding any aspect of the critical appraisal the original authors were contacted for further information.

Disagreements were resolved by discussion or a third reviewer (D.M.). 


\section{Data extraction}

\section{Stage 1}

Two reviewers (J.W., M.L.) independently extracted the quantitative data using JBISUMARI ${ }^{53}$ including details about the interventions, populations, study methods and outcomes of relevance to the review question/objectives.

Two reviewers (J.W., L.C.) read each qualitative study, discussed the key themes related to the objectives of the review and agreed the level of theme for data extraction. Qualitative data were extracted independently (J.W., L.C.) using JBISUMARI ${ }^{53}$. The data extracted included specific details about the phenomena of interest, populations, study methods and outcomes of relevance to the review question/objectives. Where possible verbatim data from research participants was extracted to illustrate each finding. Where this was not provided in the source papers the authors description of the theme was extracted.

\section{Stage 2}

The results of each single-method synthesis included in the mixed-methods review was extracted in numerical, tabular or textual format. Syntheses of quantitative data consisted of appropriate elements of the meta-analysis forest plot. For qualitative data, it consisted of appropriate elements of the QARI-view table.

\section{Data synthesis}

This review employed a parallel-results convergent design ${ }^{20}$ where the quantitative and qualitative evidence were analysed and presented separately (Stage 1 of data synthesis), otherwise known as a segregated design ${ }^{44}$. The synthesised findings yielded from each separate analysis were complementary as they addressed 
different aspects of PNE. The final stage of the mixed-methods synthesis (stage 2) was configuration, where the complementary findings were juxtaposed and organised into a line of argument ${ }^{44,45}$.

Further details of stage 1 data synthesis for each single-method synthesis:

The primary statistics extracted from each quantitative study were mean changes in pain, disability, pain catastrophising and kinesiophobia for intervention and control groups, in addition to the associated standard deviations (SDs) of these changes. When a SD of change was not reported, and could not be obtained by contacting the authors, it was either calculated from other information given such as standard error, or estimated from the baseline and follow up SDs, according to methods described in the Cochrane handbook ${ }^{18}$. Where there was uncertainty a robust data set was used. Where possible, treatment effect sizes were pooled in a meta-analysis using comprehensive meta-analysis (CMA) software version 3, and double data entry was carried out for all results. Pooled effects sizes (and associated 95\% confidence intervals) were quantified in a weighted fashion using the inverse variance approach. I-squared and Tau-squared statistics were used to quantify heterogeneity, and the sources of any heterogeneity were explored using meta-regression. 95\% prediction intervals (representing the likely range of for the pooled mean effect size in a future similar RCT) were also calculated according the methods reported by IntHout et al. $(2016)^{21}$. Where statistical pooling was not possible, the findings were presented in narrative form including tables and figures to aid in data presentation wherever appropriate. 
Qualitative research findings were pooled using JBI SUMARI software ${ }^{53}$. This involved the aggregation or synthesis of findings to generate a set of statements that represent that aggregation. This was achieved by assembling the findings (level 1 findings) rated according to their quality and categorising these findings based on their similarity of meaning (level 2 findings). These categories were then subjected to a meta-synthesis generating a single comprehensive set of synthesized findings (level 3 findings). Where textual pooling was not possible, the findings were presented in a narrative form ${ }^{52}$.

\section{Quality of evidence}

The Grades of Recommendation, Assessment, Development and Evaluation (GRADE) approach ${ }^{15}$ was used to rate the overall quality of quantitative evidence for each outcome. A Summary of Findings table created using GradePro is presented (Table 1). The ConQual approach outlined by Munn et al., $(2014)^{36}$ based on principles of GRADE was used to establish confidence in the qualitative findings. JBI levels of credibility (U Unequivocal, C Credible, US Unsupported) ${ }^{52}$ and dependability are presented in a ConQual table (Table 2).

\section{Results}

Following removal of duplicates, 12,137 publications were identified (Figure 1). Sixtythree potentially relevant full texts and were evaluated against the inclusion criteria. No further studies were found by checking the reference lists or citing articles. Forty- 
three quantitative, two qualitative and one mixed-methods publication were excluded at this stage. See document, SDC2 for a list of excluded publications and reasons for exclusion.

For the quantitative component of the review,13 publications reporting data from 12 RCTs were included ${ }^{2,11,25,27,28,30,31,35,41,48,57,58,60}$. For the qualitative component of the review, 4 publications reporting 4 studies were included $23,24,42,61$.

\section{Methodological quality}

\section{Quantitative studies}

Thirteen publications from 12 RCTs were critically appraised. Quality scores ranged from 1-6 out of 7; 7 RCTs scored $\geq 5$ (Table 3; Figure 2 and 3 produced by using RevMan software (Review Manager. Version 5.3. Copenhagen: The Nordic Cochrane Centre. The Cochrane Collaboration, 2014).

Seven authors were contacted to provide additional information regarding study methods, with only one not responding $11,28,35,41,48,57,60$. The critical appraisal was updated accordingly for the six that replied. 
Four publications were appraised. Quality scores ranged from 4-9/10. One study scored $4 / 10^{23}$ however given this is applied qualitative research, scoring "yes" on Q1-5 was inappropriate. Both reviewers (L.C., K.C.) believed the study was methodologically sound with appropriate methods applied. Table 4 presents the results of the critical appraisal.

Description of quantitative studies

A summary of all publications are presented in Table 5

The diagnosis of CMP differed across the 12 RCTs, the most prevalent being CLBP $(n=5)$. There was a total of 755 participants in the sample of 12 included RCTs with the number of participants ranging from 12-120. All studies included more women than men ranging from $7 \%$ male to $46 \%$ male. The mean age of participants ranged from 37 to 70 years. The mean baseline pain across all studies ranged from 43/100 to $79 / 100$.

Studies were conducted in a range of locations including private rehabilitation clinics $(n=2)$ and University facilities $(n=3)$. Studies were conducted in several countries including the USA, Europe and Australia. The duration of educational intervention ranged from 0.5 hours to 3 hours. Written information was the main intervention for two studies. Participants were given 3 and 6 weeks respectively to read and absorb the information.

PNE was delivered in single and multiple sessions. We defined 'multiple' as having a PNE contact with a member of the study team on more than one occasion via faceto-face, telephone or email. Written information alone was defined as 1 contact, however supporting leaflets/materials were not included when given in addition to 
face-face. PNE was delivered in a single session by four studies, and over multiple sessions in eight studies.

Description of qualitative studies

A summary of all publications are presented in Table 6 . Three of the four qualitative studies included participants with heterogeneous CMP. The remaining study included participants whose primary complaint was CLBP (+/- leg symptoms). Three studies were carried out in the UK in an NHS Pain Clinic by the same research group. The other was carried out in the Netherlands in participants own homes ( $\mathrm{n}=$ 14) or a physiotherapy practice $(n=1)$.

All studies used individual semi-structured interviews with open questions to collect data. Two conducted repeat interviews. One study also conducted a focus group made up of healthcare professionals $(n=6)$ to discuss, optimise, and verify the theory constructed from the patient interviews. Interviews in all studies were audiorecorded and transcribed verbatim. Data was analysed using a range of qualitative techniques including interpretive phenomenological analysis, grounded theory, and theoretical thematic analysis.

Included studies provided data regarding the (i) experiences of participating in PNE for patients with CMP (ii) the extent, and nature of patients reconceptualisation of their CMP following PNE. (iii) experiences of patients with CMP who recently received $P N E$ in a transdisciplinary setting. 


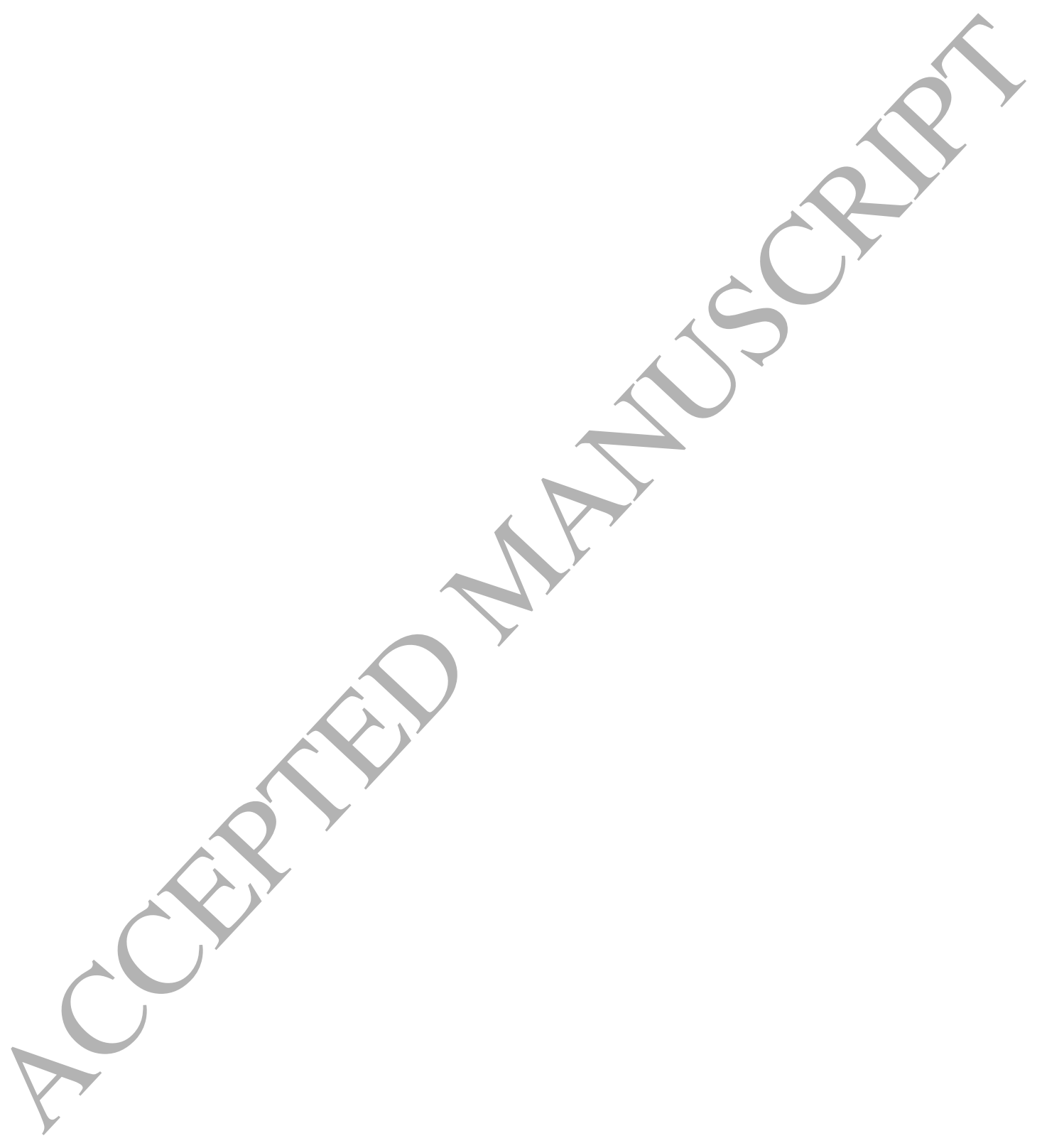


Deviations from original protocol

In addition to the two primary outcome measures of pain and disability, there were several outcome measures, which under our protocol were classified as secondary outcome measures including; 12 validated psychosocial outcome measures; four physical performance outcome measures; and three objective outcome measures of pain pressure threshold. A summary can be seen in document SDC3.

Jackson and Turner $(2017)^{22}$ recommend only pooling data where there are no less than five studies to ensure that the power from a random-effects meta-analysis is greater than that of the individual studies. Thus, only pain, disability, pain catastrophising, and kinesiophobia met this criterion and could be pooled. The decision was made to only report results for those measures that met this criterion to keep the review focussed and coherent within the confines of a single article. Thus, pain, disability and pain catastrophising were pooled in the short ( $<3$ months) and medium-term ( $\geq 3-6$ months). Kinesiophobia was pooled in the short-term only. Where pooling was not appropriate for the included outcomes, it was presented narratively.

\section{Findings of the review}

\section{Quantitative component}

Data was classified under three time points including short-term ( $<3$ months), medium-term ( $\geq 3-6$ months) and long-term ( $\geq 12$ months) ${ }^{7}$.

Primary outcome - Pain 
Ten RCTs collected data on pain. A variety of outcome measures were used to collect pain data including 0-10 numerical rating scales (NRS) by four studies $^{2,11,27,28,48} 100 \mathrm{~mm}$ visual analogue scales (VAS) by three studies ${ }^{35,41,60}$ the Medical Outcomes Short-Form 36 Health Status Survey (SF-36), for which the category 'bodily pain' was used by one study ${ }^{58}$; the Fibromyalgia impact questionnaire, for which the 0-10 NRS was used by one study ${ }^{57}$; and The Western Ontario and McMaster Universities Osteoarthritis Index (WOMAC) by one study ${ }^{25}$. Three studies assessed pain using pain pressure thresholds ${ }^{25,31,58}$. However, it was inappropriate to pool this data with the questionnaires from other studies.

Data was available for nine RCTs for which pain was assessed in the short-term, and seven in the medium-term. All pain outcomes were converted into a $100 \mathrm{~mm}$ VAS to allow pooling, with a higher percentage indicating more pain ${ }^{6}$.

\section{Short-term}

The random effects pooled results across all PNE interventions vs control in nine studies $^{2,11,27,28,35,41,48,57,58,60}(n=524$ participants) showed the mean pain reduction of PNE to be $3.20 \mathrm{~mm}$ greater on the $100 \mathrm{~mm}$ VAS $(95 \% \mathrm{Cl}:-6.66$ to 0.27$)$ than control $(P=0.07)$ : high quality évidence (Fig. 4 Forest). Heterogeneity was low $\left(I^{2}=3.79\right.$, $\operatorname{tau}= \pm 1.07)$.

Medium-term

The random effects pooled results across all PNE interventions vs control in seven studies $^{2,11,27,28,41,57,58,60}$ ( $\mathrm{n}=457$ participants) showed mean pain reduction of PNE to 
be $4.22 \mathrm{~mm}$ greater on the $100 \mathrm{~mm}$ VAS $(95 \% \mathrm{Cl}:-16.44$ to 8.01$)$ than control $(\mathrm{P}=$ 0.499): low quality evidence (Fig. 5 Forest). Heterogeneity was considerable $\left(I^{2}=\right.$ $85.87, \operatorname{tau}= \pm 14.30)$.

Long-term

Only two studies reported on pain in the long term and thus were not pooled. Von Bertouch, McAuley and Moseley, (2011) compared PNE plus PMP vs Back book education plus PMP, with both groups showing decreases from baseline of $53 \mathrm{~mm}$ and $22 \mathrm{~mm}$ on $100 \mathrm{~mm}$ VAS respectively.

Louw (2014/16) compared PNE plus lumbar surgery vs lumbar surgery alone, with both groups showing decreases from baseline at 12 months for leg pain of 3.7 and 3.3 points on $0-10$ NRS for the PNE and control groups respectively $(P>0.075)$. At 36 months, the groups showed reductions from baseline of 3.4 and 3.7 points for the PNE and control groups respectively $(P=0.028)$.

Primary outcome-Disability

Eleven RCTs collected data on disability. A variety of outcome measures were used including the Roland Morris Disability Questionnaire (RMDQ) by three studies ${ }^{2,35,48 \text {; }}$ the Oswestry Disability Index (ODI) by two studies ${ }^{27,28,48}$; the Patient Specific Functional Scale (PSFS) by three studies ${ }^{11,60}$; The Pain Disability Index by one study ${ }^{30}$; the Medical Outcomes Short-Form 36 Health Status Survey (SF-36), for 
which the category 'physical functioning' was used by one study ${ }^{58}$; the Fibromyalgia impact questionnaire, for which 'physical functioning' was used by one study ${ }^{57}$; the Quebec Back Pain Disability Scale by one study ${ }^{41}$; the WOMAC by one study ${ }^{25}$.

Disability data were available for $10 \mathrm{RCTs}$ in the short term, and seven in the medium-term. All measures of disability were converted into a score /100 to facilitate pooling, with a higher score indicating greater disability.

\section{Short-term}

The random effects pooled results across all PNE interventions vs control in ten studies $^{2,11,27,28,30,35,41,48,57,58,60}(\mathrm{n}=644$ participants) showed mean disability reduction of PNE to be $4.10 / 100(95 \% \mathrm{Cl}:-7.89$ to -0.32$)$ greater than control $(\mathrm{P}=0.03)$ : moderate quality evidence (Fig. 6 Forest). Heterogeneity was considerable $\left(\mathrm{I}^{2}=\right.$ 86.17, tau $= \pm 4.65)$. Téllez-García et al $(2015)^{48}$ collected two disability outcome measures (RMDQ and ODI).Following discussion, we chose to use the ODI within the analysis and undertook a sensitivity analysis replacing the ODI with the RMDQ. This had no statistically or clínically significant effect on the results.

\section{Medium-term}

The random effects pooled results across all PNE interventions vs control in seven studies $^{2,11,27,28,41,57,58,60}(\mathrm{n}=457$ participants) showed mean disability reduction of PNE to be $8.23 / 100(95 \% \mathrm{Cl}:-15.61$ to -0.84$)$ greater than control $(P=0.03)$ : 
moderate quality evidence (Fig. 7 Forest). Heterogeneity was considerable $\left(I^{2}=\right.$ 95.53, tau $= \pm 9.25)$.

Long-term

Only two studies reported on disability in the long term and thus were not pooled. Von Bertouch, McAuley and Moseley, $(2011)^{60}$ compared PNE plus a PMP vs Back book education plus a PMP, with both groups showing decreases from baseline of 6.3 and 5.1 points $/ 10$ on the PSFS respectively. Louw et al. ${ }^{27,28}$ compared PNE plus lumbar surgery vs lumbar surgery alone, with both groups showing decreases for disability of 19 and 23 points on $0-100$ ODI respectively at 12 months follow up. The effect of group did not reach statistical significance $(P>0.075)$. At 36 months, the groups showed reductions of 21 and 22 points, respectively. The effect of group did not reach statistical significance $(P=0.317)$. There were no significant differences between year 1 and $3(P=0.761)$.

Secondary outcome-Pain Catastrophising

Ten RCTs collected data on pain catastrophising $2,11,25,27,28,31,30,35,57,58,60$. All studies used the Pain Catastrophising Scale (PCS). PCS datum for one study was not available and could not be provided by the author on request ${ }^{60}$.

Short-term 
The random effects pooled results across all PNE interventions vs control in nine studies $^{2,11,25,27,28,30,31,35,57,58}$ ( $\mathrm{n}=598$ participants) showed mean pain catastrophising reduction of PNE to be 3.33 points /52 on the PCS (95\% Cl: -6.01 to -0.65$)$ greater than control $(P=0.02)$ : moderate quality evidence (Fig. 8 Forest). Heterogeneity was considerable $\left(I^{2}=97.62\right.$, tau $\left.= \pm 3.79\right)$.

Medium-term

The random effects pooled results across all PNE interventions vs control in six studies $^{2,11,25,27,28,57,58}$ ( $\mathrm{n}=375$ participants) showed mean pain catastrophising reduction of PNE to be 5.26 points /52 on the PCS ( $95 \%$ Cl: -10.59 to 0.08$)$ greater than control $(P=0.053)$ : moderate quality evidence (Fig. 9 Forest). Heterogeneity was considerable $\left(I^{2}=99.03\right.$, tau $\left.= \pm 6.35\right)$.

Long-term

Only one study reported on pain catastrophising in the long term ${ }^{27,28}$ comparing PNE plus lumbar surgery vs lumbar surgery alone, with both groups showing decreases for pain catastrophising of 12.3 and 13.3 points on 0-52 PCS respectively at 12 months follow up. The statistical significance of this is unknown. At 36 months, the groups showed reductions of 15.0 and 19.3 points respectively. The statistical significance of this is unknown. 
Secondary outcome - Kinesiophobia

Seven RCTs collected data on Kinesiophobia ${ }^{2,25,30,31,41,48,58}$. All studies used the Tampa Scale for Kinesiophobia (TSK), with three studies using the 17-item version $\left(\right.$ TSK-17) ${ }^{30,48,58}$; one study using the 17-item chronic fatigue syndrome version (TSKCFS $)^{31}$; one study using the 13 -item version (TSK-13) ${ }^{41}$; and two studies using the 11 -item version $(\text { TSK-11 })^{2,25}$. TSK data was converted into a percentage to allow pooling, with a higher percentage indicating greater kinesiophobia.

Short-term

The random effects pooled results across all PNE interventions vs control in seven studies $^{2,20,30,31,41,48,58}$ ( $\mathrm{n}=372$ participants) showed mean reduction in kinesiophobia of PNE to be $13.55 \%$ on the TSK (95\% Cl: -25.89 to -1.21$)$ greater than control $(P=$ 0.03): moderate quality evidence (Fig. 10 Forest). Heterogeneity was considerable $\left(I^{2}=97.25, \operatorname{tau}= \pm 16.19\right)$.

Medium-term

Four studies investigated kinesiophobia. Van Oosterwijck et al. $(2013)^{58}$ compared PNE vs Self-management advice, with both groups showing decreases from baseline at 3 months of 3 and 1 points respectively on 17-68 TSK-CFS. The exact $P$ value was not provided however the authors did report it was not statistically significant. Pires et al. (2015) ${ }^{41}$ compared PNE plus aquatic therapy to aquatic therapy alone, with both groups showing decreases from baseline at 3 months of 5 
and 3 points respectively on $13-52$ TSK-13. This was not statistically significant. Lluch et al. (2018) ${ }^{25}$ compared PNE plus knee joint mobilisations and total knee replacement to biomedical education plus knee joint mobilisations and total knee replacement with both groups showing reductions from baseline at 5 months of 13 and 3 points on the 11-44 TSK-11. This reached statistical significance $(P<0.01)$ in favour of PNE. Bodes et al. (2018) ${ }^{2}$ compared PNE plus therapeutic exercise to therapeutic exercise alone with both groups showing reductions from baseline at 3 months of 13 and 4 points on 11-44 TSK-11. This reached statistical significance in favour of PNE; $\mathrm{P}=<.01$.

Long-term

No studies looked at kinesiophobia in the long term.

Possible sources of heterogeneity (Publication bias, study quality, age, \%male, baseline pain, duration of pain, PNE alone or PNE + intervention and duration of education) were explored using meta-regression analyses (See document SDC4).

For pain in the short-term all covariates were not significant $(P>0.05)$ except for PNE alone or PNE + intervention $(P=0.01)$, coefficient $=-8.9074$. For pain in the medium-term all covariates were not significant $(P>0.05)$.

For disability in the short-term all covariates were not significant $(P>0.05)$. For disability in the medium-term all covariates were not significant $(P>0.05)$ except for PNE alone or PNE + intervention $(P<0.01)$, coefficient $=-15.2197$ and duration of education $(P=0.03)$, coefficient $=-7.0841$. 
For PCS in the short-term all covariates were not significant $(P>0.05)$ except for PNE alone or PNE + intervention $(P<0.01)$, coefficient $=-7.6528$. For $P C S$ in the medium-term all covariates were not significant $(P>0.05)$ except for PNE alone or PNE + intervention $(P<0.01)$, coefficient $=-9.7706$ and duration of education $(P<$ 0.01 , coefficient $=-6.8079$.

For TSK in the short-term all covariates were not significant $(P>0.05)$ except for baseline pain $(P<0.01)$, coefficient $=-0.8468$.

\section{Qualitative component}

Two synthesised findings were generated from 23 study findings extracted from four studies (See document SDC5). Findings were illustrated using direct participant quotes and authors' descriptions, therefore they were assigned a mix of unequivocal and credible levels of credibility. Findings were grouped according to similarity of concept into five categories (See document SDC6), and two synthesised findings:

Synthesised finding 1: A comprehensive assessment allowing the patient to tell their own story should be undertaken to ensure they feel heard. This will also facilitate the identification of their prior understanding and beliefs. PNE can then be delivered in a manner relevant to that patient. In addition, patients clarifying their story to a healthcare professional may raise their awareness of the biopsychosocial nature of pain, promoting readiness to engage with PNE. (See SDC7).

Synthesised finding 2: Achieving pain reconceptualisation can enhance patients' ability to cope with their condition. To promote pain reconceptualisation PNE should 
be delivered by health care professionals (HCPs) skilled in PNE delivery and facilitation of group, or one-to-one interactions with, and between, patients and other HCPs. Progress towards reconceptualisation should be monitored throughout, tailoring concepts that have not been accommodated to ensure relevance of PNE to the individual. (See SDC8).

\section{Discussion}

This mixed methods review aimed to undertake a segregated synthesis of quantitative and qualitative studies to investigate the clinical effectiveness, and patients' experience of, PNE for people with CMP, Data from 12 RCTs $(n=755$ participants) demonstrated that PNE can reduce pain, disability, pain catastrophising and kinesiophobia in the short-to-medium-term. Data from four qualitative studies (n $=50$ participants) identified several key components important for enhancing the patient experience of PNE such as allowing the patient to tell their own story. These components can enhance pain reconceptualisation, which appears to be an important process to facilitate patients' ability to cope with their condition.

An improvement in clinical outcomes of $10 \%$ has been proposed as a minimally clinically important difference (MCID) in the recent NICE guidelines for back and radicular pain ${ }^{37}$. Pooled data showed a reduction in pain and disability in favour of PNE ranging from 3-8/100units, which are likely of little clinical benefit. In contrast, pooled data showed a reduction in pain catastrophising in favour of PNE of 5.26 units $(\mathrm{Cl}:-10.59$ to 0.08$)$ in the medium-term (A change of 5.2 units (10\%) is considered clinically meaningful) and a reduction in Kinesiophobia of 13.55/100 units 
(Cl: -25.89 to -1.21$)$ in the short-term. Thus, in the short-to-medium-term clinically meaningful improvements were seen in these psychosocial outcome measures.

Previous narrative reviews have concluded that there is 'compelling' and 'strong' evidence that PNE positively effects pain and disability ${ }^{26,29}$, which contrasts with our findings likely due to the differences in methodological approach and the inclusion of a number of additional studies not published at the time of those previous reviews ${ }^{2,25,30}$. Moseley and Butler $(2015)^{33}$ were more reserved in the conclusions of their narrative review stating that alone PNE is not a viable intervention for improving pain and disability. This is broadly in keeping with our findings.

Our findings for short-term pain relief $(-3.20 / 100 \mathrm{~mm})$ are similar in magnitude to the effect reported by Clarke et al. $(2011)^{7}(-5 / 100 \mathrm{~mm})$ and Wood and Hendrick, $(2018)^{63}$ $(-0.73 / 10)$. In contrast Tegner et al. $(2018)^{47}$ reported an improvement above the MCID (-1.03/10) more in keeping with previous narrative reviews ${ }^{26,29}$. Our findings for pain relief in the medium-term $(-4.22 / 100 \mathrm{~mm})$ also differ from Tegner et al. $(2018)^{47}$ who found a clinically relevant effect $(-1.09 / 10)$.

Our findings for short-erm disability (-4.10/100units) show smaller effects compared to Wood and Hendrick, $(2018)^{63}(-2.28 / 24)$ and Tegner et al. $(2018)^{47}(-1 / 10)$. In contrast our findings for medium-term disability (-8.23/100units) are similar in magnitude to Tegner et al. $2018(-0.82 / 10)^{47}$.

Previous narrative reviews have reported favourable findings for PNE reducing pain catastrophising ${ }^{7,26,29}$. Our findings in part support this previous work finding PNE to produce a clinically meaningful improvement in pain catastrophising in the mediumterm, though not the short-term. It may be that in the case of certain psychosocial measures there is a time lag in the effect. We can only hypothesise as to why this 
lag may occur though it may be that a period of reflection and experimentation with the knowledge gained from PNE is needed to facilitate pain reconceptualisation and/or clinical improvements.

For kinesiophobia previous narrative reviews have reported inconclusive findings with mixed results ${ }^{26,29}$ and no clear conclusions made. This differs to our work where we found PNE to have a greater effect on kinesiophobia than any other measure investigated in the short-term (-13.55\%). This is likely due to the inclusion of three recently published studies ${ }^{2,25,30}$, two of which found PNE to have a particularly large beneficial effect for kinesiophobia. Our findings for kinesiophobia in the short-term are greater than that of Tegner et al. $(2018)^{47}(-5.73 / 68)$ and Wood and Hendrick $(2018)^{63}(-4.72 / 52)$.

The current work builds on the three previous meta-analysis on $\mathrm{PNE}^{7,47,63}$. Firstly, we registered a protocol prior to commencing the review. Secondly, this is the first metaanalysis where the pooled data included the minimum five recommended studies to ensure sufficient statistical power ${ }^{22}$ Thirdly, the current work could isolate the effect of PNE through the inclusion of studies that compared (i) PNE to true control (or usual care), (ii) concomitant studies, where PNE has been delivered in addition to another intervention where that other intervention has been received by both groups, (iii) head-to-head studies where PNE has been compared to another active intervention. Finally, the current review meta-analysed data from studies' whose samples included heterogeneous CMP. This is the first meta-analysis to be performed on this sample in PNE. The second, third and final points may also go some way in explaining the differences in pooled effects found between the current and past reviews s,47,63. $^{7}$. 
With the exception of pain in the short-term, there was substantial heterogeneity between studies. To explore this heterogeneity a series of meta-regressions were undertaken. Greater effects for pain (short-term), disability (medium-term) and pain catastrophising (short and medium-term) were seen when PNE was combined with another intervention compared to PNE delivered in isolation. Similarly, greater effects for disability (medium-term) and pain catastrophising (medium-term) were seen when longer durations of PNE were delivered. However, the slopes of the meta-regressions were shallow indicating that the unit improvements in these outcomes for combined interventions (and longer duration interventions) are small and of questionable clinical relevance. Our findings are in keeping with Wood and Hendrick (2018) ${ }^{63}$ and a recent doctoral thesis meta-analysis reporting PNE combined with another therapy to be more effective than PNE alone for pain and disability in individuals with CLBP ${ }^{63,64}$. This finding is also in agreement with two previous narrative reviews ${ }^{29,33}$. However, the combination of PNE with other interventions should be done in a co-ordinated way to ensure that patients do not get mixed-messages potentially reducing the effectiveness of $\mathrm{PNE}^{43}$.

The two synthesised findings were split into principles to facilitate the mixed-methods analysis. See Table 7.

It was difficult to discern if the principles identified within the qualitative work were used by the included individual RCTs given the information provided. Only two principals were identified across the RCTs (S2a and S2c).

Principal S2a was identified in 6 RCTs where the skill of the PNE deliverer was described using terms such as 'experienced',2,25,35, 'with clinical experience ${ }^{\text {,30 }}$, and 'specially trained ${ }^{\prime 58,60}$. Whilst we interpreted these terms all to mean skilled in PNE 
delivery, we accept that it is possible that a HCP could be 'specially trained', 'experienced' or have 'clinical experience' and still not be 'skilled' in the delivery of PNE.

Four RCTs monitored pain reconceptualisation throughout PNE, tailoring concepts not understood to the individual (principal S2c). Pain reconceptualisation was monitored via participant questions in two RCTs ${ }^{30,48}$ whilst the two other RCTs used questionnaires ${ }^{25,58}$.

The qualitative synthesis suggests that PNE is helpful for coping with CMP when pain reconceptualisation is achieved (S2d). Our meta-analysis found PNE to produce clinically significant reductions in kinesiophobia (short-term) and pain catastrophising (medium-term). Whilst not a direct measure of pain reconceptualisation, they do provide an insight into how an individual understands their pain, and how threatened they feel because of it. We can infer that one of the ways PNE is helpful for coping is by reducing the threat value of pain. This less threatening and fearful state of being (reduced fear of movement and reduced catastrophic thinking) may change a patients' priority away from pain control towards pursuit of valued life goals, breaking the cycle of fear-avoidance-interference-negative affect-pain illustrated by the fearavoidance model of pain ${ }^{59}$. Furthermore, the patient may be more open to active interventions such as exercise, where previously this would have been avoided due to fear of pain, thus promoting recovery.

PNE usually includes pacing and graded exposure, such as the twin peaks model in the Explain Pain manual ${ }^{4}$. Importantly, this goes some way in showing the patient how to engage in their valued life goals/exercise whilst avoiding the Boom-Bust cycle. It is likely that working out how to engage in valued life goals/exercise will be 
challenging for patients, and thus may take time before progress is made in this domain. This is in part reflected in the quantitative component of this review where disability approached clinical significance in the medium-term, but not the short-term. As patients begin to master the skills of pacing and graded exposure, their engagement in valued life goals/exercise may increase, with associated decreases in disability.

\section{Strengths and Limitations}

One limitation of this review was that it did not look at economic outcomes such as cost effectiveness. A recent RCT on acute low back pain (and thus not eligible for this review) by Traeger et al. $(2018)^{54}$ found PNE to reduce health care utilisation at 3 months (but not 12 months) over control. Louw et al. ${ }^{27,28}$ and Moseley (2002) ${ }^{32}$ found PNE to reduce healthcare usage within a CMP sample and therefore may be a cost-effective intervention, an important consideration given the large financial burden associated with CMP.

The heterogeneity of design, participants, outcome measures, delivery methods and comparators could be considered a limitation of this review. Some may question the validity of pooling such data. However, by reporting $\mathrm{I}^{2}$ and Tau we have been transparent about the statistical heterogeneity and we have explored the heterogeneity using meta-regression.

Another limitation was that only studies published in English were eligible for inclusion as no facility for translation was available. Thus, important data from nonEnglish studies may have been missed.

Lack of response and/or inadequate reporting in the original studies resulted in the SD of change being estimated for four RCTs reporting on pain and disability, five 
studies reporting on pain catastrophising and three studies reporting on kinesiophobia. While this is accepted Cochrane review practice it is still an estimation.

There was a paucity of qualitative studies with three of those coming from our group. The studies from our group were assessed for quality by members of the review team who were not authors on those original qualitative studies to minimise bias.

\section{Conclusions and implications of this review}

\section{Implications for policy and practice}

The qualitative component of this review identified several important components for optimising the patient experience such as the need for a skilled clinician to deliver the intervention with expertise in group facilitation and/or one-to-one interactions. These have implications not just for how PNE should be delivered but also for the training of the education provider. The quantitative findings also provide useful direction for how PNE should be delivered to enhance effectiveness such as delivering longer total durations of PNE and combining PNE with other interventions.

\section{Implications for research}

Given the apparent additional effects of longer durations of PNE and delivering PNE in combination with other interventions, future research should explore the dosage response to PNE and combinations with other interventions to provide guidance on the development of optimal interventions. In addition, the qualitative component of this review has identified a number of components which optimise the patient experience. Quantitative studies are needed to explore what influence optimising 
these components have on patient outcomes. More studies investigating costeffectiveness are needed. There is a need for more RCTs to investigate the longterm effectiveness of PNE. There is a need for more qualitative research into PNE from a wider number of research groups to explore and enhance the transferability of our qualitative findings.

\section{References}

1. Altman R, Asch E, Bloch D, Bole G, Borenstein D, Brandt K, Christy W, Cooke TD, Greenwald R, Hochberg M, Howell D. Development of criteria for the classification and reporting of osteoarthritis: classification of osteoarthritis of the knee. Arthritis Rheum 29:103949, 1986

2. Bodes GP, Lluch EG, Roussel NA, Gallego TI, Jimenez VP, Pecos DM. Pain Neurophysiology Education and Therapeutic Exercise for Patients With Chronic Low Back Pain: A Single-Blind Randomized Controlled Trial. Arch Phys Med Rehabil 99:338-47, 2018

3. Breivik H, Collett B, Ventafridda V, Cohen R, Gallacher D. Survey of chronic pain in Europe: prevalence, impact on daily life, and treatment. Eur J Pain 10:287-333, 2006

4. Butler DS, Moseley GL. Explain pain. Adelaide, S. Aust. Noigroup, 2003.

5. Butler DS, Moseley GL. Explicando el dolor. Noigroup Publications; 2010.

6. Busse JW, Bartlett SJ, Dougados M, Johnston BC, Guyatt GH, Kirwan JR, Kwoh K, Maxwell LJ, Moore A, Singh JA, Stevens R. Optimal strategies for reporting pain in clinical trials and systematic reviews: recommendations from an OMERACT 12 workshop. J Rheumatol 2015. Available from http://www.jrheum.org/content/early/2015/05/11/jrheum.141440.tab-article-info [Accessed 26/06/2018]

7. Clarke CL, Ryan CG, Martin DJ. Pain neurophysiology education for the management of individuals with chronic low back pain: A systematic review and meta-analysis. Man ther $16: 544-49,2011$

8. Cuenda-Gago JD, Espejo-Antunez L. Effectiveness of education based on neuroscience in the treatment of musculoskeletal chronic pain. Rev Neurol 65:1-12, 2017 
9. Frost H, Lamb SE, Doll HA, Carver PT, Stewart-Brown S. Randomised controlled trial of physiotherapy compared with advice for low back pain. BMJ 329:708, 2004

10. Fukuda K, Straus SE, Hickie I, Sharpe MC, Dobbins JG, Komaroff A. The chronic fatigue syndrome: a comprehensive approach to its definition and study. International Chronic Fatigue Syndrome Study Group. Ann Intern Med 121:953-9, 1994

11. Gallagher L, McAuley J, Moseley, GL. A randomized-controlled trial of using a book of metaphors to reconceptualize pain and decrease catastrophizing in people with chronic pain. Clin J Pain 29:20-5, 2013

12. Geneen LJ, Martin DJ, Adams N, Clarke C, Dunbar M, Jones D, McNamee P, Schofield P, Smith BH. Effects of education to facilitate knowledge about chronic pain for adults: a systematic review with meta-analysis. Syst Rev 4:132, 2015

13. Gifford L. Pain, the tissues and the nervous system: a conceptual model. Physiotherapy $84: 27-36,1998$

14. Goldberg DS, McGee SJ. Pain as a global public health priority. BMC public health 11:770, 2011

15. Guyatt GH, Oxman AD, Vist GE, Kunz R, Falck-Ytter Y, Alonso-Coello P, Schünemann HJ. GRADE: an emerging consensus on rating quality of evidence and strength of recommendations. BMJ 336:924-26, 2008

16. Hartvigsen J, Hancock MJ, Kongsted A, Louw Q, Ferreira ML, Genevay S, Hoy D, Karppinen J, Pransky G, Sieper J, Smeets RJ. What low back pain is and why we need to pay attention. Lancet 1-12, 2018

17. Higgins JP, Altman DG, Sterne JA. Chapter 8: Assessing risk of bias in included studies. In: Higgins JP, Green S, editor(s). Cochrane Handbook for Systematic Reviews of Interventions Version 5.1.0 (updated March 2011). The Cochrane Collaboration, 2011. Available from handbook.cochrane.org. [Accessed 26/06/2018].

18. Higgins JPT, Deeks JJ, Altman DG (editors). Chapter 16: Special topics in statistics. In: Higgins JPT, Green S (editors), Cochrane Handbook for Systematic Reviews of Interventions Version 5.1.0 (updated March 2011). The Cochrane Collaboration, 2011. Available from www.handbook.cochrane.org. [Accessed 26/06/2018]. 
19. Hong J, Reed C, Novick D. Happich M. Costs associated with treatment of chronic low back pain: an analysis of the UK General Practice Research Database. Spine 38:75-82, 2013

20. Hong QN, Pluye P, Bujold M, Wassef M. Convergent and sequential synthesis designs: implications for conducting and reporting systematic reviews of qualitative and quantitative evidence. Syst Rev 6:61, 2017

21. IntHout J, loannidis JP, Rovers MM and Goeman JJ. Plea for routinely presenting prediction intervals in meta-analysis. BMJ open, 6(7), 2016

22. Jackson D, Turner R. Power analysis for random-effects meta-analysis. Res Synth Methods 8:290-302, 2017

23. King R, Robinson V, Elliot-Button HL, Watson JA, Ryan CG, Martin DJ. Pain reconceptualisation after Pain Neurophysiology Education in Adults with Chronic Low Back Pain: A Qualitative Study. Pain Res Treat 1-10, 2018

24. King R, Robinson V, Ryan CG, Martin DJ. An exploration of the extent and nature of reconceptualisation of pain following pain neurophysiology education: A qualitative study of experiences of people with chronic musculoskeletal pain. Patient Educ Couns 99:1389-93, 2016

25. Lluch E, Dueñas L, Falla D, Baert I, Meeus M, Sánchez-Frutos J, Nijs J. Preoperative pain neuroscience education combined with knee joint mobilization for knee osteoarthritis: a randomized controlled trial. Clin J Pain 34:44-52, 2018

26. Louw A, Diener I, Butler DS, Puentedura EJ. The effect of neuroscience education on pain, disability, anxiety, and stress in chronic musculoskeletal pain. Arch Phys Med Rehabil 92:2041-56, 2011

27. Louw A, Diener I, Landers MR, Puentedura EJ. Preoperative pain neuroscience education for lumbar radiculopathy: a multicenter randomized controlled trial with 1-year follow-up. Spine $39: 1449-57,2014$

28. Louw A, Diener I, Landers MR, Zimney K, Puentedura EJ. Three-year follow-up of a randomized controlled trial comparing preoperative neuroscience education for patients undergoing surgery for lumbar radiculopathy. J Spine Surg 2:289, 2016 
29. Louw A, Zimney K, Puentedura EJ, Diener I. The efficacy of pain neuroscience education on musculoskeletal pain: A systematic review of the literature. Physiother Theory Pract 32:33255,2016

30. Malfliet A, Kregel J, Meeus M, Roussel N, Danneels L, Cagnie B, Dolphens M, Nijs J. Blended-Learning Pain Neuroscience Education for People With Chronic Spinal Pain: Randomized Controlled Multicenter Trial. Phys Ther 98:357-68, 2018

31. Meeus M, Nijs J, Van Oosterwijck J, Van Alsenoy V, Truijen S. Pain physiology education improves pain beliefs in patients with chronic fatigue syndrome compared with pacing and self-management education: a double-blind randomized controlled trial. Arch Phys Med Rehabil 91:1153-59, 2010

32. Moseley L. Combined physiotherapy and education is efficacious for chronic low back pain. Aust J Physiother 48:297-302, 2002

33. Moseley GL, Butler DS. Fifteen years of explaining pain: the past, present, and future. J Pain $16: 807-13,2015$

34. Moseley GL, Butler DS. Explain pain supercharged. Adelaide: Noigroup Publications, 2017.

35. Moseley GL, Nicholas MK, Hodges PW. A randómized controlled trial of intensive neurophysiology education in chronic low back pain. Clin J Pain 20:324-30, 2004

36. Munn A, Porritt K, Lockwood C, Aromataris E, Pearson A. Establishing confidence in the output of qualitative research synthesis: The ConQual approach. BMC Med Res Methodol $14: 108,2014$

37. National Institute for Health and Clinical Excellence (NICE) (2016) Low back pain and sciatica in over 16s: assessment and management draft. (NICE guideline NG59). https://www. nice.org.uk/guidance/ng59/documents/draft-guideline. Accessed October 2018.

38. National Institute for Health and Clinical Excellence (NICE) (2016) Low back pain and sciatica in over 16s: assessment and management. (NICE guideline NG59). https://www.nice.org.uk/guidance/ng59. Accessed October 1, 2018.

39. National Institute for Health and Clinical Excellence (NICE) (2009) Low back pain: early management of persistent non-specific low back pain. 2009; NICE clinical guideline 88. 
40. National Institute for Health and Clinical Excellence (NICE) (2015) Osteoarthritis (Quality standard [QS87] ). https://www.nice.org.uk/guidance/qs87. Accessed October 1, 2018.

41. Pires D, Cruz EB, Caeiro C. Aquatic exercise and pain neurophysiology education versus aquatic exercise alone for patients with chronic low back pain: a randomized controlled trial. Clin Rehabil 29:538-47, 2015

42. Robinson V, King R, Ryan CG, Martin DJ. A qualitative exploration of people's experiences of pain neurophysiological education for chronic pain: The importance of relevance for the individual. Man Ther 22:56-61, 2016

43. Ryan CG, Gray HG, Newton M, Granat MH. Pain biology education and exercise classes compared to pain biology education alone for individuals with chronic low back pain: a pilot randomised controlled trial. Man Ther 15:382-87, 2010

44. Sandelowski M, Voils Cl, Barroso J. Defining and designing mixed research synthesis studies. Res Sch 13:29, 2006

45. Sandelowski M, Voils Cl, Leeman J, Crandell JL. Mapping the mixed methods-mixed research synthesis terrain. J Mix Methods Res 6:317-31, 2012

46. Simons DG, Travell JG, Simons LS. Myofascial pain and dysfunction: the trigger point manual, vol 1. Upper half of body. Baltimore, MA: Williams \& Wilkins. 1999:11-89.

47. Tegner H, Frederiksen P, Esbensen BA, Juhl C. Neurophysiological Pain Education for Patients With Chronic Low Back Pain. Clin J Pain 34:778-86, 2018

48. Téllez-García M, de-la-Llave-Rincón AI, Salom-Moreno J, Palacios-Ceña M, Ortega-Santiago R, Fernández-de-las-Peñas C. Neuroscience education in addition to trigger point dry needling for the management of patients with mechanical chronic low back pain: $\mathrm{A}$ preliminary clinical trial. J Bodyw Mov Ther 19:464-72, 2015

49. The British Pain Society. Guidelines for Pain Management Programmes for adults - An evidence-based review prepared on behalf of the British Pain Society. $2^{\text {nd }}$ Ed. The British Pain Society. London: The British Pain Society; 2013.

https://www.britishpainsociety.org/static/uploads/resources/files/pmp2013 main FINAL v6.p df. Accessed October 1, 2018.

50. The Joanna Briggs Institute (JBI-a). Critical Appraisal Tools. http://joannabriggs.org/research/critical-appraisal-tools.html. 2018. Accessed October 1, 2018. 
51. The Joanna Briggs Institute (JBI-b). Joanna Briggs Institute Reviewers' Manual: 2014 edition / Supplement. 2014 Edition ed. Adelaide: The Joanna Briggs Institute; 2014. http://joannabriggs.org/assets/docs/sumari/ReviewersManual Mixed-Methods-ReviewMethods-2014-ch1.pdf. Accessed October 1, 2018.

52. The Joanna Briggs Institute (JBI-c). Joanna Briggs Institute Reviewer's Manual. Aromataris E, Munn Z, editors. Joanna Briggs Institute Reviewer's Manual. Adelaide. Joanna Briggs Institute. 2017. https://reviewersmanual.joannabriggs.org/. Accessed October 1, 2018.

53. The Joanna Briggs Institute (JBI-d). The System for the Unified Management, Assessment and Review of Information (SUMARI) is the Joanna Briggs Institute's premier software for the systematic review of literature. JBI SUMARI. https://www.jbisumari.org. 2017. Accessed October 1, 2018.

54. Traeger AC, Lee H, Hübscher M, Skinner IW, Moseley GL, Nicholas MK, Henschke N, Refshauge KM, Blyth FM, Main CJ and Hush JM. Effect of Intensive Patient Education vs Placebo Patient Education on Outcomes in Patients With Acute Low Back Pain: A Randomized Clinical Trial. JAMA neurol., 2018

55. Turk DC, McCarberg B. Non-pharmacological treatments for chronic pain: a disease management context. Dis Manag Health Out 13:19-30, 2004

56. Tüzün EH. Quality of life in chronic musculoskeletal pain. Best Pract Res Clin Rhumatol $21: 567-79,2007$

57. van Ittersum MW, Wilgen CP, Schans CP, Lambrecht L, Groothoff JW, Nijs J. Written pain neuroscience education in fibromyalgia: A multicenter randomized controlled trial. Pain Pract 2014;14:689-700, 2014

58. Van Oosterwijck J, Meeus M, Paul L, De Schryver M, Pascal A, Lambrecht L, Nijs J. Pain physiology education improves health status and endogenous pain inhibition in fibromyalgia: a double-blind randomized controlled trial. Clin J Pain 29:873-82, 2013

59. Vlaeyen JW, Crombez G, Linton SJ. The fear-avoidance model of pain. Pain 157:1588-89, 2016

60. Von Bertouch L, McAuley JH, Moseley GL. Explaining pain before a multidisciplinary pain management programme improves long term pain and disability outcomes. Proceedings of the Australian Pain Society 31st annual scientific meeting, Darwin, Australia, 2011. 
61. Wijma AJ, Speksnijder CM, Crom-Ottens AF, Knulst-Verlaan JC, Keizer D, Nijs J, van Wilgen, $\mathrm{CP}$. What is important in transdisciplinary pain neuroscience education? A qualitative study. Disabil Rehabil 40:1-11, 2017

62. Wolfe F, Smythe HA, Yunus MB, Bennett RM, Bombardier C, Goldenberg DL, Tugwell P, Campbell SM. Abeles M, Clark P, Fam AG. The American College of Rheumatology 1990 criteria for the classification of fibromyalgia: report of the Multicenter Criteria Committee. Arthritis Rheum 33:160-72, 1990

63. Wood L, Hendrick P. A systematic review and meta-analysis of pain neuroscience education for chronic low back pain: short-and long-term outcomes of pain and disability. Eur J Pain 2018. https://onlinelibrary.wiley.com/doi/abs/10.1002/ejp.1314. Accessed October 1, 2018.

64. Yun J. A comparison of pain neurophysiology education with therapeutic interventions versus therapeutic interventions alone on pain and function in individuals with chronic low back pain: a meta-analysis (Doctoral dissertation).

http://repository.library.fresnostate.edu/handle/10211.3/192495. Accessed October 1, 2018.

65. Zimney K, Louw A, Puentedura EJ. Use of Therapeutic Neuroscience Education to address psychosocial factors associated with acute low back pain: A case report. Physiother Theory Pract 30:202-9, 2014

Figures: 


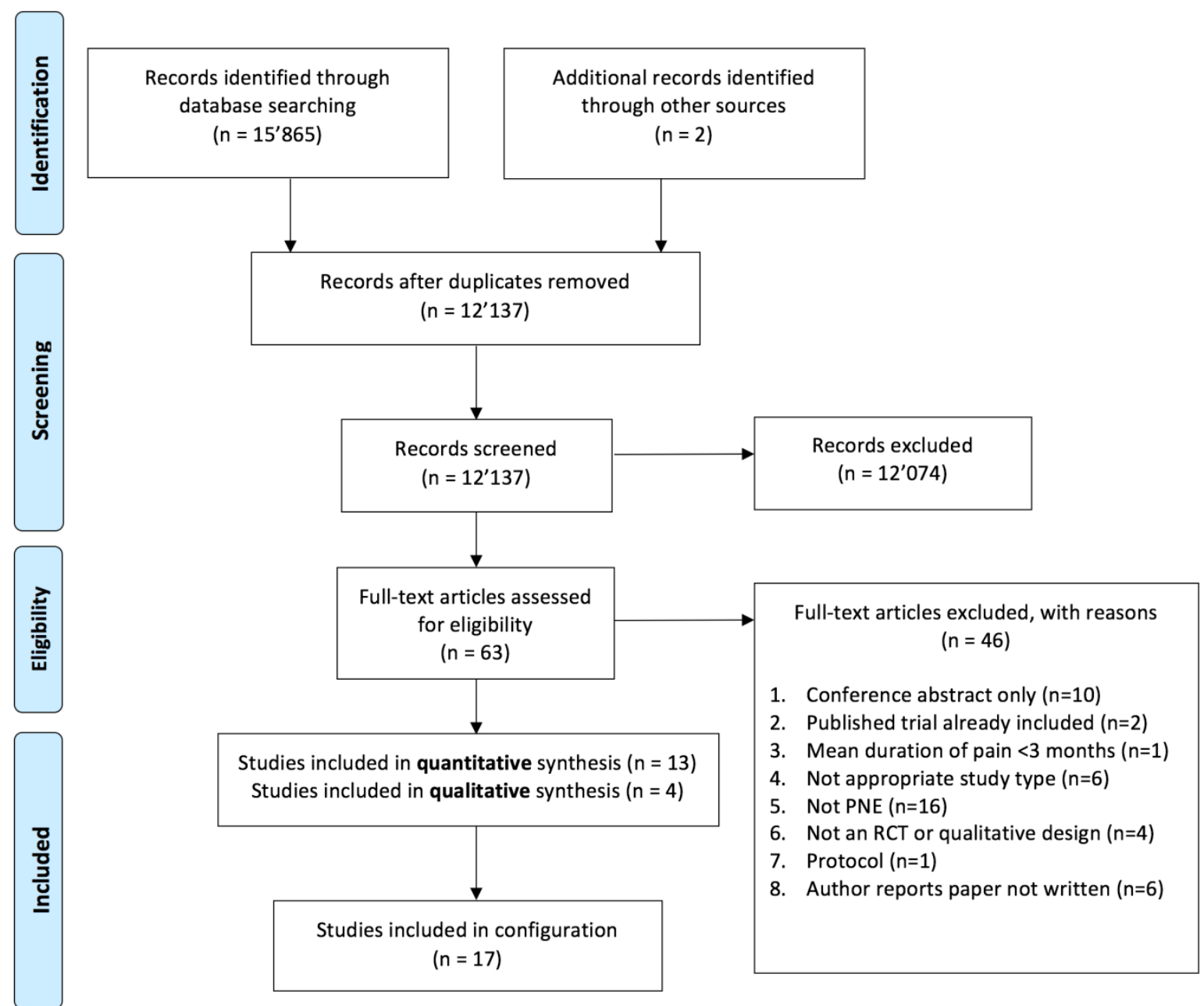

Figure 1: PRISMA flow diagram of search and study selection process

Random sequence generation (selection bias)

Allocation concealment (selection bias)

Blinding of participants and personnel (performance bias)

Blinding of outcome assessment (detection bias)

Incomplete outcome data (attrition bias)

Selective reporting (reporting bias)

Other bias

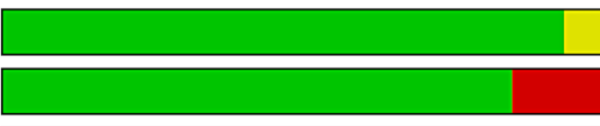

-
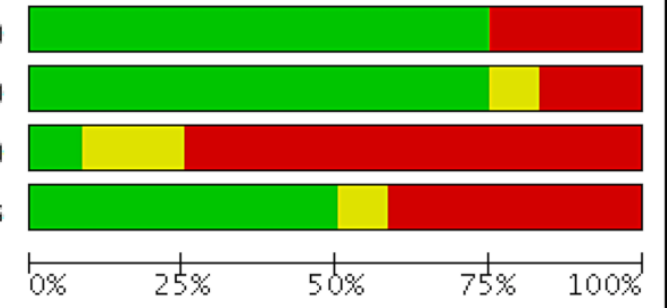
Figure 2: Risk of bias graph: review authors' judgements about each risk of bias item presented as percentages across all included studies.

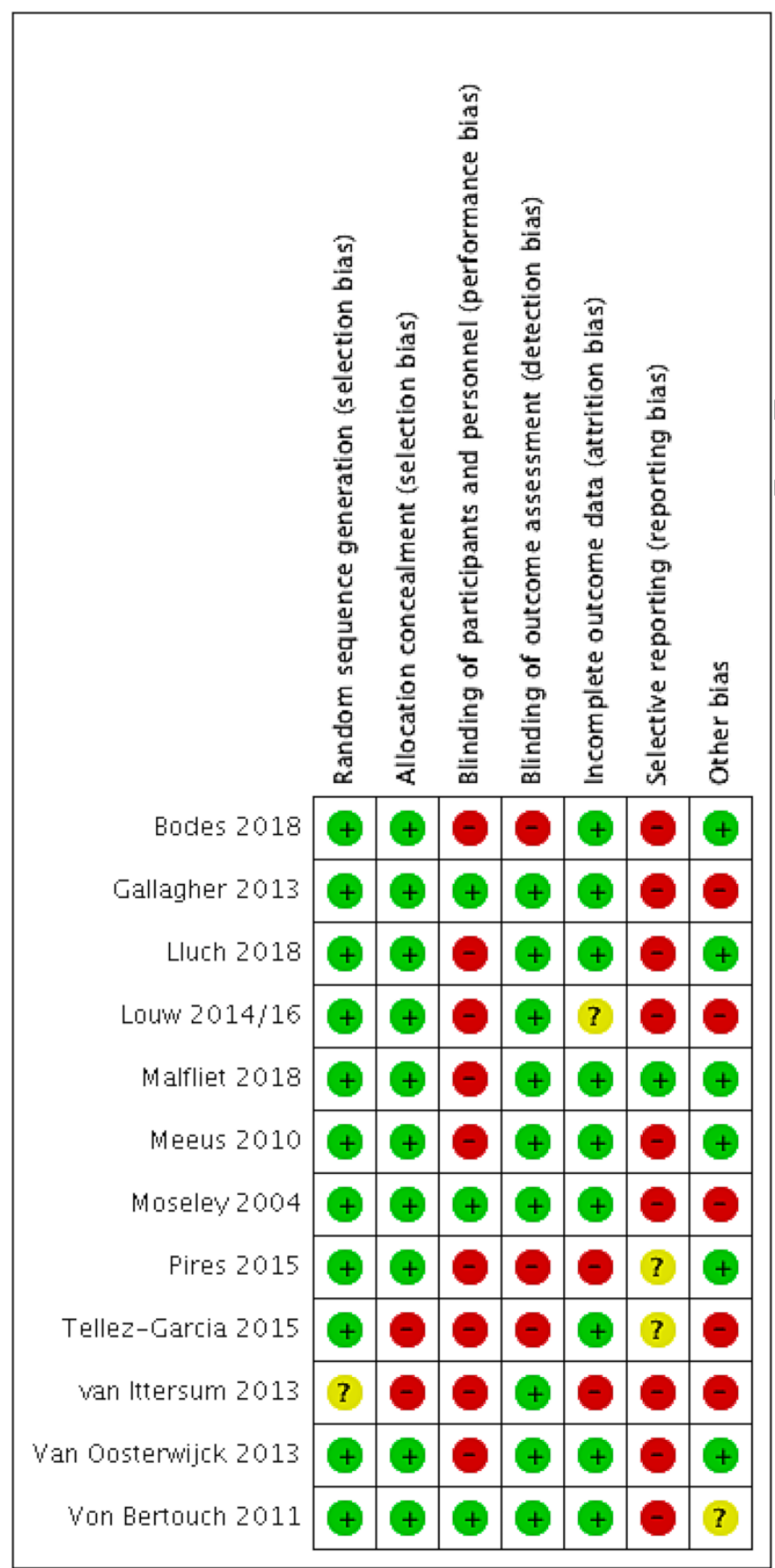


Figure 3: Risk of bias summary: review authors' judgements about each risk of bias item for each included study.

\section{Pain - Short Term}

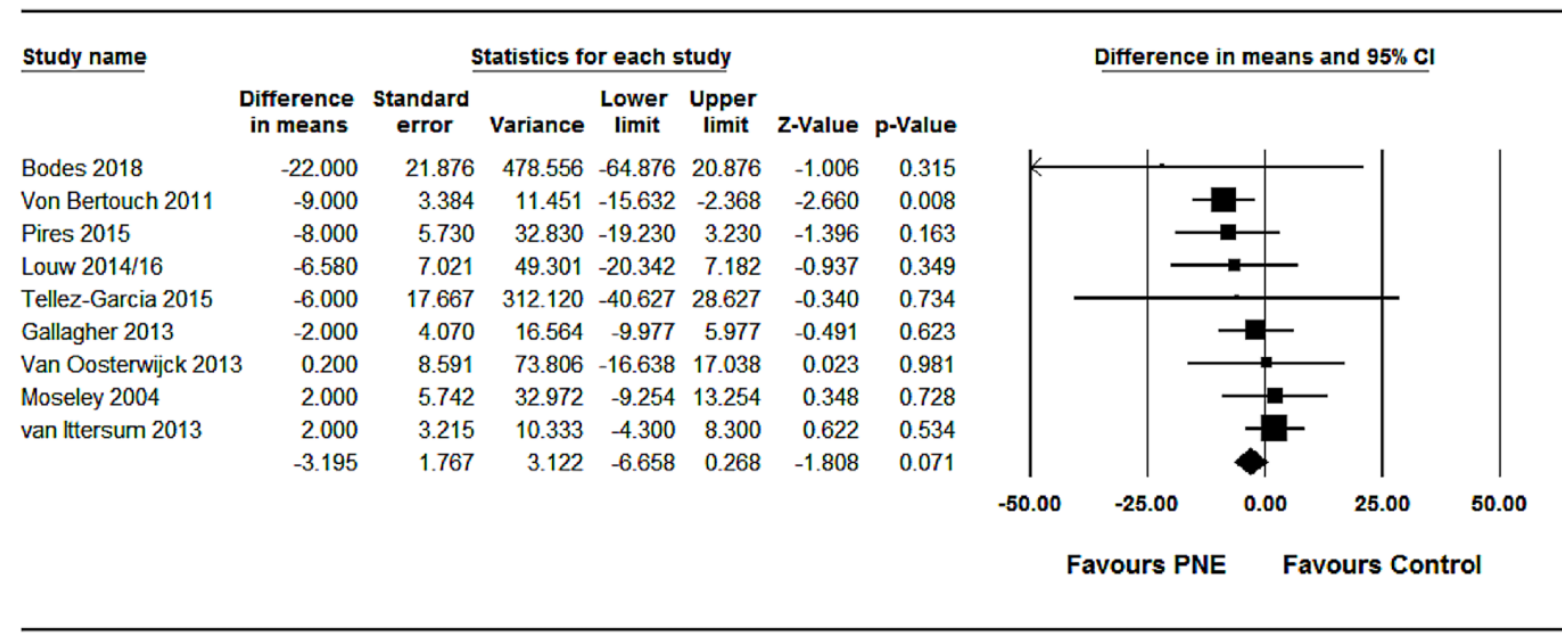

Figure 4: Forest plot of PNE versus control in short-term; primary outcome pain. The $95 \%$ prediction interval for the mean effect was -7.95 to 1.56 . 


\section{Pain - Medium Term}

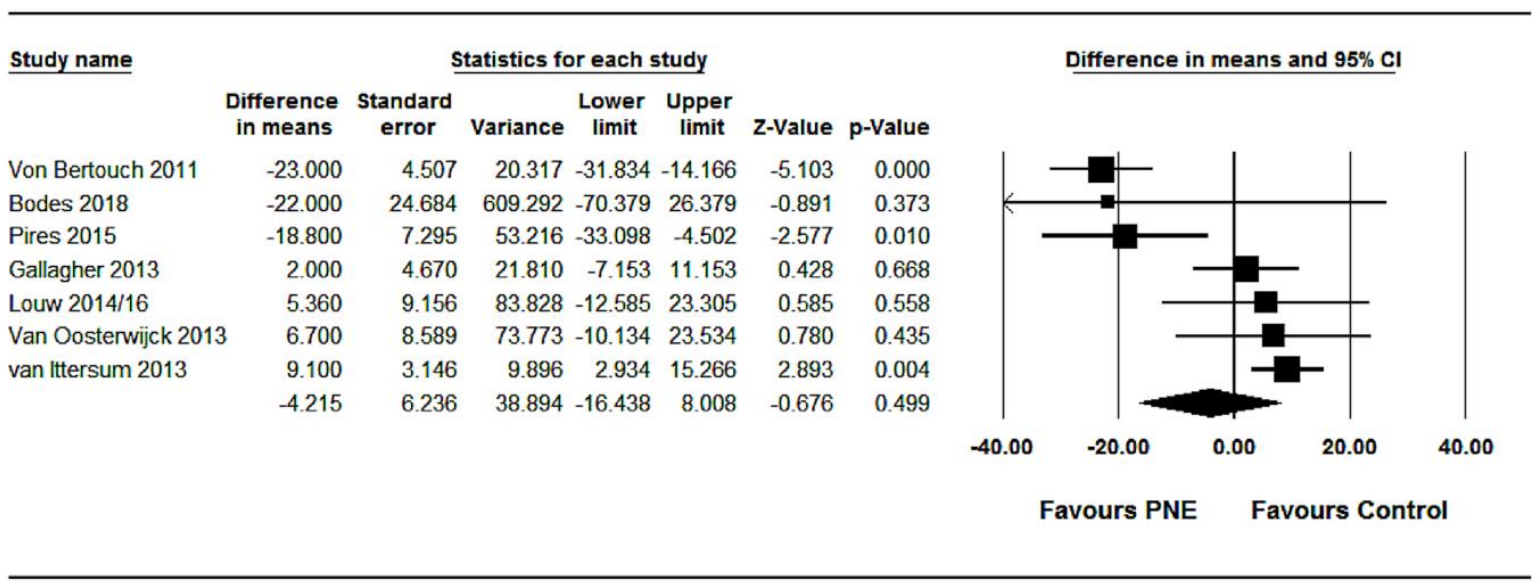

Figure 5: Forest plot of PNE versus control in medium-term; primary outcome pain.

The $95 \%$ prediction interval for the mean effect was -42.38 to 33.95 .

\section{Disability - Short Term}

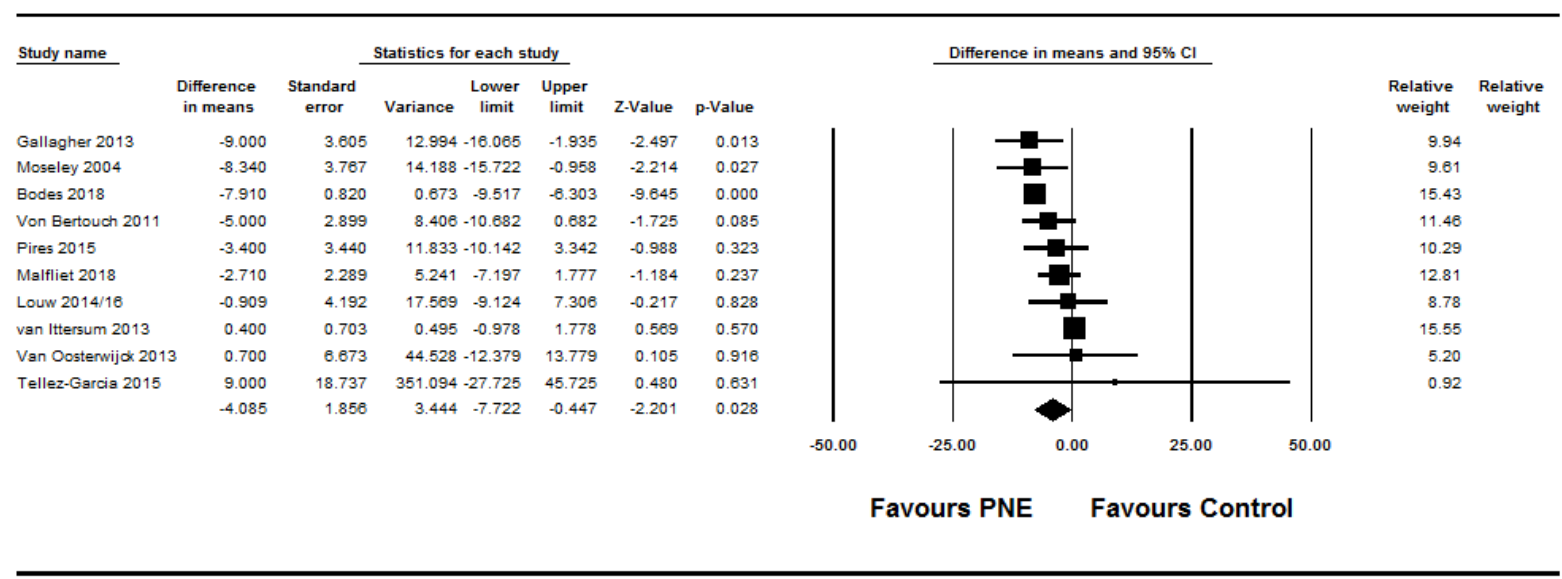

Figure 6: Forest plot of PNE versus control in short-term; primary outcome disability.

The $95 \%$ prediction interval for the mean effect was -15.42 to 7.25 . 


\section{Disability - Medium Term}

\begin{tabular}{|c|c|c|c|c|c|c|c|}
\hline \multirow[t]{2}{*}{ Study name } & \multicolumn{7}{|c|}{ Statistics for each study } \\
\hline & $\begin{array}{l}\text { Difference } \\
\text { in means }\end{array}$ & $\begin{array}{l}\text { Standard } \\
\text { error }\end{array}$ & Variance & $\begin{array}{l}\text { Lower } \\
\text { limit }\end{array}$ & $\begin{array}{c}\text { Upper } \\
\text { limit }\end{array}$ & Z-Value & p-Value \\
\hline Von Bertouch 2011 & -27.000 & 3.354 & 11.252 & -33.575 & -20.425 & -8.049 & 0.000 \\
\hline Bodes 2018 & -11.660 & 1.025 & 1.051 & -13.669 & -9.651 & -11.375 & 0.000 \\
\hline Pires 2015 & -10.900 & 3.767 & 14.193 & -18.284 & -3.516 & -2.893 & 0.004 \\
\hline Gallagher 2013 & -5.000 & 4.163 & 17.333 & -13.160 & 3.160 & -1.201 & 0.230 \\
\hline Van Oosterwijck 2013 & -1.600 & 6.908 & 47.716 & -15.139 & 11.939 & -0.232 & 0.817 \\
\hline van Ittersum 2013 & 0.800 & 0.864 & 0.746 & -0.893 & 2.493 & 0.926 & 0.354 \\
\hline \multirow[t]{2}{*}{ Louw 2014/16 } & 1.468 & 5.882 & 34.597 & -10.060 & 12.996 & 0.250 & 0.803 \\
\hline & -8.140 & 3.807 & 14.490 & -15.600 & -0.679 & -2.138 & 0.032 \\
\hline
\end{tabular}

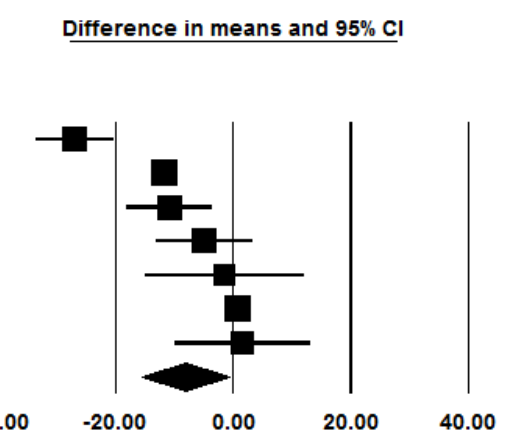

Favours PNE Favours Control

Figure 7: Forest plot of PNE versus control in medium-term; primary outcome disability. The $95 \%$ prediction interval for the mean effect was -32.62 to 16.34 . 


\section{PCS - Short Term}

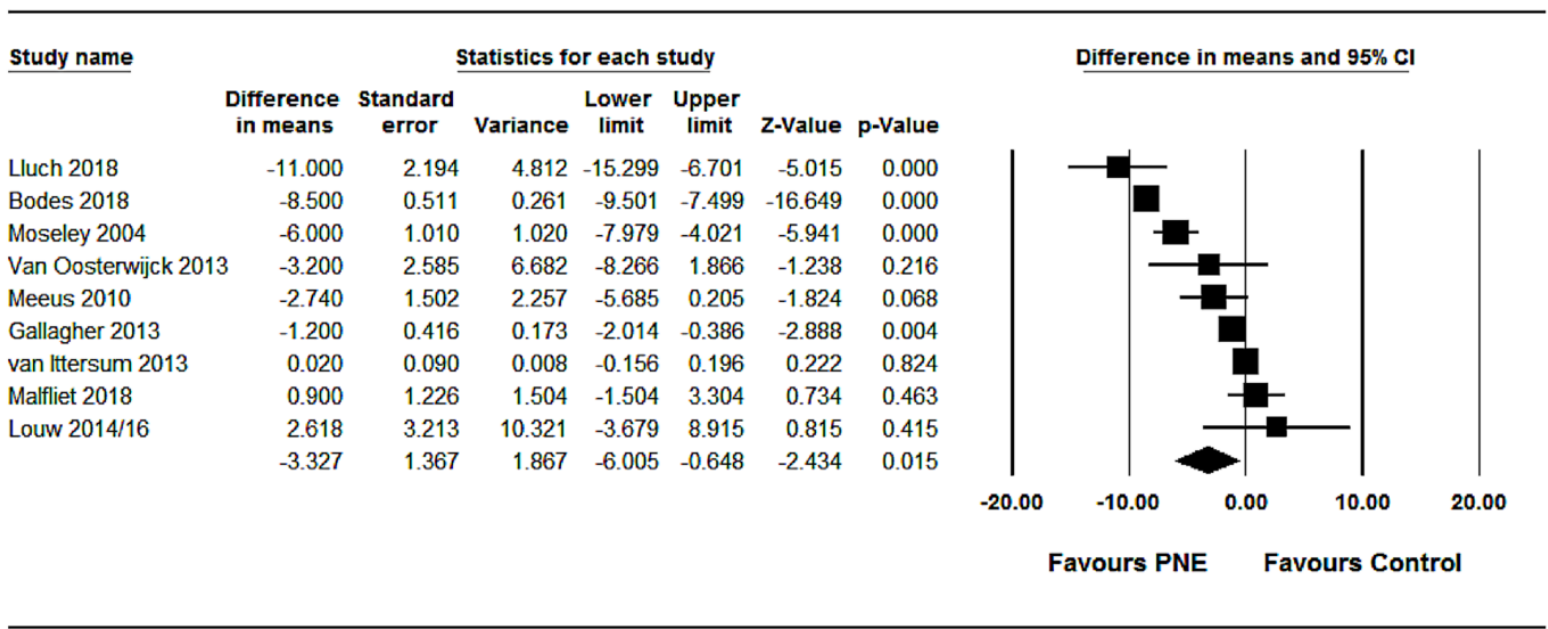

Figure 8: Forest plot of PNE versus control in short-term; secondary outcome pain catastrophising. The $95 \%$ prediction interval for the mean effect was -12.61 to 5.96 .

\section{PCS - Medium Term}

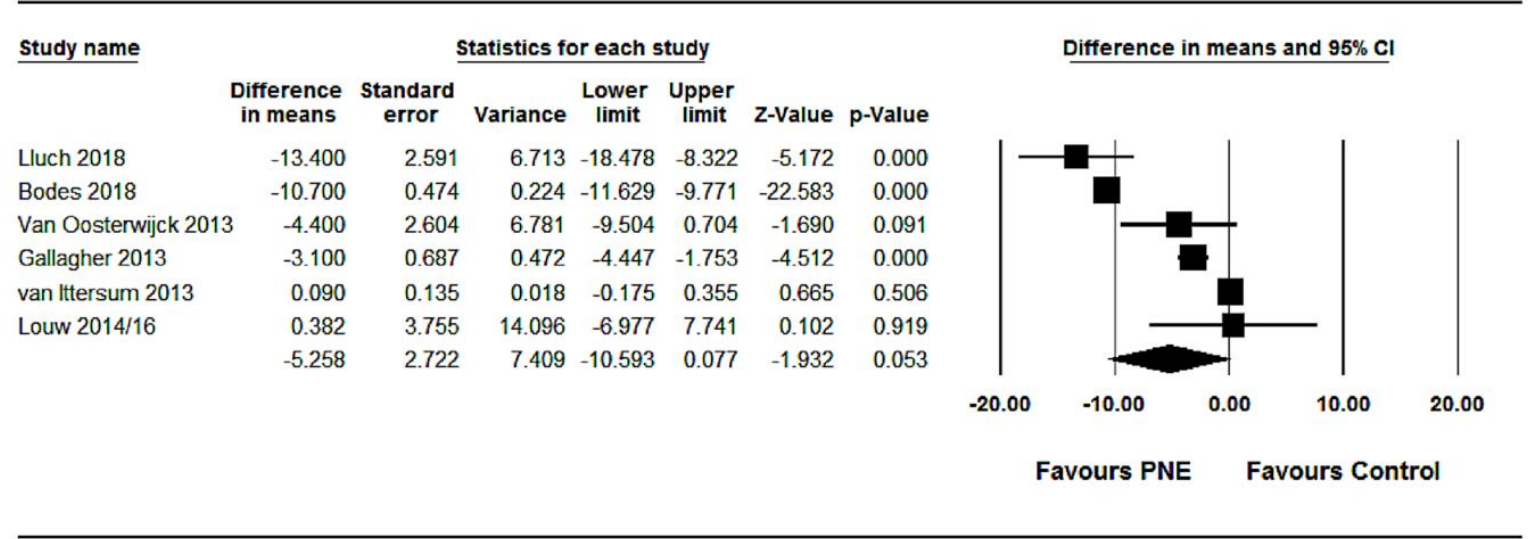

Figure 9: Forest plot of PNE versus control in medium-term; secondary outcome pain catastrophising. The $95 \%$ prediction interval for the mean effect was -23.01 to 12.49 . 


\section{TSK - Short Term}

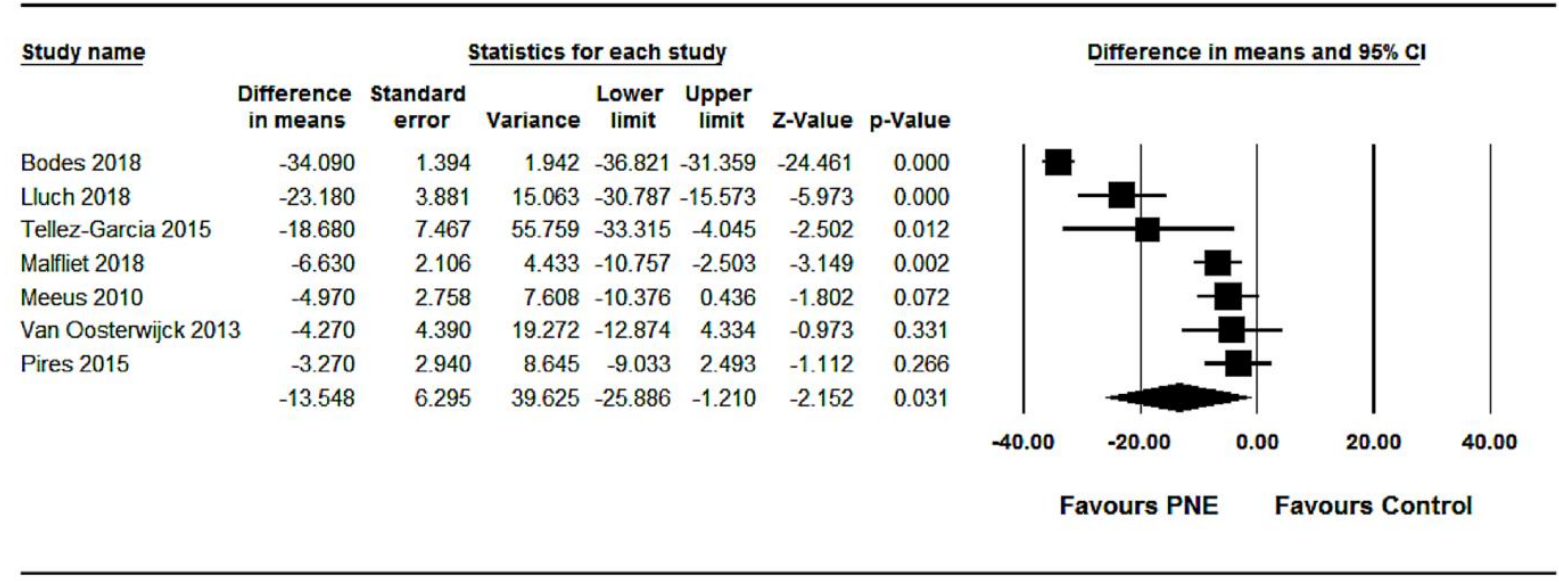

Figure 10: Forest plot of PNE versus control in short-term; secondary outcome kinesiophobia. The $95 \%$ prediction interval for the mean effect was -56.06 to 28.96 .

Tables:

Table 1 Summary of findings

\section{PNE compared to control for treatment of adults with chronic musculoskeletal pain}

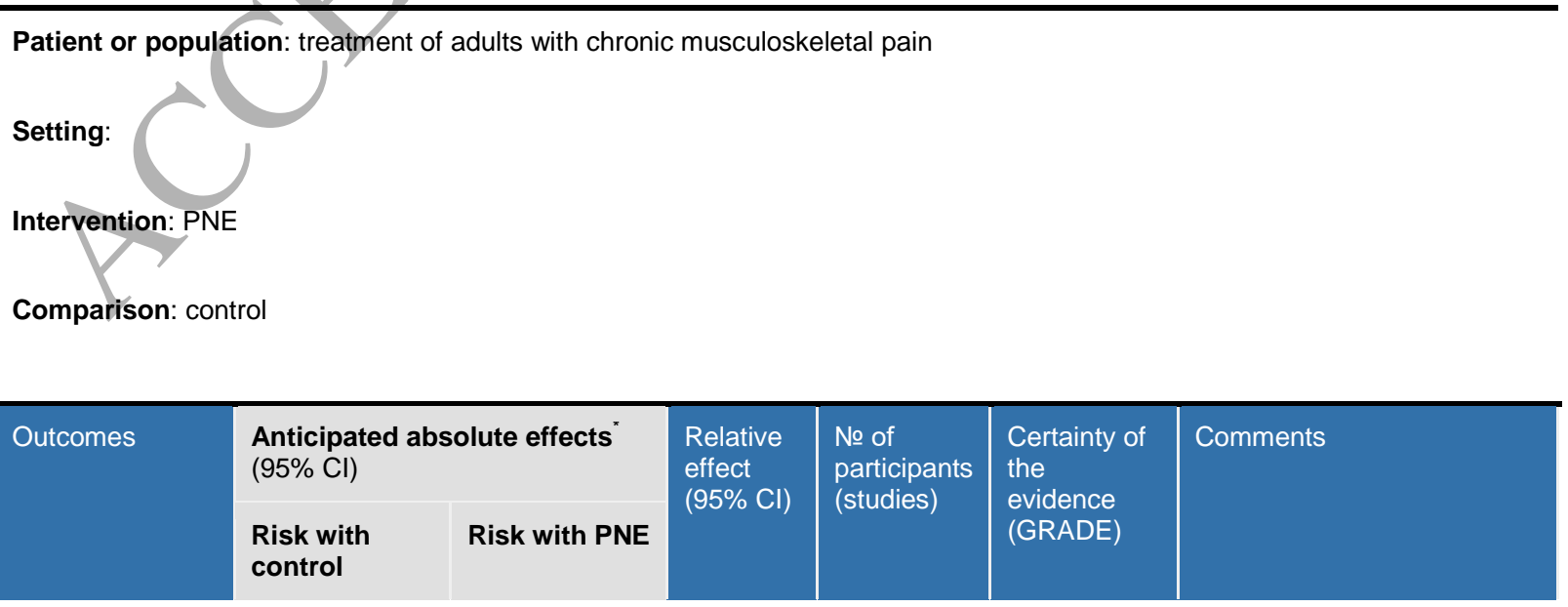




\section{PNE compared to control for treatment of adults with chronic musculoskeletal pain}

Patient or population: treatment of adults with chronic musculoskeletal pain

\section{Setting:}

Intervention: PNE

Comparison: control

\begin{tabular}{|c|c|c|c|c|c|c|}
\hline \multirow[t]{2}{*}{ Outcomes } & \multicolumn{2}{|c|}{$\begin{array}{l}\text { Anticipated absolute effects } \\
(95 \% \mathrm{Cl})\end{array}$} & \multirow{2}{*}{$\begin{array}{l}\text { Relative } \\
\text { effect } \\
(95 \% \mathrm{Cl})\end{array}$} & \multirow{2}{*}{$\begin{array}{l}\text { № of } \\
\text { participants } \\
\text { (studies) }\end{array}$} & \multirow{2}{*}{$\begin{array}{l}\text { Certainty of } \\
\text { the } \\
\text { evidence } \\
\text { (GRADE) }\end{array}$} & \multirow[t]{2}{*}{ Comments } \\
\hline & $\begin{array}{l}\text { Risk with } \\
\text { control }\end{array}$ & Risk with PNE & & & & \\
\hline $\begin{array}{l}\text { Pain score in } \\
\text { the short term } \\
\text { (ST Pain) } \\
\text { assessed with: } \\
100 \mathrm{~mm} \text { VAS } \\
\text { Scale from: } 0 \\
\text { to } 100 \text { (Higher } \\
\text { is worse) }\end{array}$ & $\begin{array}{l}\text { The mean } \\
\text { change in pain } \\
\text { score in the } \\
\text { short term was } \\
-15 \mathrm{~mm}\end{array}$ & $\begin{array}{l}\text { The mean } \\
\text { change in pain } \\
\text { score in the } \\
\text { short term in } \\
\text { the } \\
\text { intervention } \\
\text { group was } \\
\text { 3mm lower (7 } \\
\text { lower to } 0 \\
\text { higher) than } \\
\text { the control } \\
\text { group }\end{array}$ & - & 524 & 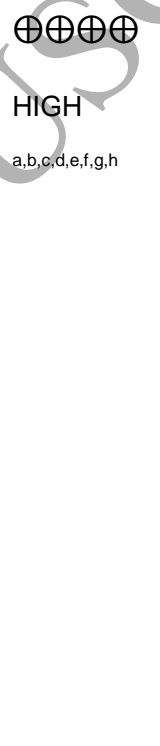 & $\begin{array}{l}\text { Lower score indicates lower } \\
\text { pain. A change of less than } \\
10 \mathrm{~mm} \text { is considered not } \\
\text { clinically important. PNE } \\
\text { does not reduce pain score } \\
\text { in the short term. }\end{array}$ \\
\hline
\end{tabular}




\section{PNE compared to control for treatment of adults with chronic musculoskeletal pain}

Patient or population: treatment of adults with chronic musculoskeletal pain

\section{Setting:}

Intervention: PNE

Comparison: control

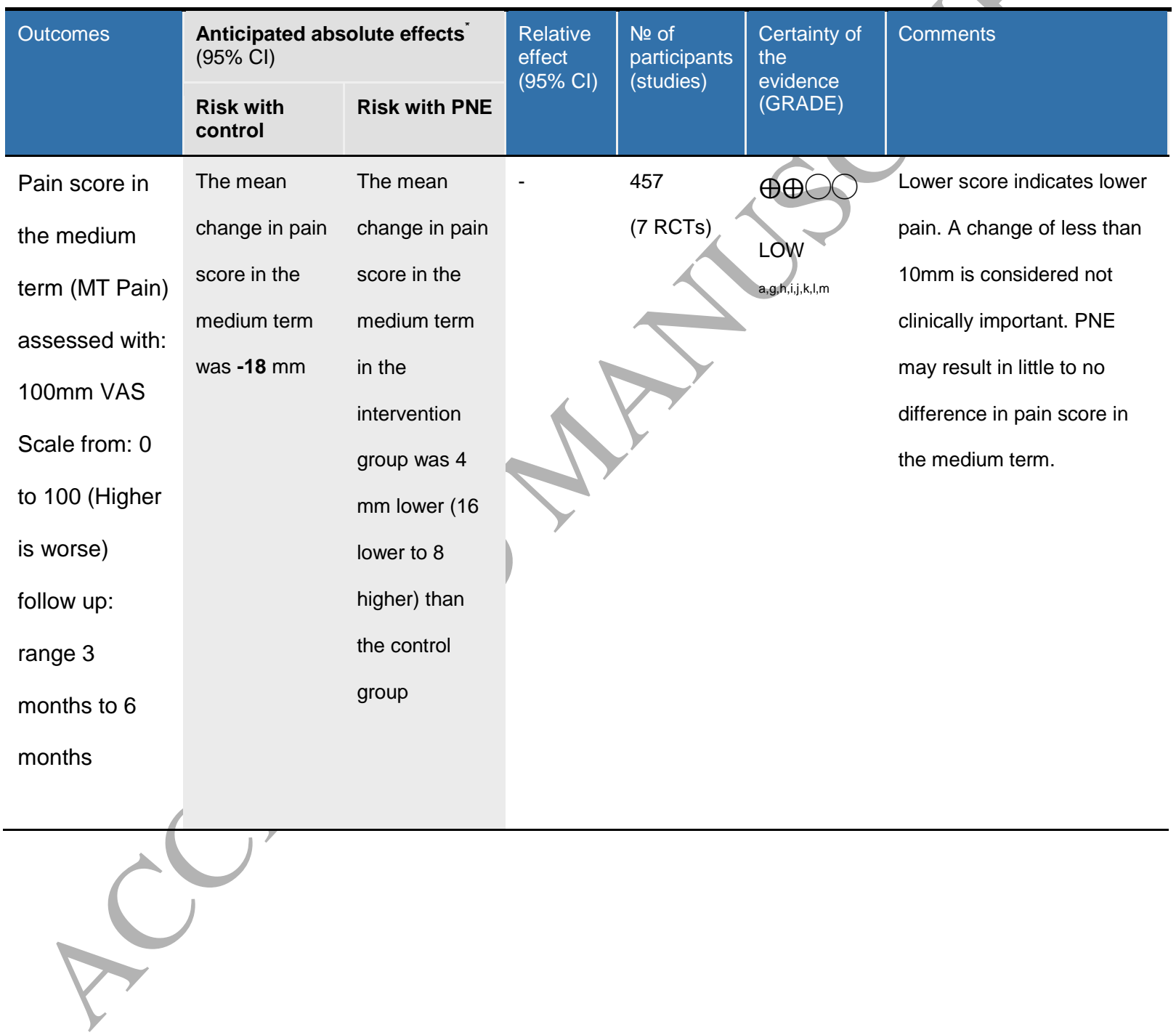




\section{PNE compared to control for treatment of adults with chronic musculoskeletal pain}

Patient or population: treatment of adults with chronic musculoskeletal pain

\section{Setting:}

Intervention: PNE

Comparison: control

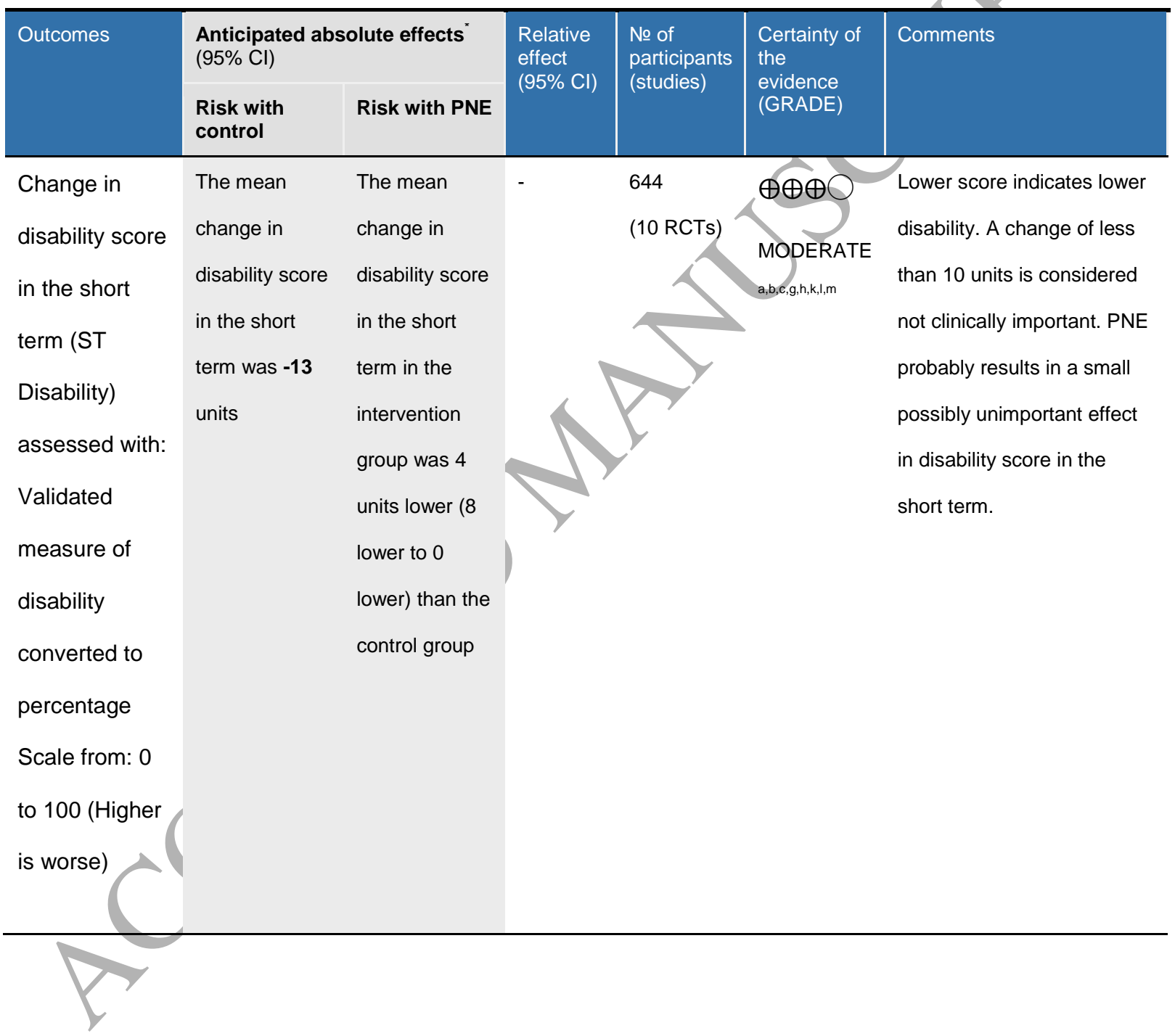




\section{PNE compared to control for treatment of adults with chronic musculoskeletal pain}

Patient or population: treatment of adults with chronic musculoskeletal pain

\section{Setting:}

Intervention: PNE

Comparison: control

\begin{tabular}{|c|c|c|c|c|c|c|}
\hline \multirow[t]{2}{*}{ Outcomes } & \multicolumn{2}{|c|}{$\begin{array}{l}\text { Anticipated absolute effects } \\
(95 \% \mathrm{Cl})\end{array}$} & \multirow{2}{*}{$\begin{array}{l}\text { Relative } \\
\text { effect } \\
(95 \% \mathrm{Cl})\end{array}$} & \multirow{2}{*}{$\begin{array}{l}\text { № of } \\
\text { participants } \\
\text { (studies) }\end{array}$} & \multirow{2}{*}{$\begin{array}{l}\text { Certainty of } \\
\text { the } \\
\text { evidence } \\
\text { (GRADE) }\end{array}$} & \multirow[t]{2}{*}{ Comments } \\
\hline & $\begin{array}{l}\text { Risk with } \\
\text { control }\end{array}$ & Risk with PNE & & & & \\
\hline $\begin{array}{l}\text { Change in } \\
\text { disability score } \\
\text { in the medium } \\
\text { term (MT } \\
\text { Disability) } \\
\text { assessed with: } \\
\text { Validated } \\
\text { measure of } \\
\text { disability } \\
\text { converted to } \\
\text { percentage } \\
\text { Scale from: } 0 \\
\text { to } 100 \text { (Higher } \\
\text { is worse) } \\
\text { follow up: } \\
\text { range } 3 \\
\text { months to } 6 \\
\text { months }\end{array}$ & $\begin{array}{l}\text { The mean } \\
\text { change in } \\
\text { disability score } \\
\text { in the medium } \\
\text { term was -13 } \\
\text { units }\end{array}$ & $\begin{array}{l}\text { The mean } \\
\text { change in } \\
\text { disability score } \\
\text { in the medium } \\
\text { term in the } \\
\text { intervention } \\
\text { group was } 8 \\
\text { units lower (16 } \\
\text { lower to } 1 \\
\text { lower) than the } \\
\text { control group }\end{array}$ & & 457 & 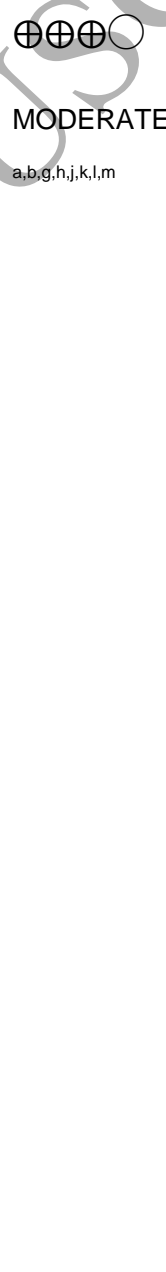 & $\begin{array}{l}\text { Lower score indicates lower } \\
\text { disability. A change of less } \\
\text { than } 10 \text { units is considered } \\
\text { not clinically important. PNE } \\
\text { probably results in a small } \\
\text { possibly unimportant effect } \\
\text { in disability score in the } \\
\text { medium term. }\end{array}$ \\
\hline
\end{tabular}




\section{PNE compared to control for treatment of adults with chronic musculoskeletal pain}

Patient or population: treatment of adults with chronic musculoskeletal pain

\section{Setting:}

Intervention: PNE

Comparison: control

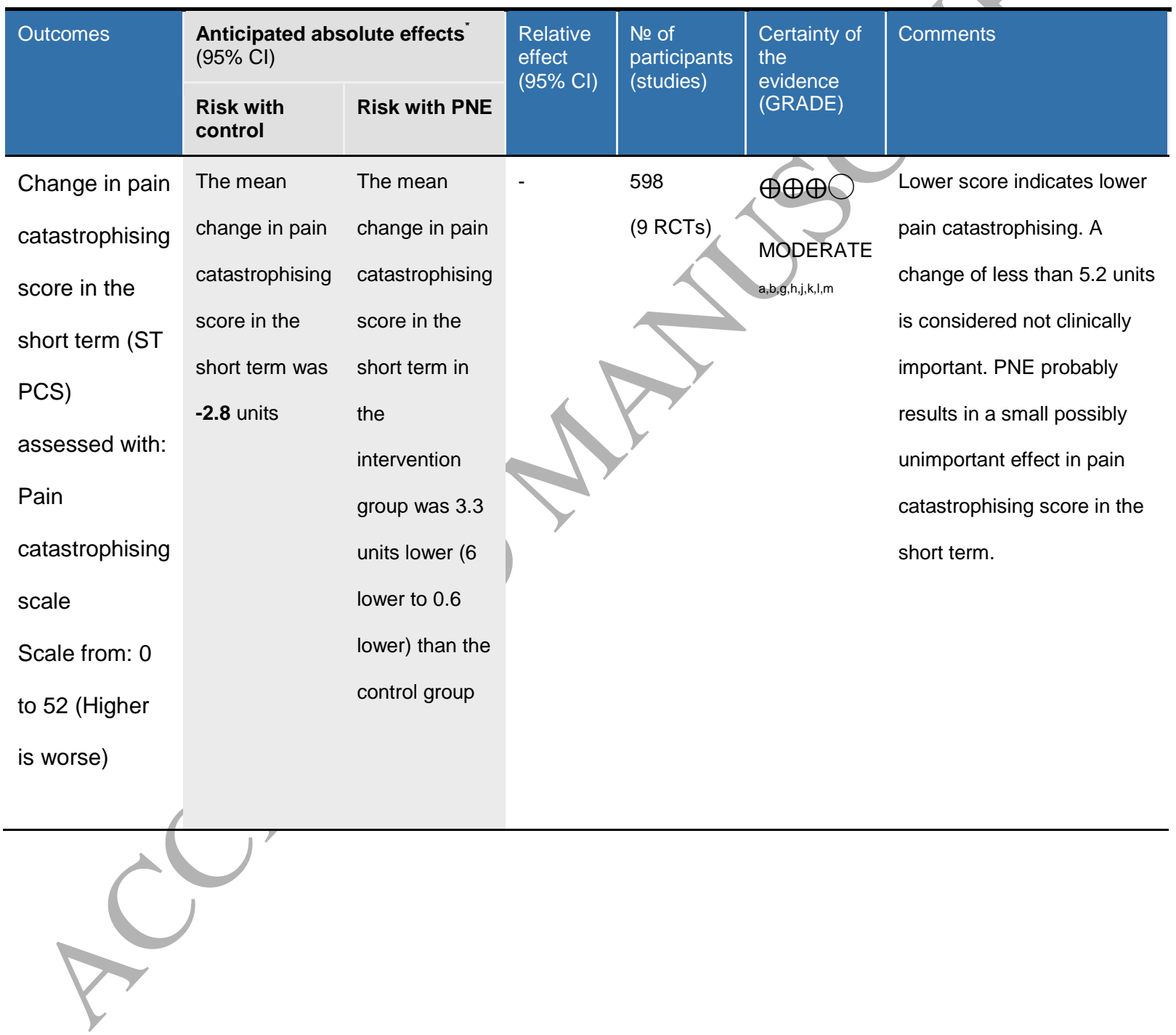




\section{PNE compared to control for treatment of adults with chronic musculoskeletal pain}

Patient or population: treatment of adults with chronic musculoskeletal pain

\section{Setting:}

Intervention: PNE

Comparison: control

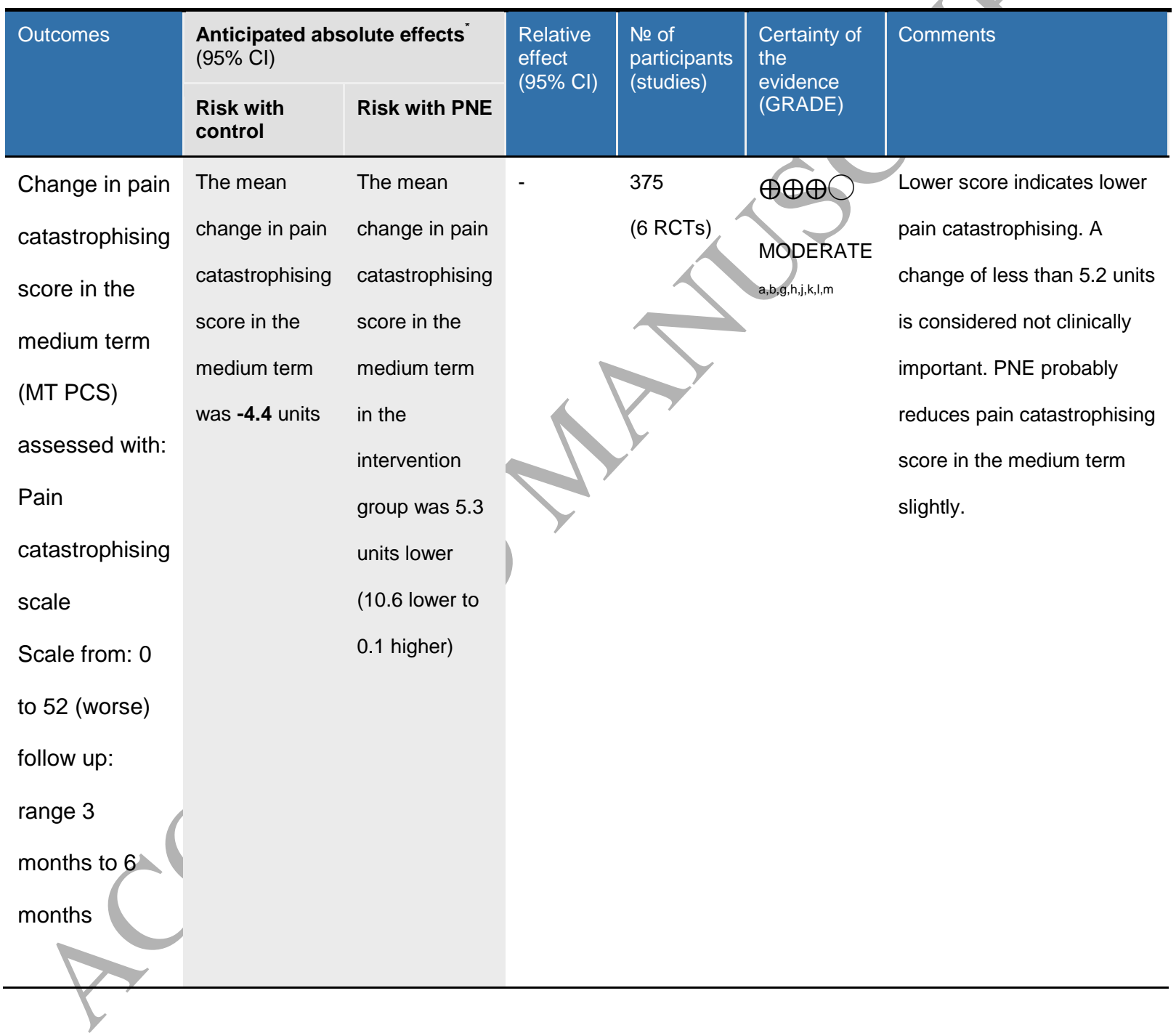




\section{PNE compared to control for treatment of adults with chronic musculoskeletal pain}

Patient or population: treatment of adults with chronic musculoskeletal pain

\section{Setting:}

Intervention: PNE

Comparison: control

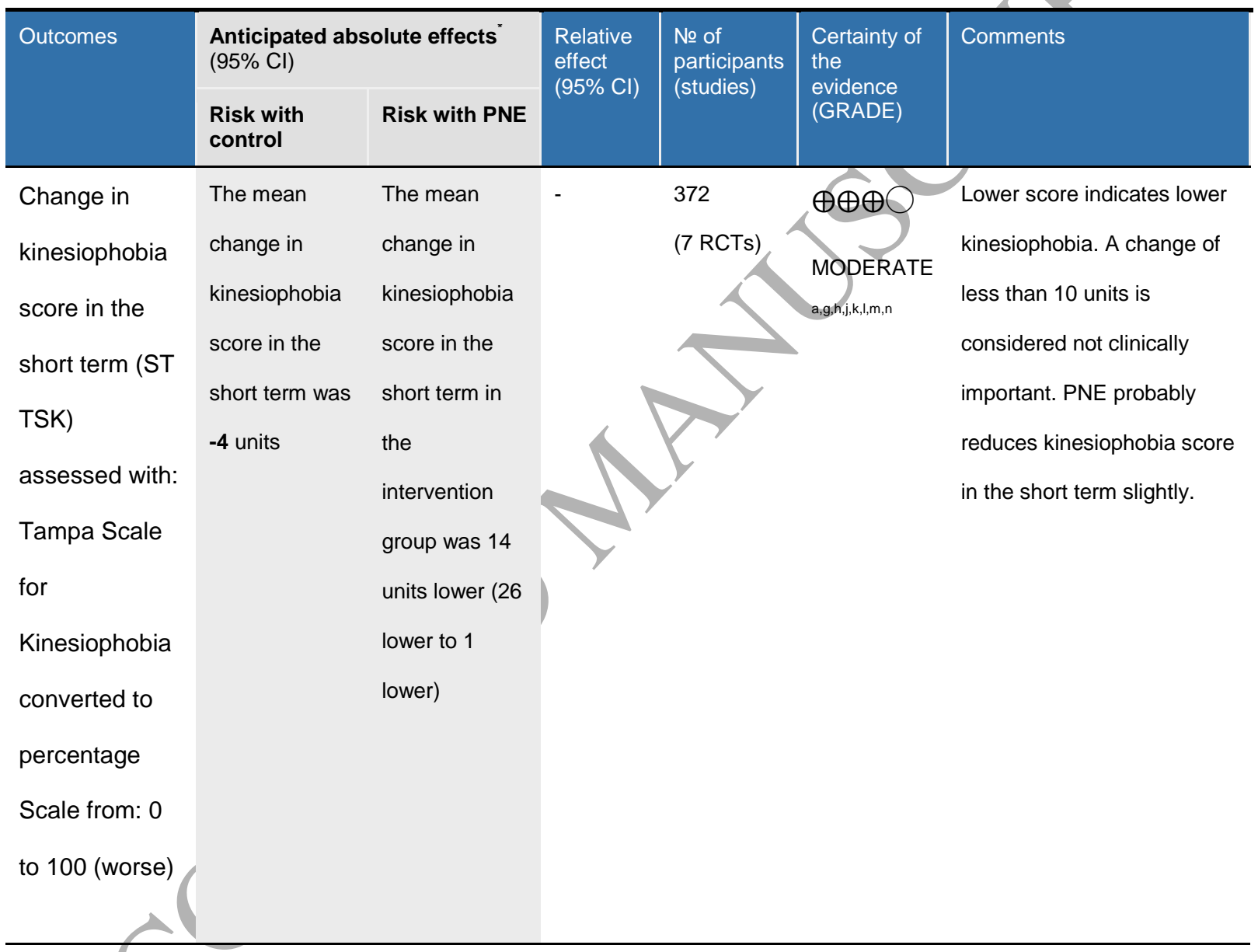

${ }^{*}$ The risk in the intervention group (and its $95 \%$ confidence interval) is based on the assumed risk in the comparison group and the relative effect of the intervention (and its $95 \% \mathrm{Cl}$ ).

Cl: Confidence interval 


\section{PNE compared to control for treatment of adults with chronic musculoskeletal pain}

Patient or population: treatment of adults with chronic musculoskeletal pain

\section{Setting:}

Intervention: PNE

Comparison: control

\begin{tabular}{|l|l|l|l|l|l}
\hline Outcomes & $\begin{array}{l}\text { Anticipated absolute effects } \\
(95 \% \mathrm{Cl})\end{array}$ & $\begin{array}{l}\text { Relative } \\
\text { effect } \\
(95 \% \mathrm{Cl})\end{array}$ & $\begin{array}{l}\text { № of } \\
\text { participants } \\
\text { (studies) }\end{array}$ & $\begin{array}{l}\text { Certainty of } \\
\text { the } \\
\text { evidence } \\
\text { (GRADE) }\end{array}$ & Comments \\
control & Risk with PNE & & GRAth & & \\
\hline
\end{tabular}

\section{GRADE Working Group grades of evidence}

High certainty: We are very confident that the true effect lies close to that of the estimate of the effect

Moderate certainty: We are moderately confident in the effect estimate: The true effect is likely to be close to the estimate of the effect, but there is a possibility that it is substantially different

Low certainty: Our confidence in the effect estimate is limited: The true effect may be substantially different from the estimate of the effect

Very low certainty: We have very little confidence in the effect estimate: The true effect is likely to be substantially different from the estimate of effect

\section{Explanations}

a. The majority of the weight comes from low risk studies. Although there was some concern over blinding of participants and personnel, this predominantly came from lack of blinding of personnel, which is normal for such studies.

b. Some variation is size of the effect, however mostly in the same direction.

c. Good overlap of the confidence intervals.

d. Not signifiant $P$ value.

e. I-Squared below $50 \%$

f. Tau-Squared lower than point estimate

g. Sample of chronic musculoskeletal pain comparing PNE against control using an appropriate outcome measure.

h. Sample size above 300. Below the criterion (10\%) for appreciable harm.

i. Large variation in size of the effect, going in both directions 
j. Poor overlap between the confidence intervals.

k. Significant $P$ value.

I. I-Squated above $50 \%$

m. Tau-Squared higher than point estimate.

n. Some variation in the size of the effect, all going in the same direction.

Table 2 ConQual summary of findings

Systematic Review title: Pain neuroscience education for adults with chronic musculoskeletal pain: a mixed-methods systematic review

Population: adults with chronic musculoskeletal pain

Phenomena of interest: the perceptions of PNE in adults with chronic musculoskeletal pain including 1) their experiences of participating in PNE 2) their perceptions of its effectiveness 3 ) explore how it influenced their understanding of pain.

\begin{tabular}{|l|l|l|l|l|}
\hline Synthesised finding & $\begin{array}{l}\text { Type of } \\
\text { research }\end{array}$ & Dependability & Credibility & $\begin{array}{l}\text { ConQual } \\
\text { score }\end{array}$ \\
\hline $\begin{array}{l}\text { A comprehensive assessment allowing the } \\
\text { patient to tell their own story should be } \\
\text { undertaken to ensure they feel heard. This } \\
\text { will also facilitate the identification of their } \\
\text { prior understanding and beliefs. PNE can } \\
\text { then be delivered in a manner relevant to } \\
\text { that patient. In addition, patients clarifying } \\
\text { their story to a healthcare professional may } \\
\text { raise their awareness of the } \\
\text { biopsychosocial nature of pain, promoting } \\
\text { readiness to engage with PNE. }\end{array}$ & Qualitative & $\begin{array}{l}\text { Downgrade 1 } \\
\text { level* }\end{array}$ & $\begin{array}{l}\text { Downgrade } \\
1 \text { level }^{* *}\end{array}$ & Low \\
\hline $\begin{array}{l}\text { Achieving pain reconceptualisation can } \\
\text { enhance patients' ability to cope with their } \\
\text { condition. To promote pain } \\
\text { reconceptualisation PNE should be } \\
\text { delivered by health care professionals } \\
\text { (HCPs) skilled in PNE delivery and }\end{array}$ & Qualitative & $\begin{array}{l}\text { Downgrade 1 } \\
\text { level }\end{array}$ & $\begin{array}{l}\text { Downgrade } \\
1 \text { level }\end{array}$ & Low \\
\hline
\end{tabular}


facilitation of group, or one-to-one interactions with, and between, patients and other HCPs. Progress towards reconceptualisation should be monitored throughout, tailoring concepts that have not been accommodated to ensure relevance of PNE to the individual.

*Downgraded one level as whilst two studies scored perfectly on dependability, the other two studies scored 3 and 1 . The mean dependability score was 3.5 .

** Downgraded one level due to a mix of unequivocal and equivocal findings.

Table 3 Critical appraisal of quantitative studies

\begin{tabular}{|c|c|c|}
\hline Study & Score $/ 7$ & $\begin{array}{l}\text { Score } / 7 \text { as a } \\
\text { Percentage }\end{array}$ \\
\hline Bodes $2018^{2}$ & 4 & $57 \%$ \\
\hline Gallager $2013^{11}$ & 5 & $71 \%$ \\
\hline Lluch $2018^{25}$ & & $71 \%$ \\
\hline Louw 2014/1 & 3 & $43 \%$ \\
\hline 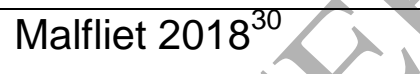 & 6 & $86 \%$ \\
\hline Meeus & 5 & $71 \%$ \\
\hline Moseley $2004^{35}$ & 5 & $71 \%$ \\
\hline Pires $2015^{41}$ & 3 & $43 \%$ \\
\hline Téllez-Garcia $2015^{48}$ & 2 & $29 \%$ \\
\hline van Ittersum $2013^{57}$ & 1 & $14 \%$ \\
\hline
\end{tabular}




\begin{tabular}{|l|l|l|}
\hline Van Oosterwijck 2013 & 58 & $71 \%$ \\
\hline Von Bertouch 2011 & & \\
& 5 & $71 \%$ \\
\hline
\end{tabular}

Table 4 Critical appraisal of qualitative studies

\begin{tabular}{|l|c|c|c|c|c|c|c|c|c|c|c|}
\hline Citation & Q1 & Q2 & Q3 & Q4 & Q5 & Q6 & Q7 & Q8 & Q9 & Q10 & Total \\
$2016^{42}$ & $\mathrm{U}$ & $\mathrm{Y}$ & $\mathrm{Y}$ & $\mathrm{Y}$ & $\mathrm{Y}$ & $\mathrm{Y}$ & $\mathrm{Y}$ & $\mathrm{Y}$ & $\mathrm{Y}$ & $\mathrm{Y}$ & 9 \\
\hline Robinson et al. & & & & & & & & & & & \\
\hline King et al. 2016 & $\mathrm{U}$ & $\mathrm{Y}$ & $\mathrm{Y}$ & $\mathrm{Y}$ & $\mathrm{Y}$ & $\mathrm{Y}$ & $\mathrm{Y}$ & $\mathrm{Y}$ & $\mathrm{Y}$ & $\mathrm{Y}$ & 9 \\
\hline Wijma et al. 201761 & $\mathrm{U}$ & $\mathrm{Y}$ & $\mathrm{Y}$ & $\mathrm{Y}$ & $\mathrm{Y}$ & $\mathrm{N}$ & $\mathrm{N}$ & $\mathrm{Y}$ & $\mathrm{U}$ & $\mathrm{Y}$ & 6 \\
\hline King et al. 2018 & $\mathrm{N}$ & $\mathrm{U}$ & $\mathrm{U}$ & $\mathrm{U}$ & $\mathrm{U}$ & $\mathrm{Y}$ & $\mathrm{N}$ & $\mathrm{Y}$ & $\mathrm{Y}$ & $\mathrm{Y}$ & 4 \\
\hline$\%$ & $0 \%$ & $75 \%$ & $75 \%$ & $75 \%$ & $75 \%$ & $75 \%$ & $50 \%$ & $100 \%$ & $75 \%$ & $100 \%$ & \\
\hline
\end{tabular}

$\mathrm{Y}=$ yes; $\mathrm{N}=\mathrm{No} ; \mathrm{U}=$ Unclear 
Table 5 Characteristics of included studies - quantitative component

\begin{tabular}{|c|c|c|c|c|c|c|c|c|}
\hline Study & $\begin{array}{l}\text { Met } \\
\text { hod } \\
\text { s }\end{array}$ & $\begin{array}{l}\text { Sam } \\
\text { ple } \\
\text { size } \\
\text { (bas } \\
\text { eline } \\
\text { )/ } \\
\text { gend } \\
\text { er/ } \\
\text { mea } \\
\text { n } \\
\text { age } \\
\text { in } \\
\text { year } \\
\text { s }\end{array}$ & $\begin{array}{l}\text { Particip } \\
\text { ants }\end{array}$ & $\begin{array}{l}\text { Interventio } \\
\mathrm{n}(\mathrm{s})\end{array}$ & $\begin{array}{l}\text { Durati } \\
\text { on of } \\
\text { educ } \\
\text { ation } \\
\text { al } \\
\text { interv } \\
\text { entio } \\
\mathrm{n}\end{array}$ & Control & $\begin{array}{l}\text { Authors } \\
\text { conclusi } \\
\text { ons/note }\end{array}$ & $\begin{array}{l}\text { Settin } \\
\mathrm{g} / \\
\text { countr } \\
y\end{array}$ \\
\hline $\begin{array}{l}\text { Mosel } \\
\text { ey, } \\
\text { Nicho } \\
\text { las } \\
\text { and } \\
\text { Hodg } \\
\text { es }\end{array}$ & 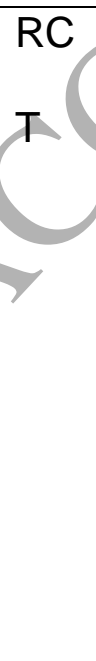 & $\begin{array}{l}43 \% \\
M \\
43.5\end{array}$ & $\begin{array}{l}\text { LBP of } \\
\text { months } \\
\text { duratio } \\
\text { n. } \\
\text { Baselin } \\
\text { e pain }\end{array}$ & $\begin{array}{l}\text { 3h } \\
\text { individual } \\
\text { PNE, with } \\
20 \mathrm{~m} \\
\text { break. } 10 \\
\text { section } \\
\text { workbook }\end{array}$ & $\begin{array}{l}\text { PNE } \\
2.67 \mathrm{~h} \\
\text { Contr } \\
\text { ol } \\
2.67 \mathrm{~h}\end{array}$ & $\begin{array}{l}\text { 3h } \\
\text { individual } \\
\text { Back } \\
\text { education, } \\
\text { with } 20 \mathrm{~m} \\
\text { break. } 10 \\
\text { section }\end{array}$ & $\begin{array}{l}\text { PNE } \\
\text { results in } \\
\text { some } \\
\text { normalis } \\
\text { ation of } \\
\text { pain } \\
\text { cognition }\end{array}$ & $\begin{array}{l}\text { Privat } \\
\text { e } \\
\text { rehabi } \\
\text { litation } \\
\text { clinics } \\
\text { Unkno } \\
\text { wn }\end{array}$ \\
\hline
\end{tabular}




\begin{tabular}{|c|c|c|c|c|c|c|c|c|}
\hline $\begin{array}{l}2004^{3} \\
5\end{array}$ & & & $\begin{array}{l}\text { as } \\
\text { mean } \\
\%= \\
59.5 \% \\
\text { Duratio } \\
\text { n of } \\
\text { pain in } \\
\text { mean } \\
\text { (SD) } \\
\text { months } \\
=29.5 \\
(12)\end{array}$ & $\begin{array}{l}\text { with } 3 \\
\text { questions } \\
\text { at end of } \\
\text { each } \\
\text { section. To } \\
\text { be } \\
\text { completed } \\
\text { over } 10 \\
\text { days. }\end{array}$ & & $\begin{array}{l}\text { workbook } \\
\text { with } 3 \\
\text { questions } \\
\text { at end of } \\
\text { each } \\
\text { section. To } \\
\text { be } \\
\text { completed } \\
\text { over } 10 \\
\text { days. }\end{array}$ & $\begin{array}{l}\text { s and } \\
\text { physical } \\
\text { performa } \\
\text { nce but } \\
\text { not self- } \\
\text { perceive } \\
\text { d } \\
\text { disability. } \\
\text { Doubts } \\
\text { raised } \\
\text { about } \\
\text { suitability } \\
\text { patholog } \\
\text { of based } \\
\text { structural } \\
\text { - }\end{array}$ & \\
\hline $\begin{array}{l}\text { Von } \\
\text { Berto } \\
\text { uch } \\
2011^{6} \\
0\end{array}$ & $\begin{array}{l}\mathrm{RC} \\
\mathrm{T}\end{array}$ & $\begin{array}{l}N= \\
64 \\
33 \% \\
M \\
42.4\end{array}$ & $\begin{array}{l}\text { All } \\
\text { chronic } \\
\text { pain } \\
\text { patient } \\
\text { s }>50 \%\end{array}$ & $\begin{array}{l}2 \times 1.5 \mathrm{~h} \\
\text { Group } \\
\text { PNE + } \\
\text { PMP. } \\
\text { Manual to }\end{array}$ & $\begin{array}{l}\text { PNE } \\
3 \mathrm{~h} \\
\text { Contr } \\
\text { ol 3h }\end{array}$ & $\begin{array}{l}\text { 2x 1.5h } \\
\text { Group } \\
\text { Back book } \\
\text { + PMP. } \\
\text { Manual to }\end{array}$ & $\mathrm{n} / \mathrm{a}$ & $\begin{array}{l}\text { Unkno } \\
\text { wn } \\
\text { Unkno } \\
\text { wn }\end{array}$ \\
\hline
\end{tabular}




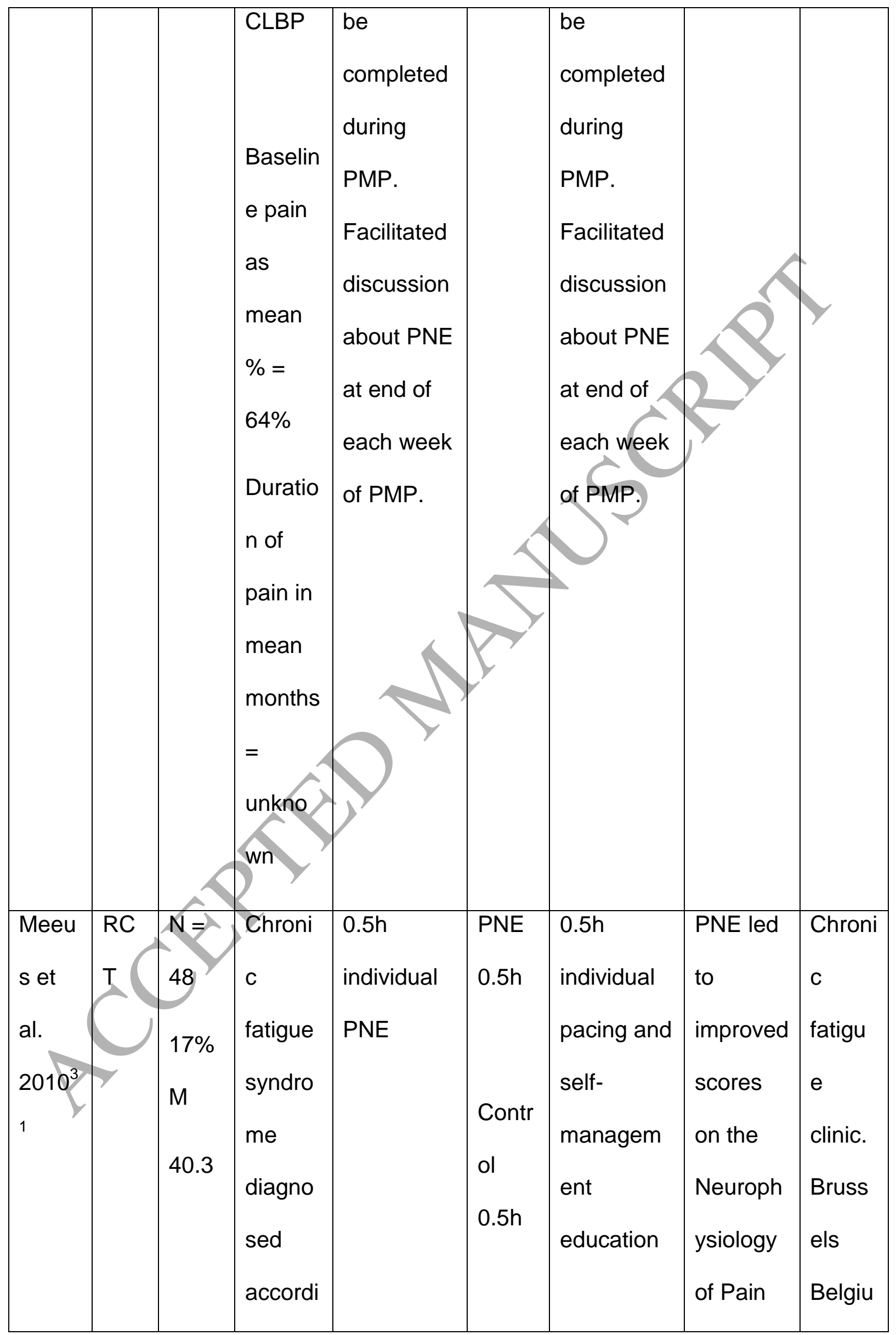




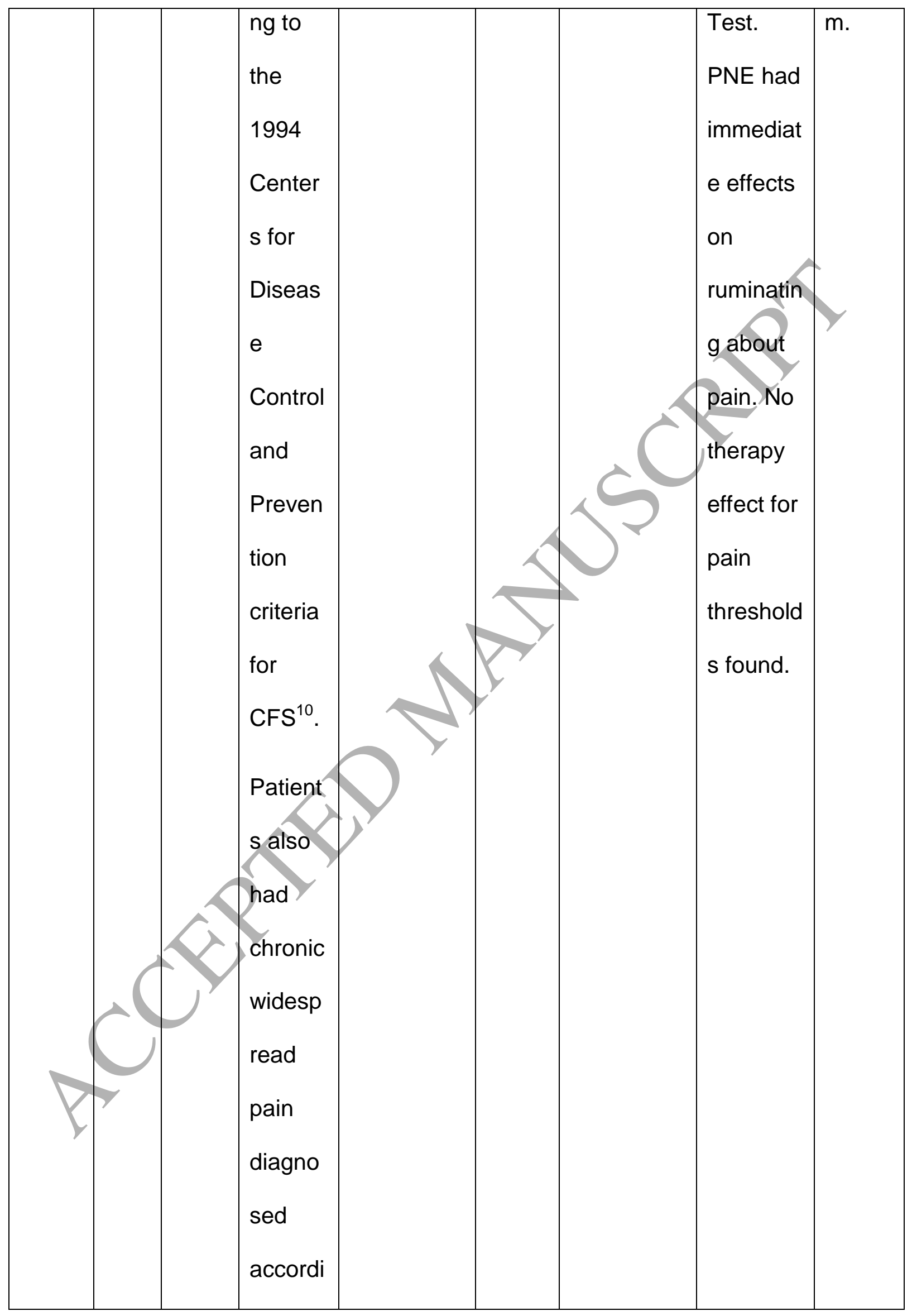




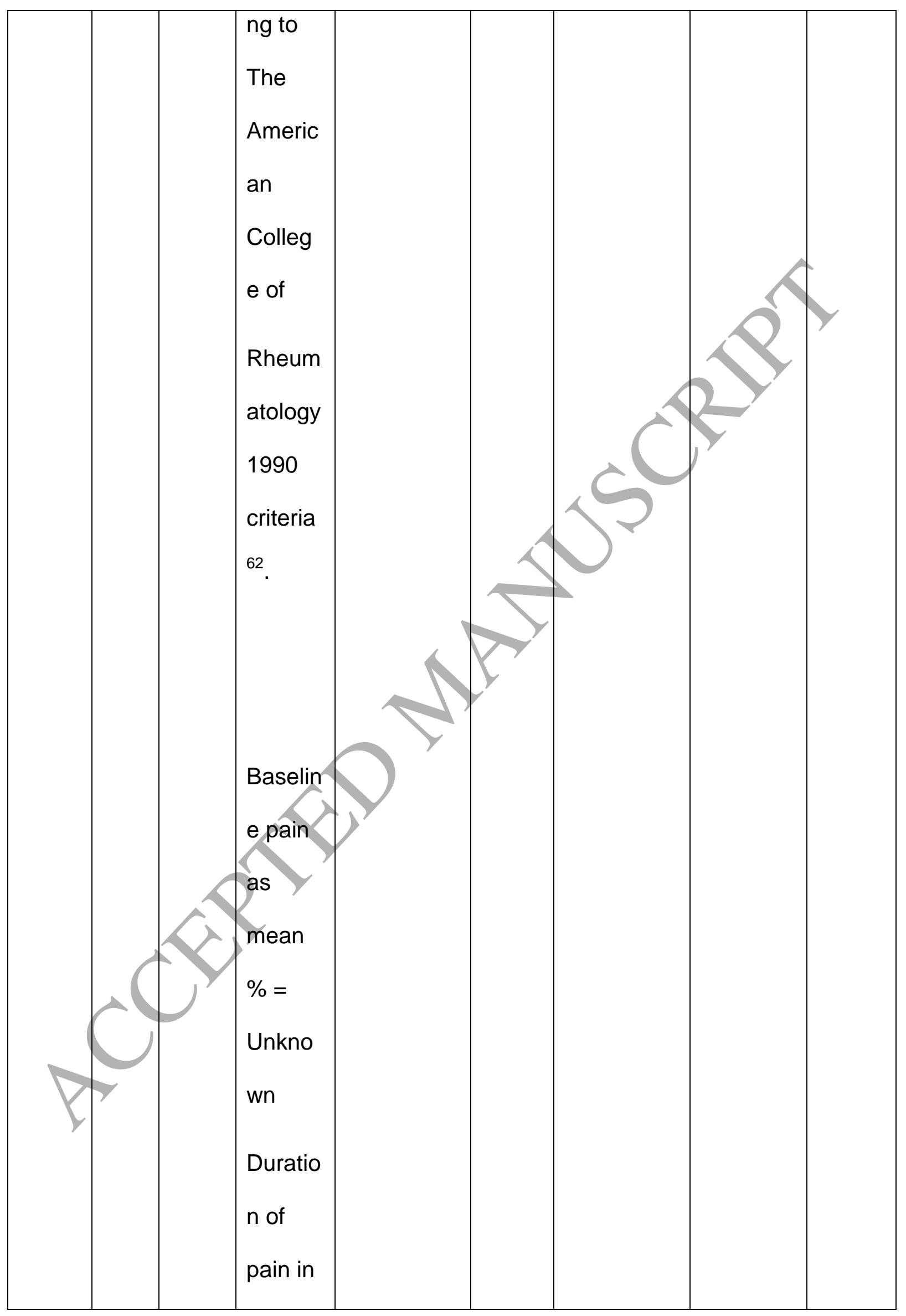




\begin{tabular}{|c|c|c|c|c|c|c|c|c|}
\hline & & & $\begin{array}{l}\text { mean } \\
\text { months } \\
= \\
\text { unkno } \\
\text { wn }\end{array}$ & & & & & \\
\hline $\begin{array}{l}\text { van } \\
\text { Itters } \\
\text { um et } \\
\text { al. } \\
2013^{5} \\
7\end{array}$ & $\begin{array}{l}\mathrm{RC} \\
\mathrm{T}\end{array}$ & $\begin{array}{l}\mathrm{N}= \\
105 \\
7 \% \\
M \\
46.7\end{array}$ & $\begin{array}{l}\text { Fibrom } \\
\text { yalgia } \\
\text { diagno } \\
\text { sed } \\
\text { accordi } \\
\text { ng to } \\
\text { The } \\
\text { Americ } \\
\text { an } \\
\text { Colleg } \\
\text { e of } \\
\text { Rheum } \\
\text { atology } \\
\text { years } \\
\text { criteria } \\
\text { 1990 }\end{array}$ & $\begin{array}{l}\text { Written } \\
\text { PNE + } 1 \\
\text { phone call } \\
\text { for } \\
\text { motivation/ } \\
\text { questions } \\
+/-2 x \\
\text { phone } \\
\text { calls/email } \\
\text { s for } \\
\text { further } \\
\text { clarificatio } \\
\text { n/question } \\
\text { s }\end{array}$ & $\begin{array}{l}\text { Unkn } \\
\text { own }\end{array}$ & $\begin{array}{l}\text { Written } \\
\text { Relaxation } \\
\text { exercises } \\
+1 \text { phone } \\
\text { call for } \\
\text { motivation/ } \\
\text { questions } \\
+/-2 x \\
\text { phone } \\
\text { calls/email } \\
\text { s for } \\
\text { further } \\
\text { clarificatio } \\
\text { n/question } \\
\text { s }\end{array}$ & $\begin{array}{l}\text { Written } \\
\text { PNE } \\
\text { effective } \\
\text { for } \\
\text { changing } \\
\text { the } \\
\text { impact of } \\
\text { the } \\
\text { illness } \\
\text { on daily } \\
\text { life, pain } \\
\text { fibromyal } \\
\text { catastrop } \\
\text { hising, or } \\
\text { ilness } \\
\text { perceptio } \\
\text { ns in }\end{array}$ & $\begin{array}{l}\text { Speci } \\
\text { alised } \\
\text { centre } \\
\text { s for } \\
\text { chroni } \\
\text { c pain } \\
\text { and } \\
\text { chroni } \\
\text { c } \\
\text { fatigu } \\
\text { e. } \\
\text { Belgiu } \\
\text { m. }\end{array}$ \\
\hline
\end{tabular}




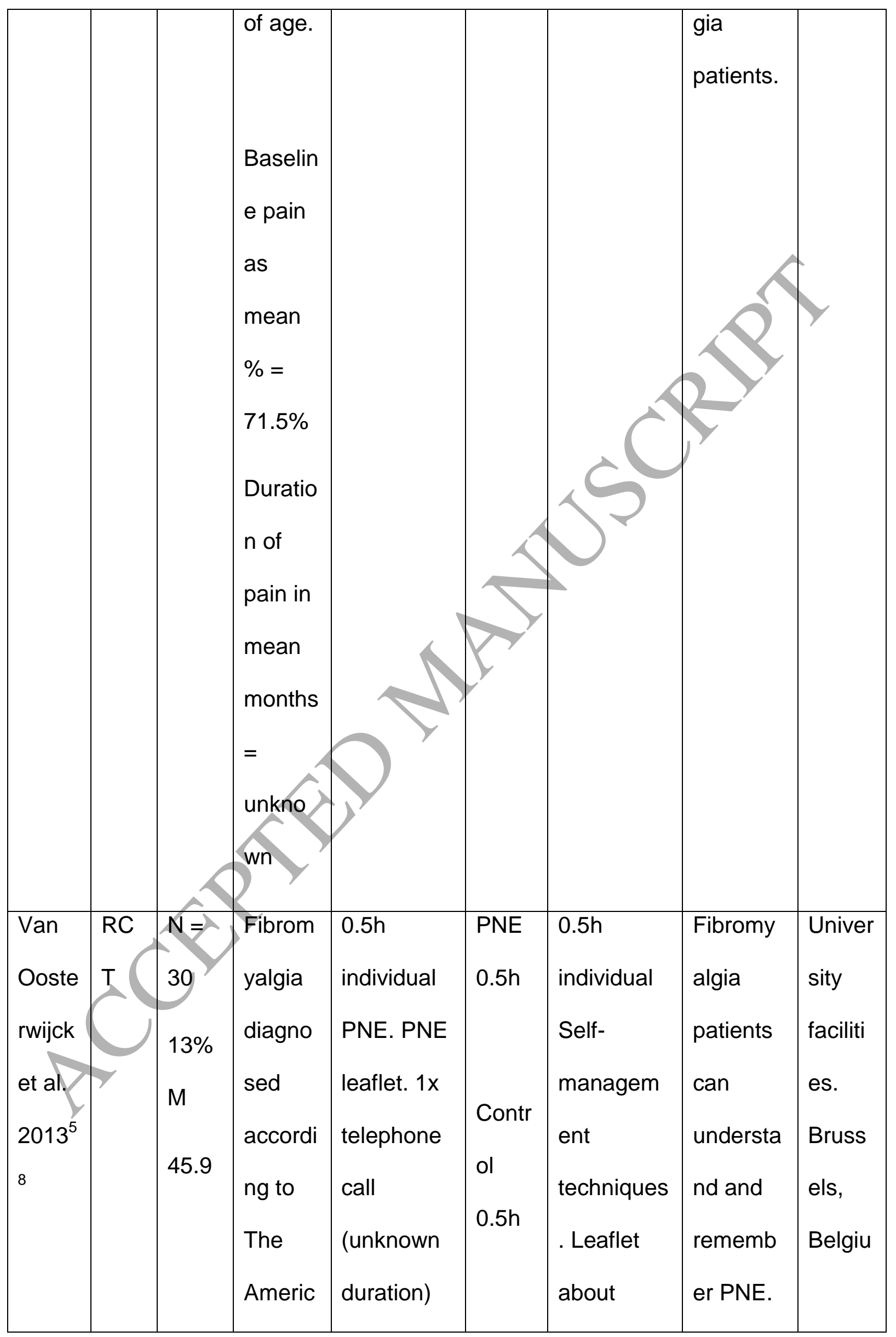




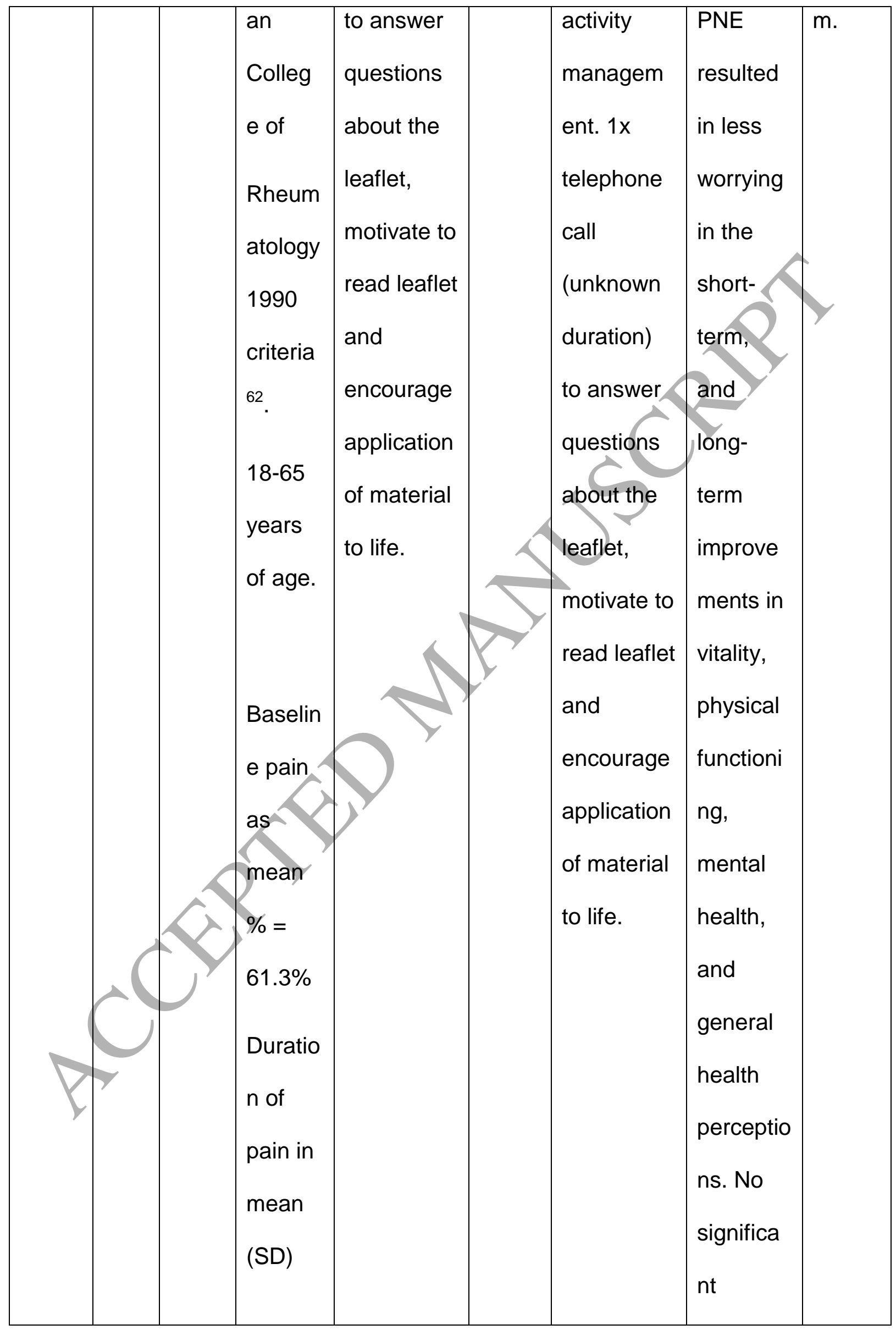




\begin{tabular}{|l|l|l|l|l|}
\hline months & & changes \\
establish & \\
ed in \\
pain \\
catastrop \\
hising, \\
hypervigi \\
lance, or \\
kinesiop \\
hobia. \\
Pain \\
pressure \\
threshold \\
s were \\
unchang \\
ed. A \\
positive \\
effect on \\
endogen \\
ous pain \\
inhibition \\
at 3- \\
month \\
follow up \\
was \\
\end{tabular}




\begin{tabular}{|c|c|c|c|c|c|c|c|c|}
\hline & & & & & & & found. & \\
\hline $\begin{array}{l}\text { Galla } \\
\text { gher, } \\
\text { McAu } \\
\text { ley } \\
\text { and } \\
\text { Mosel } \\
\text { ey } \\
2013^{1} \\
1\end{array}$ & $\begin{array}{l}\mathrm{RC} \\
\mathrm{T}\end{array}$ & $\begin{array}{l}\mathrm{N}= \\
79 \\
39 \% \\
M \\
43.5\end{array}$ & $\begin{array}{l}\text { 18-75 } \\
\text { years } \\
\text { of age } \\
\text { with } \\
\text { pain } \\
\text { that } \\
\text { had } \\
\text { been } \\
\text { sufficie } \\
\text { nt to } \\
\text { disrupt } \\
\text { moin } 3 \\
\text { their } \\
\text { the } \\
\text { activitie } \\
\text { daily of } \\
\text { for }\end{array}$ & $\begin{array}{l}\text { 80-page } \\
\text { booklet } \\
\text { divided } \\
\text { into } 11 \\
\text { sections - } \\
\text { Metaphors } \\
\text { and stories } \\
\text { to help } \\
\text { understan } \\
\text { d the } \\
\text { biology of } \\
\text { pain }\end{array}$ & $\begin{array}{l}\text { Unkn } \\
\text { own }\end{array}$ & $\begin{array}{l}\text { 80-page } \\
\text { booklet } \\
\text { divided } \\
\text { into } 11 \\
\text { sections - } \\
\text { Advice } \\
\text { about } \\
\text { managing } \\
\text { pain (The } \\
\text { back book } \\
\text { and } \\
\text { Manage } \\
\text { your pain) }\end{array}$ & $\begin{array}{l}\text { Written } \\
\text { material } \\
\text { using } \\
\text { metapho } \\
\text { rs to } \\
\text { explain } \\
\text { key } \\
\text { biologica } \\
\text { I } \\
\text { concepts } \\
\text { increase } \\
\text { thought } \\
\text { hic } \\
\text { catastrop } \\
\text { knowled } \\
\text { ge of } \\
\text { pain } \\
\text { decrease }\end{array}$ & $\begin{array}{l}\text { Unkno } \\
\text { wn } \\
\text { Unkno } \\
\text { wn }\end{array}$ \\
\hline
\end{tabular}




\begin{tabular}{|c|c|c|c|c|c|c|c|c|}
\hline & & & $\begin{array}{l}\text { Baselin } \\
\text { e pain } \\
\text { as } \\
\text { mean } \\
\%= \\
65 \% \\
\text { Duratio } \\
\text { n of } \\
\text { pain in } \\
\text { mean } \\
\text { (SD) } \\
\text { months }\end{array}$ & & & & $\begin{array}{l}\text { s about } \\
\text { pain and } \\
\text { injury } \\
\text { when } \\
\text { compare } \\
\text { d to } \\
\text { material } \\
\text { that } \\
\text { presente } \\
\text { d } \\
\text { biopsych } \\
\text { osocial } \\
\text { advice } \\
\text { for pain } \\
\text { manage } \\
\text { ment. }\end{array}$ & \\
\hline $\begin{array}{l}\text { Pires, } \\
\text { Cruz } \\
\text { and } \\
\text { Caeir } \\
\text { o, } \\
2015^{4}\end{array}$ & $\begin{array}{l}\mathrm{RC} \\
\mathrm{T}\end{array}$ & $\begin{array}{l}N= \\
62 \\
35 \% \\
M \\
51\end{array}$ & $\begin{array}{l}\text { Low } \\
\text { back } \\
\text { pain }>3 \\
\text { months } \\
\text { duratio } \\
n+/-\end{array}$ & $\begin{array}{l}\text { 2x } 1.5 \mathrm{~h} \\
\text { Group } \\
\text { PNE. } \\
12 \\
\text { sessions } \\
\text { of aquatic }\end{array}$ & $\begin{array}{l}\text { PNE } \\
3 \mathrm{~h} \\
\text { Contr } \\
\text { ol 3h }\end{array}$ & $\begin{array}{l}12 \\
\text { sessions } \\
\text { of aquatic } \\
\text { exercise } \\
\text { over } 6 \\
\text { weeks. 30- }\end{array}$ & $\begin{array}{l}\text { PNE is a } \\
\text { clinically } \\
\text { effective } \\
\text { addition } \\
\text { to } \\
\text { aquatic }\end{array}$ & $\begin{array}{l}\text { Outpa } \\
\text { tient } \\
\text { clinic. } \\
\text { Portug } \\
\text { al }\end{array}$ \\
\hline
\end{tabular}




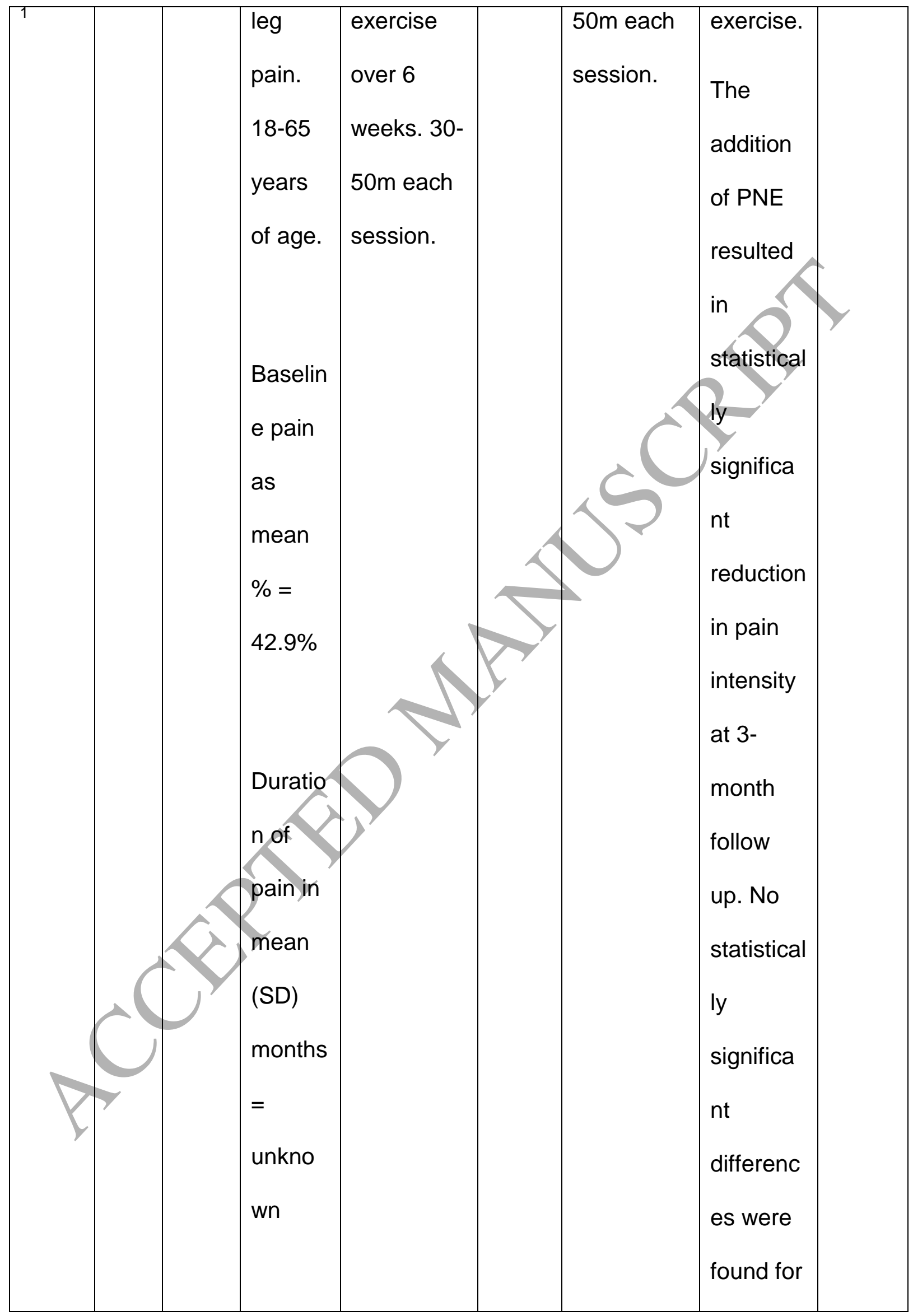




\begin{tabular}{|c|c|c|c|c|c|c|c|c|}
\hline & & & & & & & $\begin{array}{l}\text { pain } \\
\text { intensity } \\
\text { at } 6 \\
\text { weeks } \\
\text { follow up } \\
\text { or } \\
\text { functiona } \\
\text { 1 } \\
\text { disability } \\
\text { at either } \\
\text { follow } \\
\text { up. }\end{array}$ & \\
\hline $\begin{array}{l}\text { Louw } \\
\text { et al. } \\
2014 / \\
16^{27,2} \\
8\end{array}$ & $\begin{array}{l}\mathrm{RC} \\
\mathrm{T}\end{array}$ & $\begin{array}{l}N= \\
67 \\
46 \% \\
M\end{array}$ & $\begin{array}{l}\text { Patient } \\
\text { s with } \\
\text { lumbar } \\
\text { radicul } \\
\text { opathy, } \\
\text { schedu } \\
\text { led for } \\
\text { lumbar } \\
\text { surgery } \\
\text {. } 18-65 \\
\text { years } \\
\text { of age. }\end{array}$ & $\begin{array}{l}0.5 \mathrm{~h} \\
\text { individual } \\
\text { PNE. } \\
\text { booklet } \\
\text { "your } \\
\text { nerves are } \\
\text { having } \\
\text { back } \\
\text { surgery" \& } \\
\text { Lumbar } \\
\text { surgery + }\end{array}$ & $\begin{array}{l}\text { PNE } \\
0.5 \mathrm{~h} \\
\text { Contr } \\
\text { ol } 0\end{array}$ & $\begin{array}{l}\text { Lumbar } \\
\text { surgery } \\
\text { alone + } \\
\text { usual care }\end{array}$ & $\begin{array}{l}\text { Providin } \\
\mathrm{g} \text { a } \\
\text { single } \\
\text { PNE } \\
\text { session } \\
\text { to } \\
\text { patients } \\
\text { prior to } \\
\text { lumbar } \\
\text { surgery } \\
\text { (LS) } \\
\text { results in }\end{array}$ & $\begin{array}{l}7 \\
\text { Clinic } \\
\text { al } \\
\text { sites } \\
\text { in the } \\
\text { USA. }\end{array}$ \\
\hline
\end{tabular}




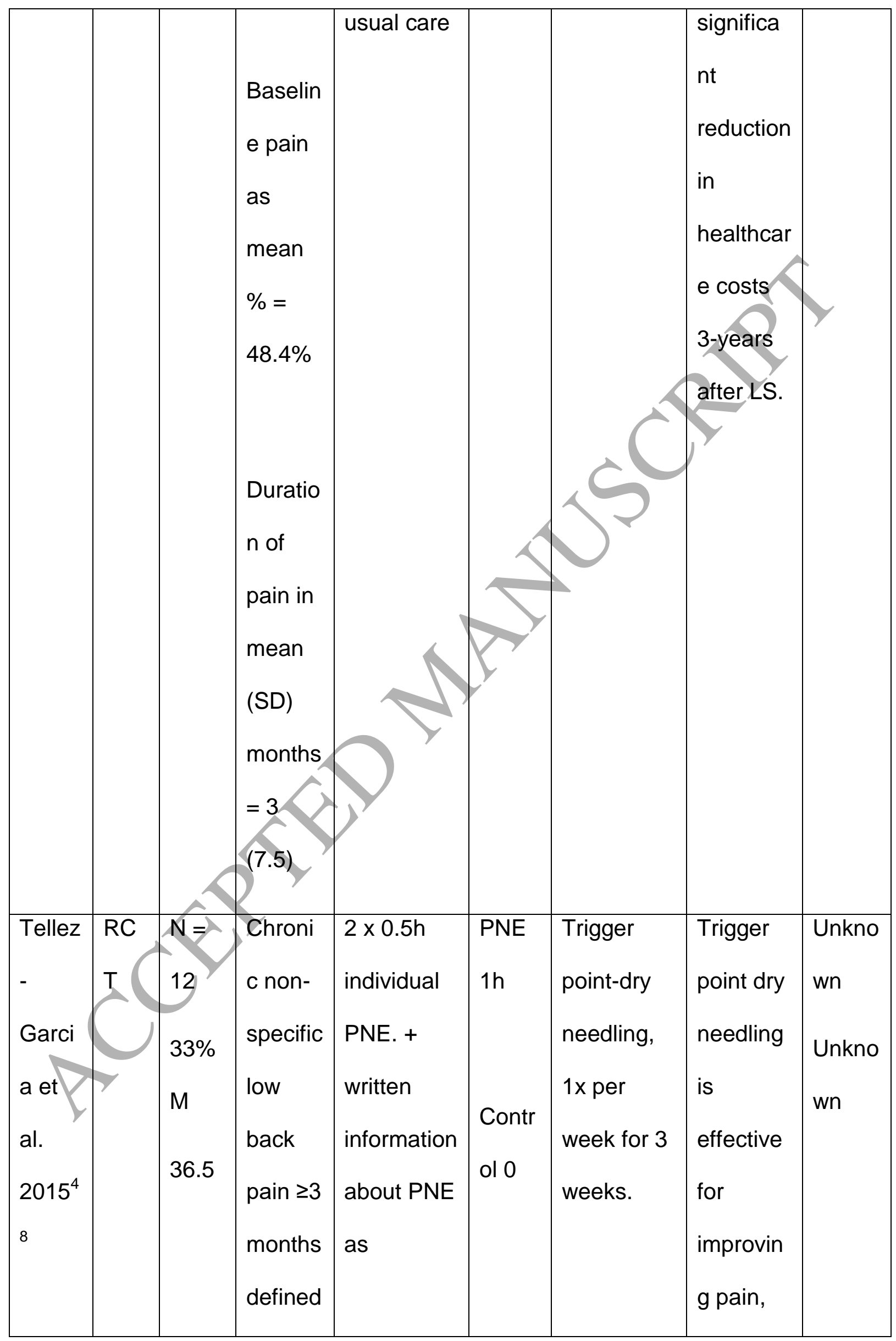




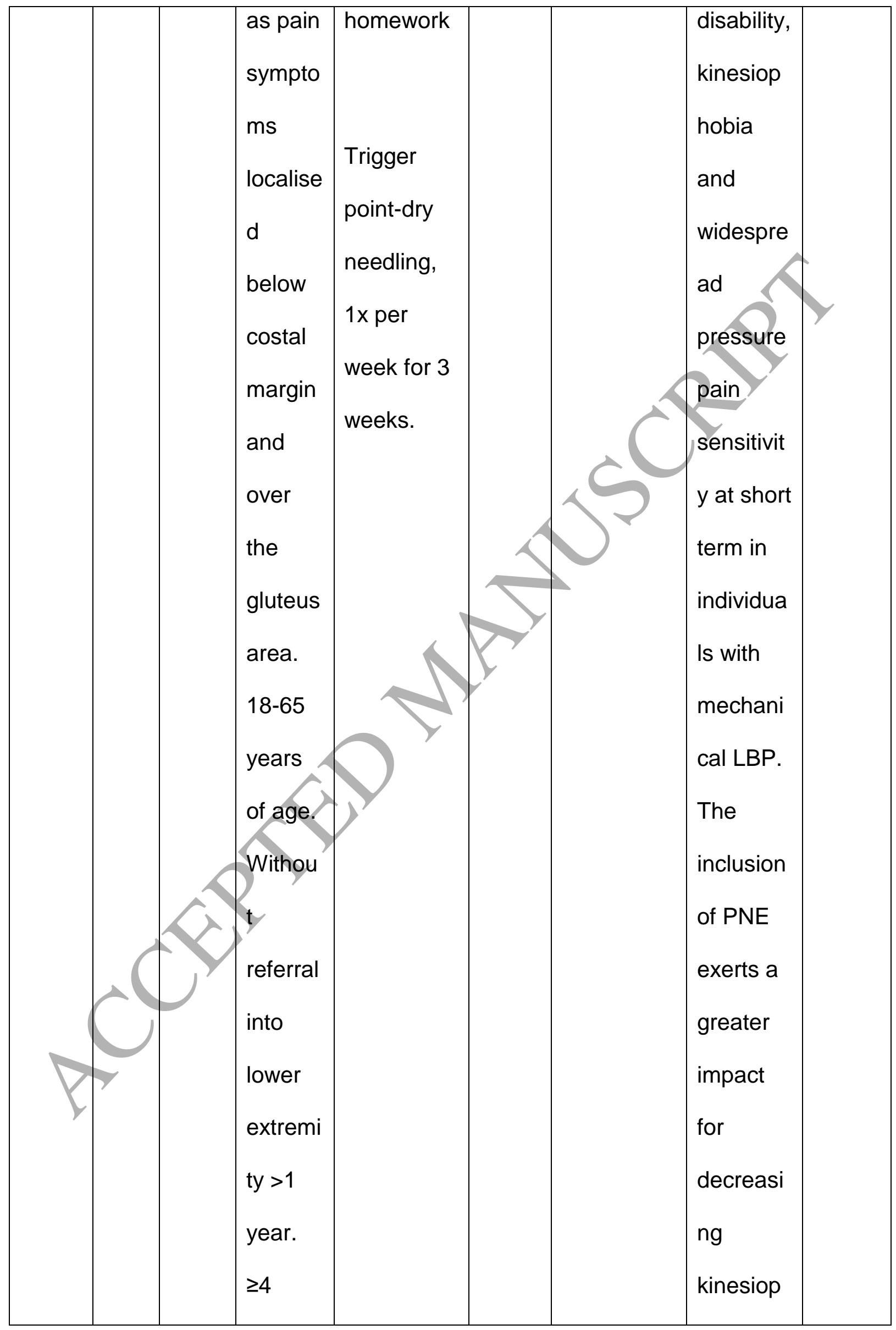




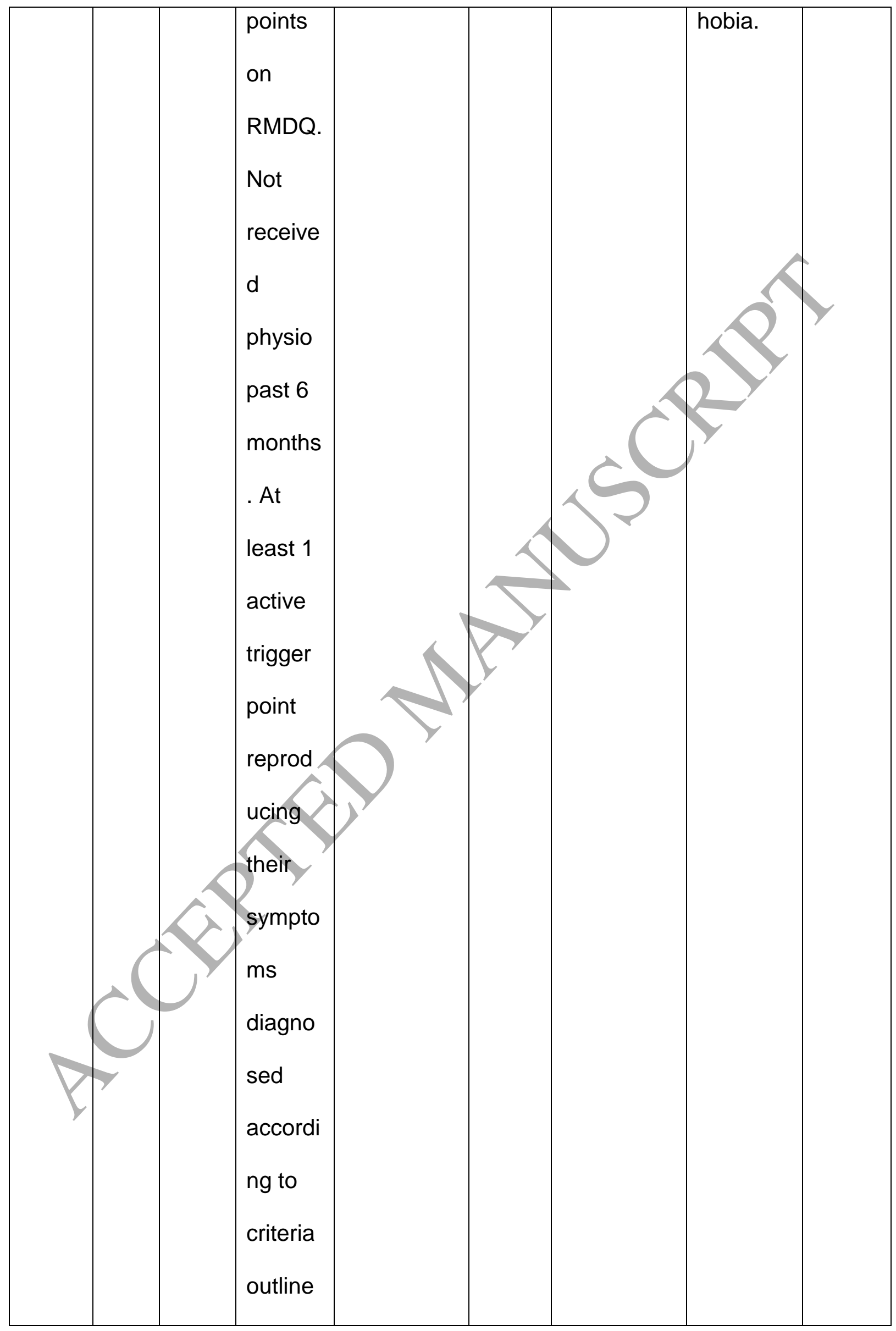




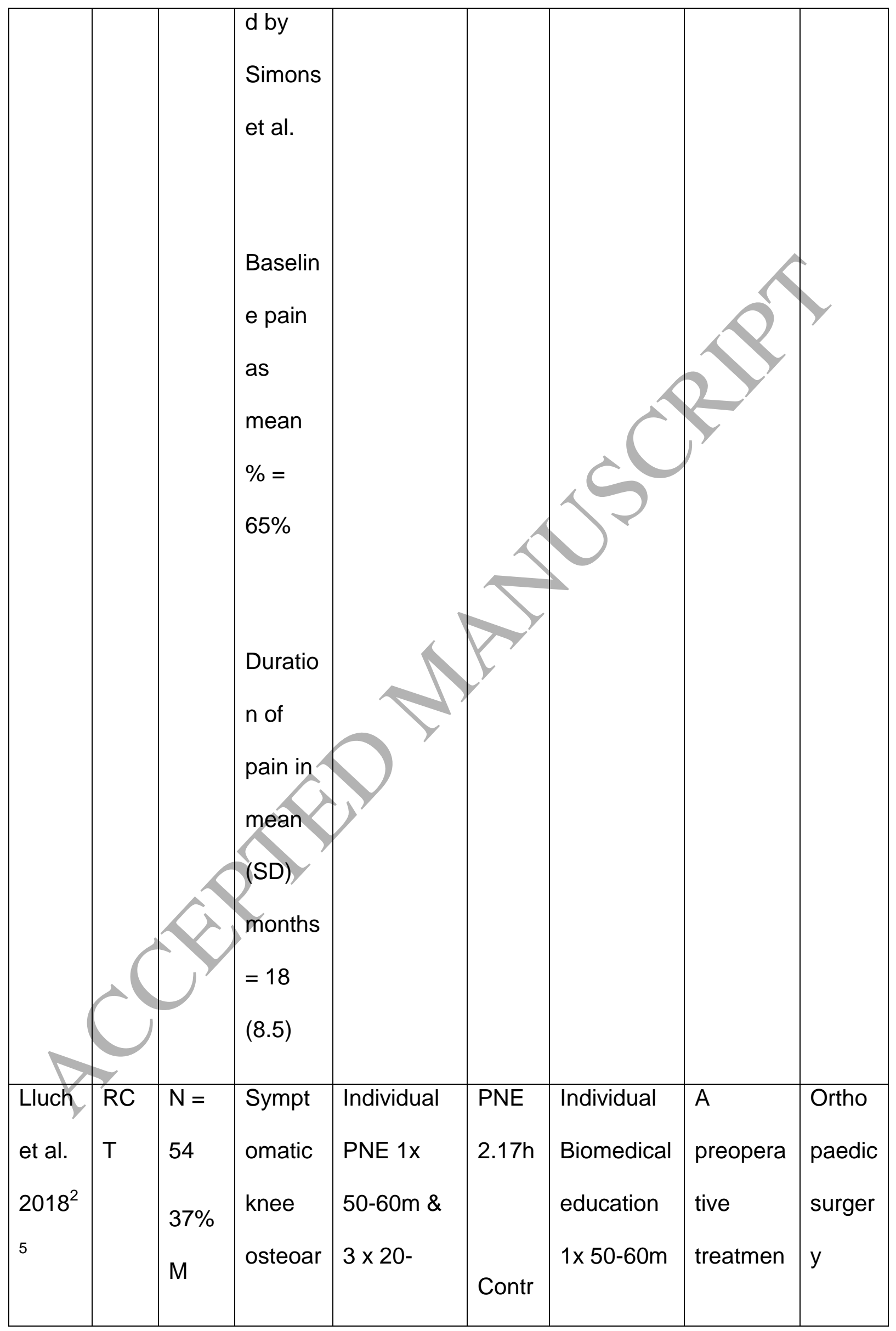




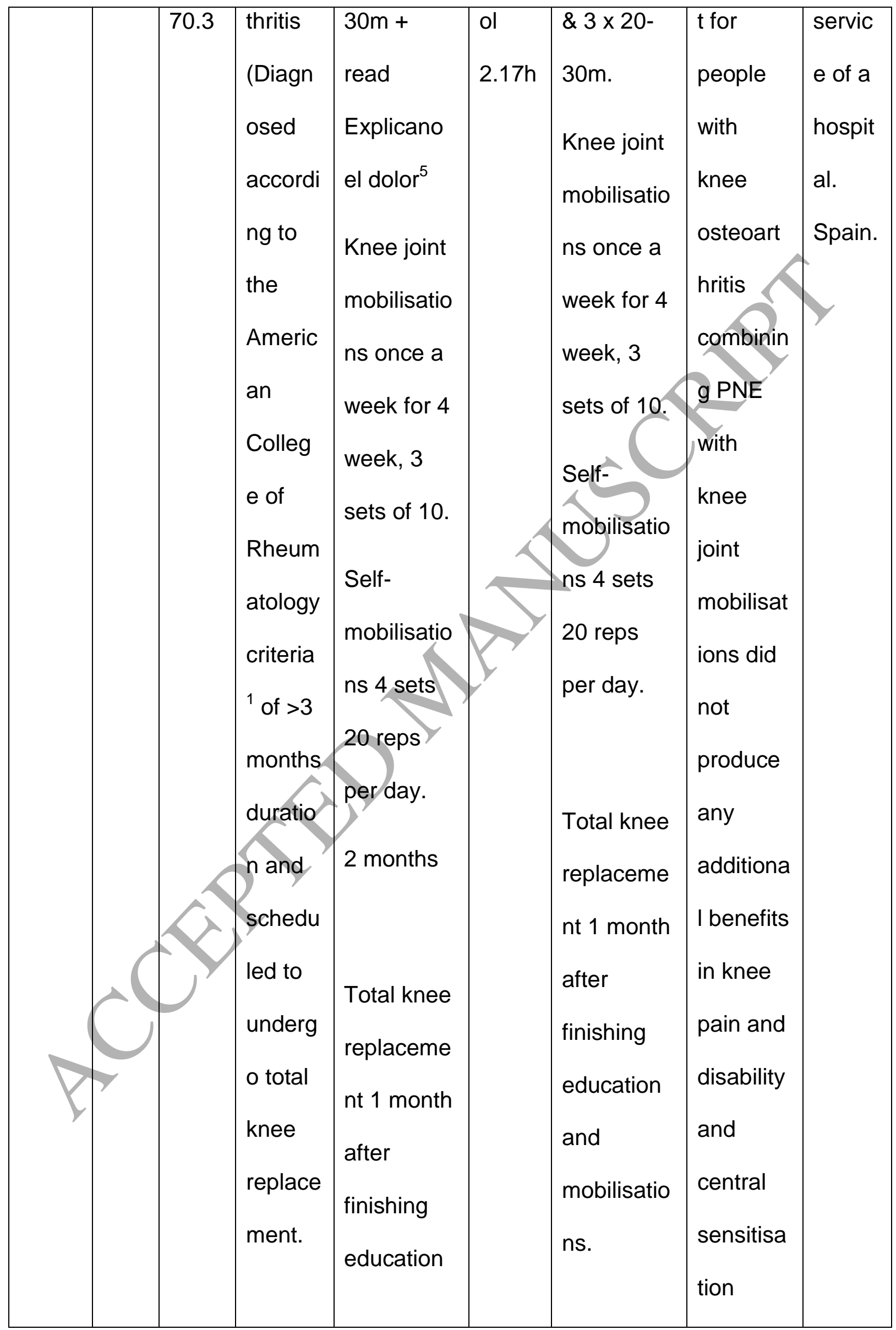




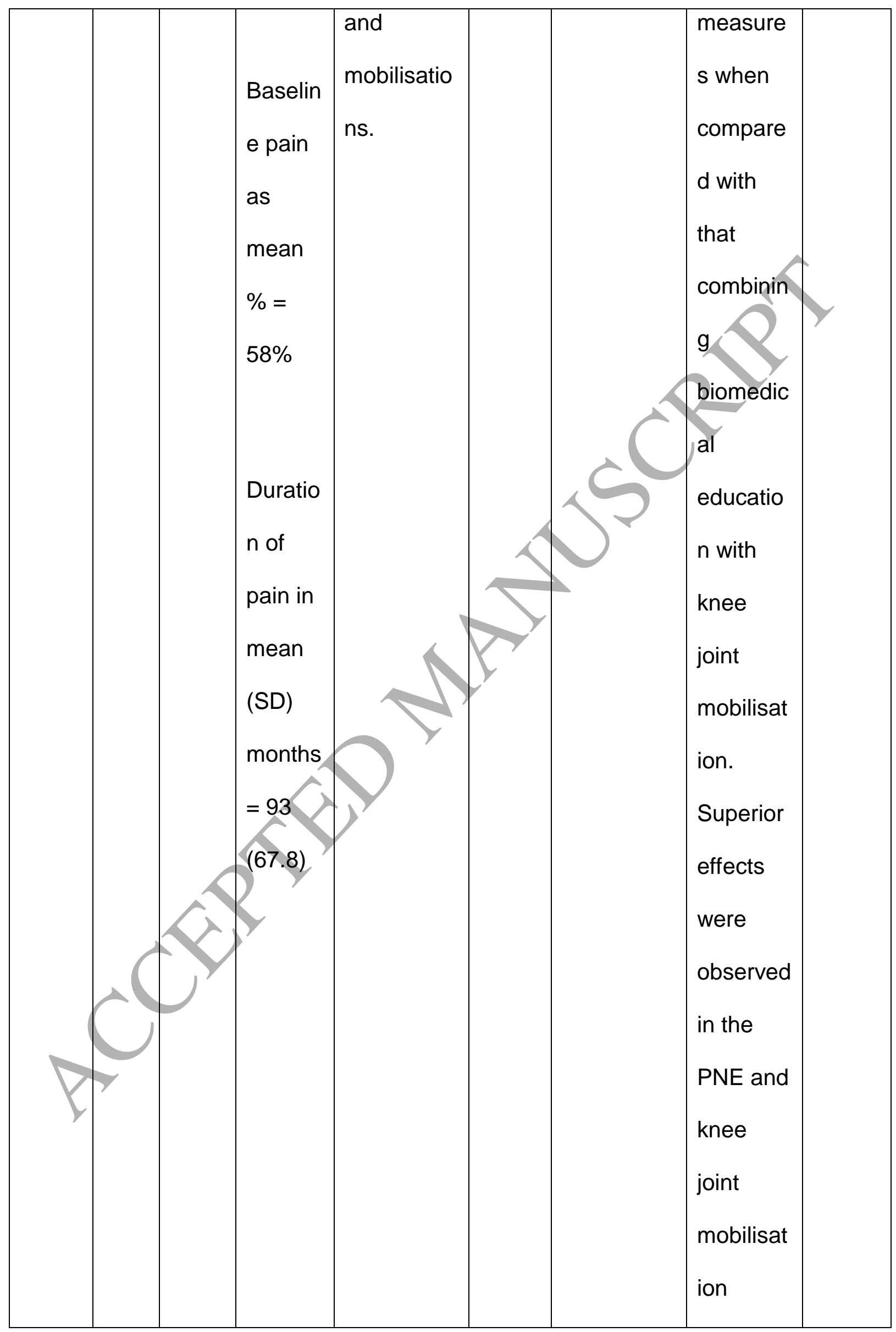




\begin{tabular}{|c|c|c|c|c|c|c|c|c|}
\hline & & & & & & & $\begin{array}{l}\text { group for } \\
\text { psychos } \\
\text { ocial } \\
\text { variables } \\
\text { related } \\
\text { to pain } \\
\text { catastrop } \\
\text { hising } \\
\text { and } \\
\text { kinesiop } \\
\text { hobia. }\end{array}$ & \\
\hline $\begin{array}{l}\text { Bode } \\
\text { s et } \\
\text { al. } \\
2018^{2}\end{array}$ & $\begin{array}{l}\mathrm{RC} \\
\mathrm{T}\end{array}$ & $\begin{array}{l}\mathrm{N}= \\
56 \\
27.3 \\
\% \mathrm{M}\end{array}$ & $\begin{array}{l}20-75 \\
\text { years } \\
\text { of age } \\
\text { Baselin }\end{array}$ & $\begin{array}{l}\text { Therapeuti } \\
\text { c exercise } \\
\text { - including } \\
\text { motor } \\
\text { control } \\
\text { exercises } \\
\text { for the } \\
\text { lumbar } \\
\text { spine, } \\
\text { stretches, } \\
\text { and } \\
\text { aerobic } \\
\text { exercise. }\end{array}$ & $\begin{array}{l}\text { PNE } \\
1.33 \mathrm{~h} \\
\text { Contr } \\
\text { ol } 0\end{array}$ & $\begin{array}{l}\text { Therapeuti } \\
\text { c exercise } \\
\text { - including } \\
\text { motor } \\
\text { control } \\
\text { exercises } \\
\text { for the } \\
\text { lumbar } \\
\text { spine, } \\
\text { stretches, } \\
\text { and } \\
\text { aerobic } \\
\text { exercise. }\end{array}$ & $\begin{array}{l}\text { A } \\
\text { program } \\
\text { of PNE } \\
\text { combine } \\
d \text { with } \\
\text { therapeu } \\
\text { tic } \\
\text { exercise } \\
\text { is more } \\
\text { effective } \\
\text { in } \\
\text { reducing } \\
\text { pain, }\end{array}$ & $\begin{array}{l}\text { Privat } \\
\mathrm{e} \\
\text { clinic } \\
\text { and } \\
\text { univer } \\
\text { sity. } \\
\text { Spain. }\end{array}$ \\
\hline
\end{tabular}




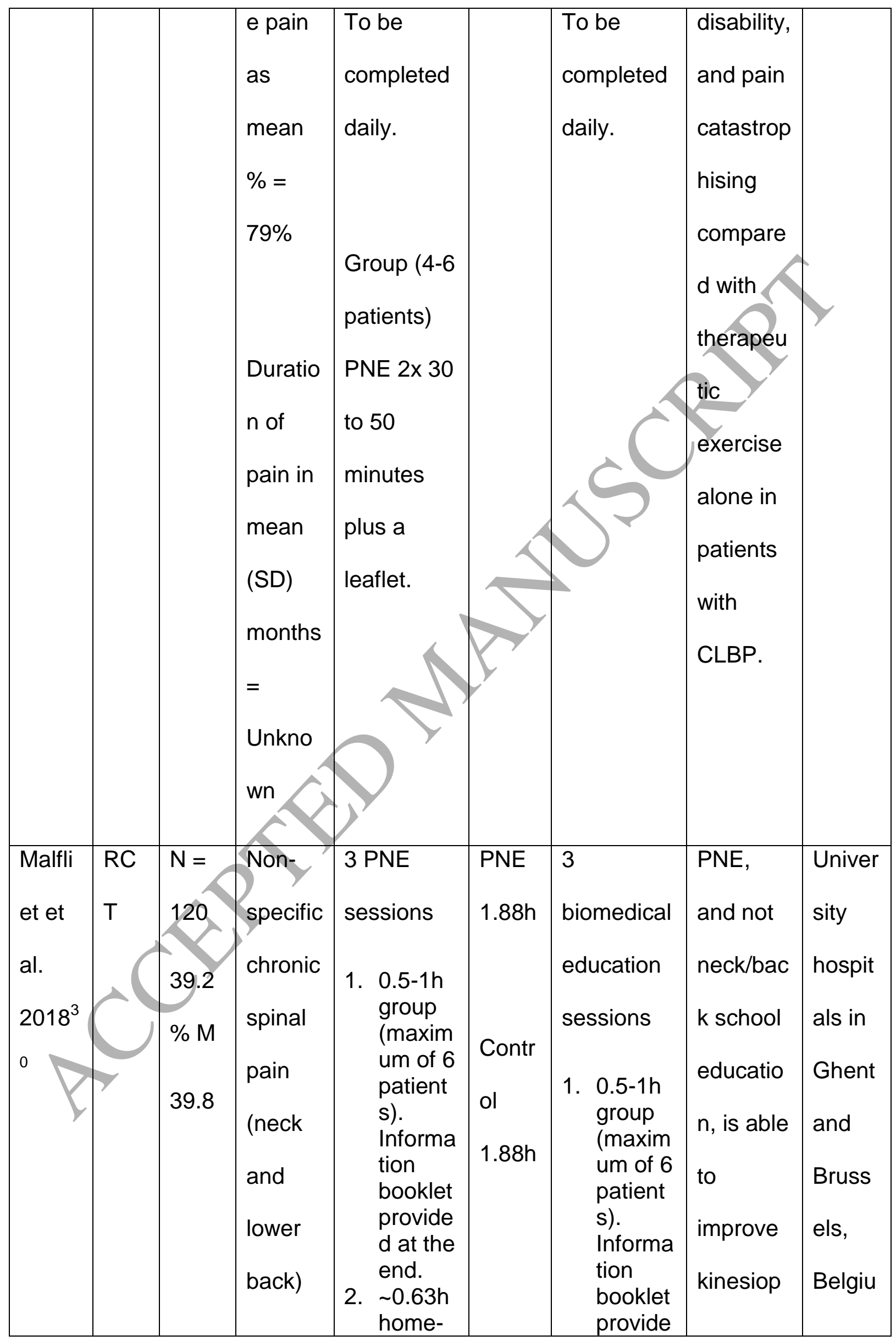




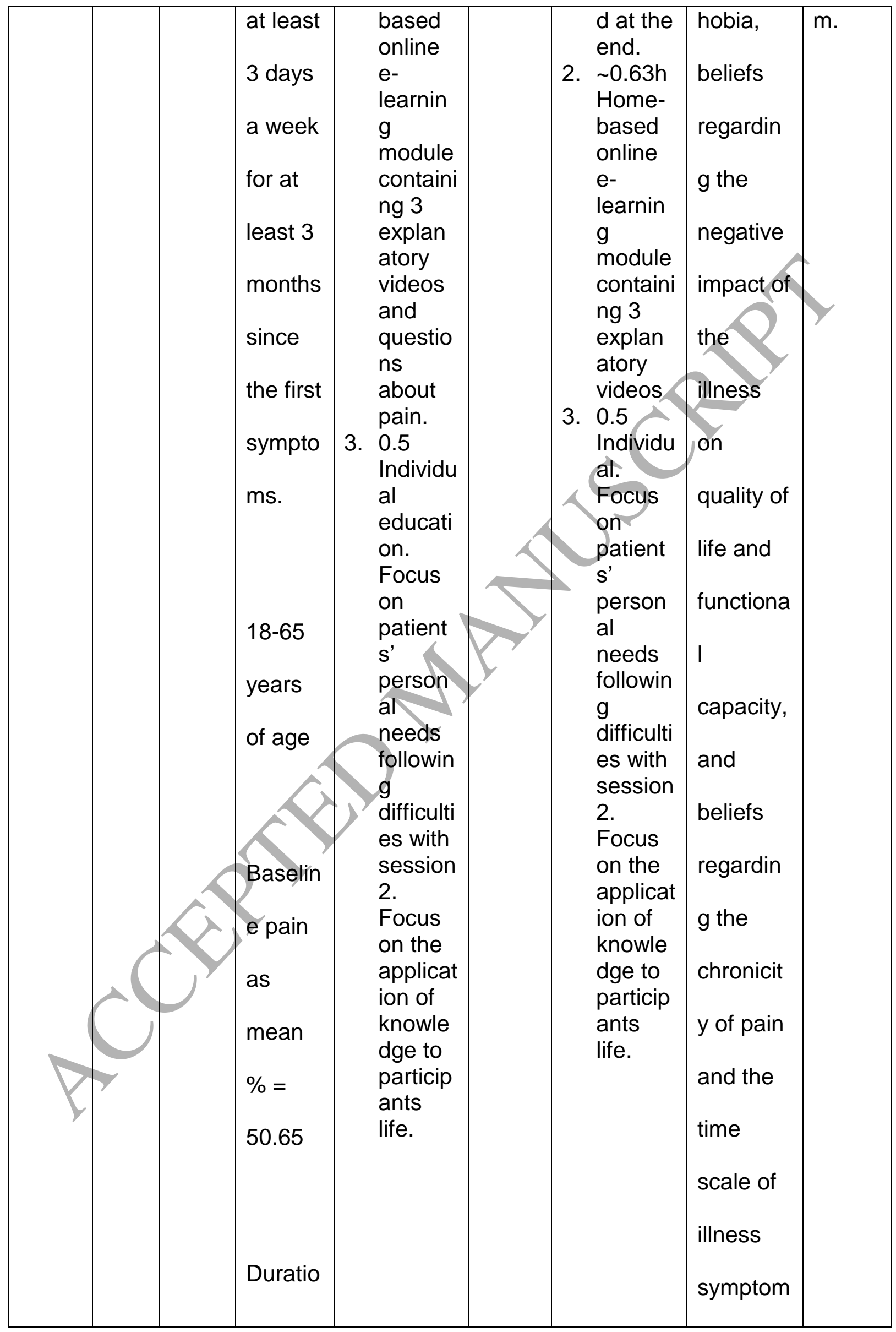




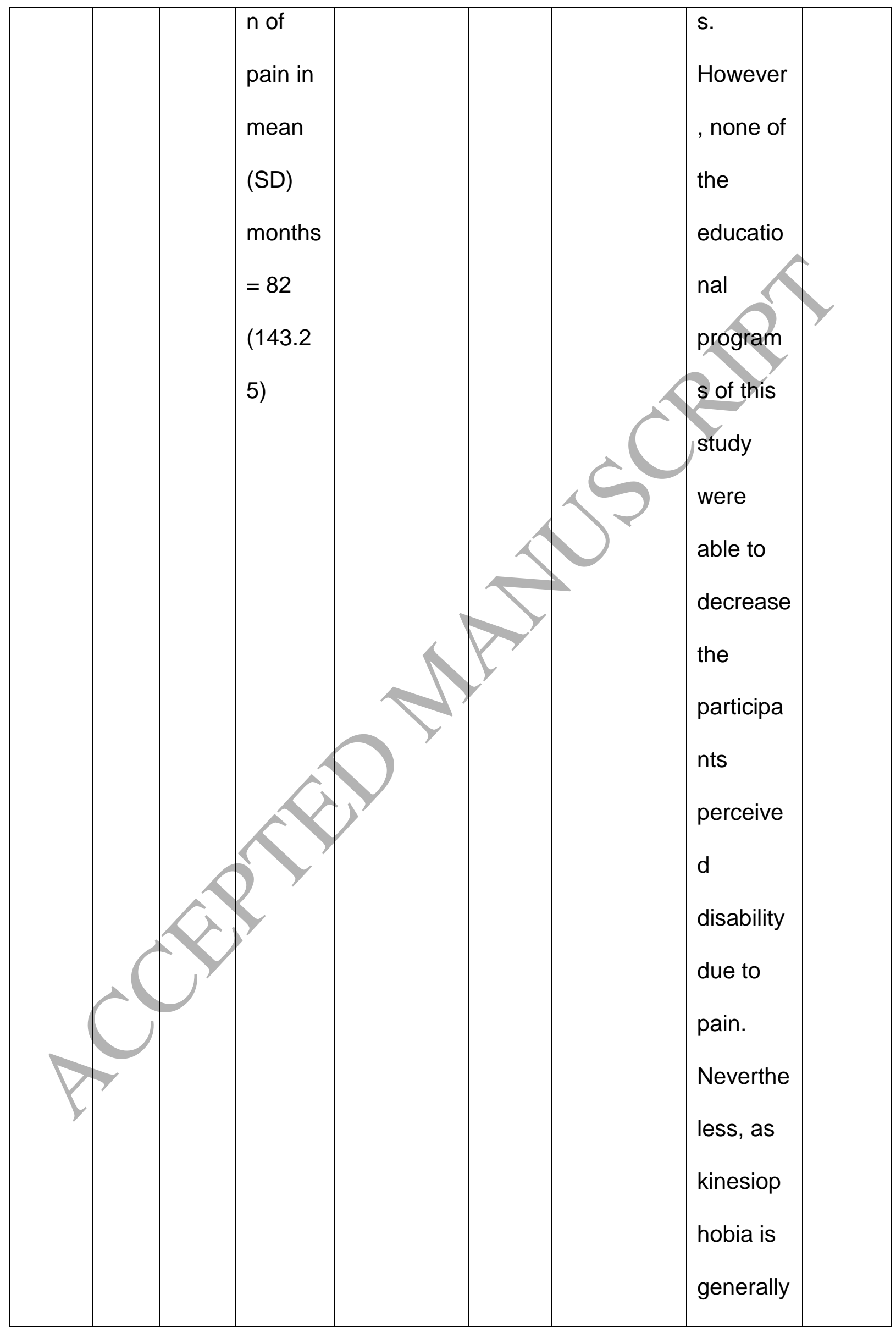




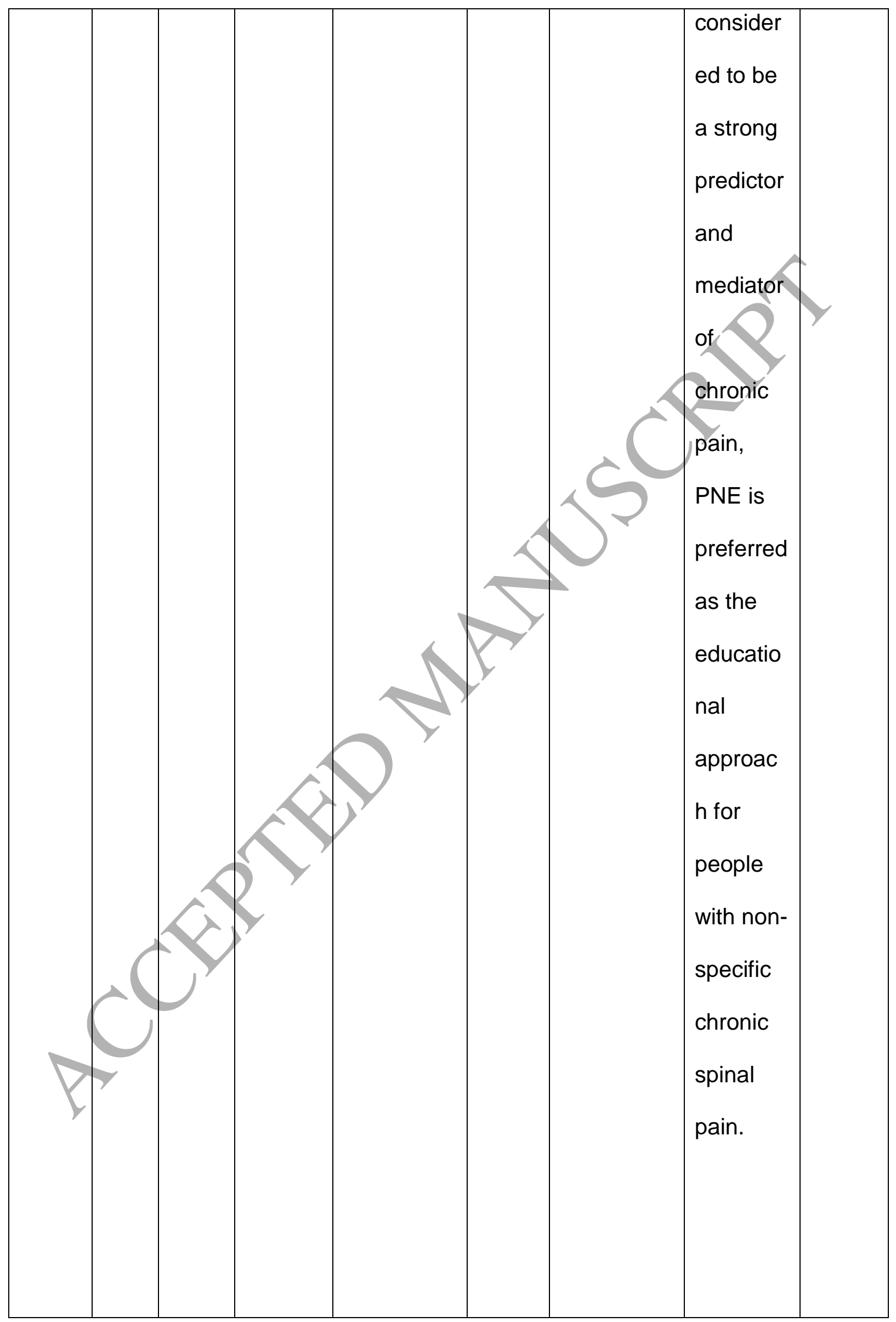


Abbreviations: RCT, randomised controlled trial; LBP, low back pain; CLBP, chronic low back pain; PNE, pain neuroscience education; PMP, pain management programme; CFS, chronic fatigue syndrome; SD, standard deviation. USA, United States of America; RMDQ, Roland Morris Disability Questionnaire.http://www.rmdq.org/

Table 6 Characteristics of included studies - qualitative component

\begin{tabular}{|c|c|c|c|c|}
\hline $\begin{array}{l}\text { Study/Cou } \\
\text { ntry }\end{array}$ & $\begin{array}{l}\text { Methodology/Me } \\
\text { thods }\end{array}$ & Participants & $\begin{array}{l}\text { Phenomena of } \\
\text { interest }\end{array}$ & Findings \\
\hline $\begin{array}{l}\text { Robinson } \\
\text { et al. } \\
2016^{42} \\
\text { UK }\end{array}$ & $\begin{array}{l}\text { Interpretive } \\
\text { phenomenologic } \\
\text { al analysis. }\end{array}$ & $\begin{array}{l}\mathrm{N}=10 \text { adults } \\
\text { with chronic } \\
\text { musculoskeletal } \\
\text { pain recruited } \\
\text { from an NHS } \\
\text { Pain Clinic. } \\
\text { Mean age = 48.5 } \\
\text { years (Range = } \\
28-64 \text { ) } \\
60 \% \text { Male. } \\
\text { Mean duration of } \\
\text { pain = 9.2 years } \\
\text { (Range = } 2-32 \text { ). }\end{array}$ & $\begin{array}{l}\text { Following a } \\
\text { single } 2 \mathrm{~h} \\
\text { group PNE } \\
\text { session: to } \\
\text { explore the } \\
\text { experience of } \\
\text { PNE for } \\
\text { people with } \\
\text { chronic pain } \\
\text { and to gain } \\
\text { insight into } \\
\text { their } \\
\text { understanding } \\
\text { of their pain }\end{array}$ & $\begin{array}{l}\text { Three themes } \\
\text { emerged: } \\
\text { perceived } \\
\text { relevance for } \\
\text { the individual } \\
\text { participant; } \\
\text { perceived } \\
\text { benefits for the } \\
\text { individual } \\
\text { participant; and } \\
\text { evidence of } \\
\text { reconceptualis } \\
\text { ation. Within } \\
\text { these themes } \\
\text { there were }\end{array}$ \\
\hline
\end{tabular}




\begin{tabular}{|c|c|c|c|c|}
\hline & & $\begin{array}{l}3 \text { unemployed, } 3 \\
\text { employed, } 1 \text { self- } \\
\text { employed, } 1 \\
\text { retired, } 2 \text { sick- } \\
\text { leave. }\end{array}$ & after PNE. & $\begin{array}{l}\text { examples of } \\
\text { positive and } \\
\text { negative } \\
\text { experiences, } \\
\text { the latter } \\
\text { manifesting as } \\
\text { lack of } \\
\text { relevance, lack } \\
\text { of benefit and } \\
\text { lack of } \\
\text { evidence of } \\
\text { reconceptualis } \\
\text { ation. An } \\
\text { interlinking } \\
\text { narrative was } \\
\text { the importance } \\
\text { of relevance. }\end{array}$ \\
\hline $\begin{array}{l}\text { King et al. } \\
2016^{24} \\
\text { UK }\end{array}$ & $\begin{array}{l}\text { Interpretive } \\
\text { phenomenologic } \\
\text { al analysis. } \\
\text { Semi-structured } \\
\text { individual } \\
\text { interviews using }\end{array}$ & $\begin{array}{l}\mathrm{N}=7 \text { adults with } \\
\text { chronic } \\
\text { musculoskeletal } \\
\text { pain recruited } \\
\text { from an NHS } \\
\text { Pain Clinic. } \\
\text { Mean duration of }\end{array}$ & $\begin{array}{l}\text { Following a } \\
\text { single } 2 \mathrm{~h} \\
\text { group PNE } \\
\text { session: to } \\
\text { investigate the } \\
\text { degree and } \\
\text { nature of }\end{array}$ & $\begin{array}{l}\text { Themes } \\
\text { described } \\
\text { variable } \\
\text { degrees of } \\
\text { reconceptualis } \\
\text { ation, including } \\
\text { none; people's }\end{array}$ \\
\hline
\end{tabular}




\begin{tabular}{|c|c|c|c|c|}
\hline & $\begin{array}{l}\text { open questions, } \\
\text { pre and post. }\end{array}$ & $\begin{array}{l}\text { pain }=9.7 \text { years } \\
\text { (Range }=2-26 \\
\text { years). }\end{array}$ & $\begin{array}{l}\text { people's } \\
\text { reconceptualis } \\
\text { ation of their } \\
\text { own chronic } \\
\text { pain following } \\
\text { PNE. }\end{array}$ & $\begin{array}{l}\text { beliefs about } \\
\text { their pain } \\
\text { before PNE as } \\
\text { barriers to or } \\
\text { facilitators of } \\
\text { reconceptualis } \\
\text { ation; and the } \\
\text { influence of } \\
\text { reconceptualis } \\
\text { ation on clinical } \\
\text { benefits of } \\
\text { PNE. }\end{array}$ \\
\hline $\begin{array}{l}\text { Wijma et } \\
\text { al. } 2017^{61} \\
\text { The } \\
\text { Netherland } \\
\text { s }\end{array}$ & $\begin{array}{l}\text { Semi-structured } \\
\text { interviews using } \\
\text { open questions. } \\
\text { Focus group with } \\
\text { healthcare } \\
\text { professionals }\end{array}$ & $\begin{array}{l}\text { Interviews } \\
\mathrm{N}=15 \text { recruited } \\
\text { from a } \\
\text { transdisciplinary } \\
\text { outpatient } \\
\text { treatment centre. } \\
\text { Mean age }=47 \\
\text { (Range } 18-62) \\
47 \% \text { Male } \\
\text { Mean duration of } \\
\text { pain = } 7 \text { years }\end{array}$ & $\begin{array}{l}\text { Explore the } \\
\text { experiences of } \\
\text { patients with } \\
\text { chronic pain } \\
\text { who recently } \\
\text { received PNE } \\
\text { in a } \\
\text { transdisciplinar } \\
\text { y setting. }\end{array}$ & $\begin{array}{l}\text { Several topics } \\
\text { and subthemes } \\
\text { emerged. The } \\
\text { pre-PNE } \\
\text { phase, in which } \\
\text { respondents } \\
\text { met the } \\
\text { healthcare } \\
\text { professionals } \\
\text { during a board } \\
\text { intake. The } \\
\text { second topic, a }\end{array}$ \\
\hline
\end{tabular}




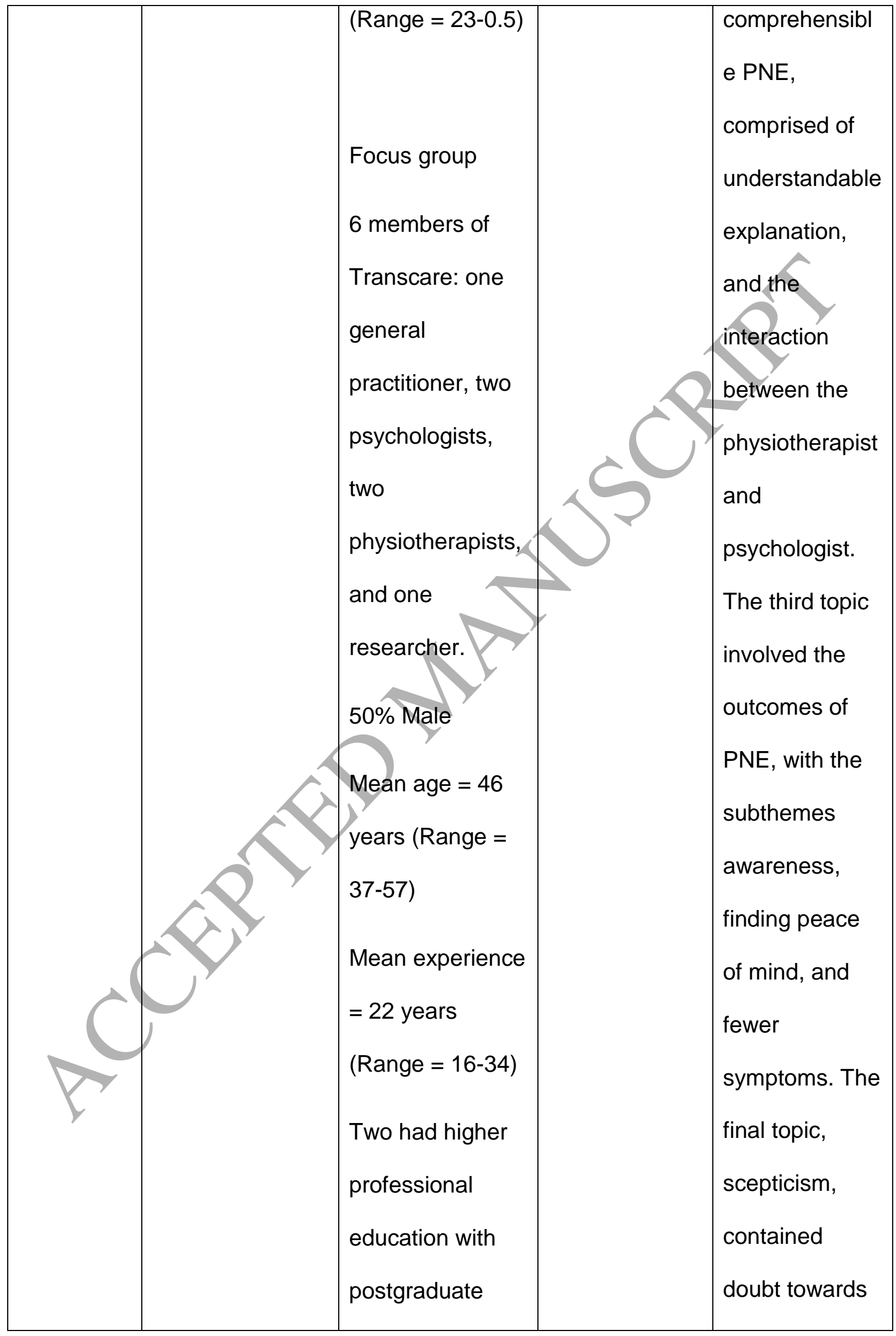




\begin{tabular}{|c|c|c|c|c|}
\hline & & $\begin{array}{l}\text { qualification. Two } \\
\text { had a University } \\
\text { postgraduate } \\
\text { qualification. Two } \\
\text { had a university } \\
\text { postgraduate } \\
\text { qualification and } \\
\text { PhD. }\end{array}$ & & $\begin{array}{l}\text { the diagnosis } \\
\text { and PNE, } \\
\text { disagreement } \\
\text { with diagnosis } \\
\text { and PNE, and } \\
\text { PNE can be } \\
\text { confronting. }\end{array}$ \\
\hline $\begin{array}{l}\text { King et al. } \\
2018^{23} \\
\text { UK }\end{array}$ & $\begin{array}{l}\text { Semi-structured } \\
\text { individual } \\
\text { interviews using } \\
\text { open questions, } \\
\text { pre and post. }\end{array}$ & $\begin{array}{l}\mathrm{N}=12 \text { adults } \\
\text { ( } \geq 18 \text { years) and } \\
\text { had a primary } \\
\text { complaint of } \\
\text { chronic (>6 } \\
\text { months duration) } \\
\text { lower back pain } \\
\text { +/- leg } \\
\text { symptoms) of a } \\
\text { neuro/musculosk } \\
\text { eletal origin. } \\
\text { Recruited from } \\
\text { an NHS Pain } \\
\text { Clinic. } \\
\text { Mean age = } 48 \\
\text { years (Range = }\end{array}$ & $\begin{array}{l}\text { Following a } \\
\text { single } 2 \mathrm{~h} \\
\text { group PNE } \\
\text { session: to } \\
\text { investigate the } \\
\text { extent, and } \\
\text { nature, of } \\
\text { people's } \\
\text { reconceptualis } \\
\text { ation of their } \\
\text { CLBP } \\
\text { following PNE. }\end{array}$ & $\begin{array}{l}\text { The a priori } \\
\text { themes - } \\
\text { degrees of } \\
\text { reconceptualis } \\
\text { ation, personal } \\
\text { relevance, } \\
\text { importance of } \\
\text { prior beliefs } \\
\text { and perceived } \\
\text { benefit of PNE } \\
\text { - were all } \\
\text { clearly } \\
\text { identifiable } \\
\text { within the data } \\
\text { and did indeed } \\
\text { provide a good }\end{array}$ \\
\hline
\end{tabular}




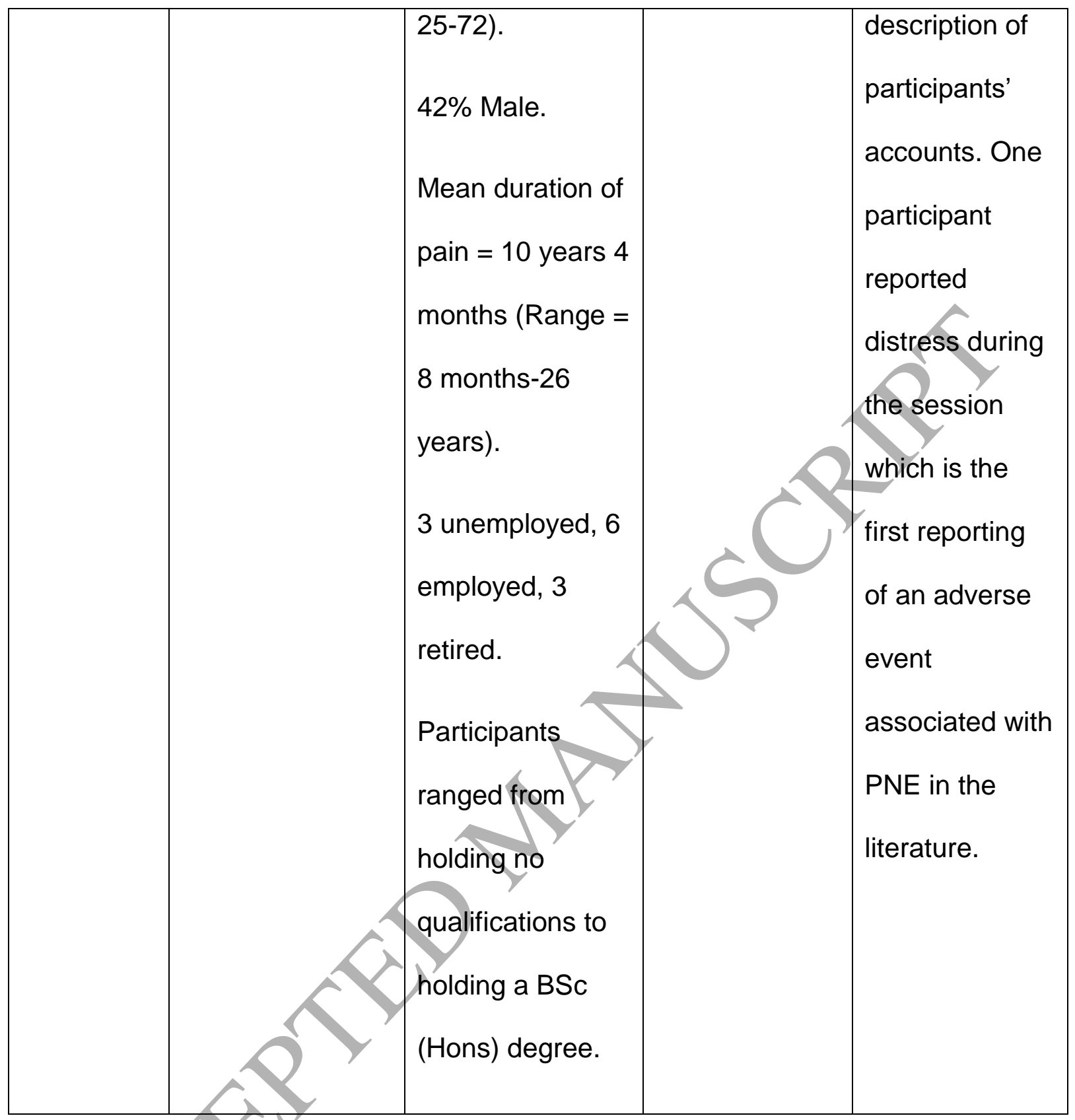

Abbreviations: UK, United Kingdom; NHS, National Health Service; PNE, pain neuroscience education; $h$, hour. 